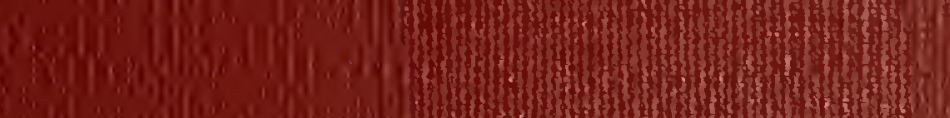
andm (1)

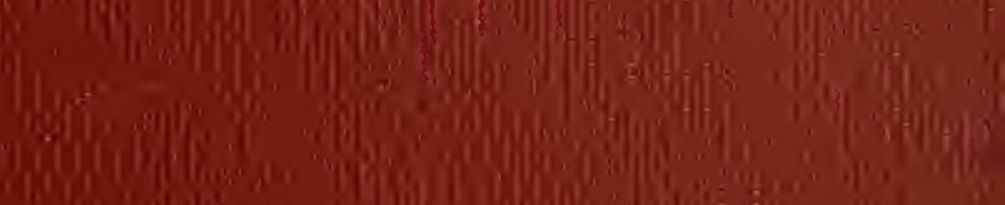
, (1) 
Soecial Collections

2

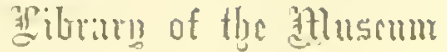

OF

COMPARATIVE ZOÖLOGY,

IT IlIRTIRD COLLGE, CIMGRIGR, IISS.

fo outued by prfortc subscrfption, in 1 S61.

$\%$

Deposited by ALEX. AGASSIZ.

No. 39.694

fune 11,1913 . 




Ghe A aesiz

Cunhige, yy. 

$Z u r$

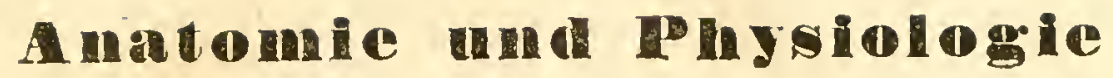

de $r$

I I e me n w ii ir me ro

Von

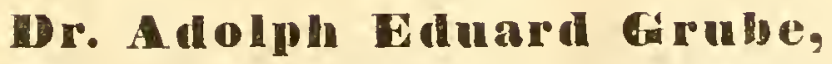

Privatdocenten an der Universität zu Königsberg.

Mit zwei Kupfertafeln.

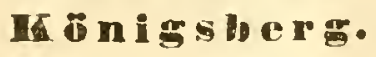

In Commission bei den Gebrudern Bornträger.

$\sin 538$. 
Soeclal Collections 
Seinem hochgehrten Lehrer

dem nera geheimen medicinalrath

Dr. Carl Friedrich Burdach. 



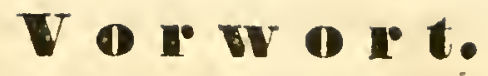

So vielfach in den letzten zwanzig Jahren die Anatomie des Blutegels und Regenwurms bearbeitet ist, so wenig sind die Thiere ans der grossen Abtheilung der Dorsibranches und Tubicoles Cuv. grïndlich untersucht worden, und es ersehien nichts, was den Beschreibungen ihrer äusseren Formen, die wir Savigny, Audouin und Fdwards verdanken, einigermassen an die Seite gesetzt werden konnte. Um sich hievon zu überzengen, darf man nur die Handbücher und Systeme der vergleichenden Anatomie nachsehlagen, und man wird finden, dass mit kleinen Ausnahmen dasjenige von diesen Würmern wiederholt ist, was Home, Oken, Cuvier und Treviranus als kurze Bemerkungen und in einzelnen Aufsätzen sehon vor längerer Zeit geliefert haben. Als Repräsentanten aller im Meer lebender Kiemenwiirmer standen fast einzig die Gattungen Arenicola und Aphrodite da, aber die ausfïhrliche Beschreibung, welche von letzterer Treviranus gegeben hat, fand bei Mecke! entschiedenen Widerspruch, und die Darstellungen, welche die drei erstgenannten Zootomen von der Arenicola - vorzüglich nur von ihrem Gefüsssystem - mitgetheilt haben, weichen so sehr von einander ab, dass man mit Recht neuere, wo möglich entscheidende Urtheile herbeiwünschen musste. Andrerseits kann man nicht läugnen, dass man gegen noch frühere Bearbeiter ungerecht gewesen war: man hatte manche Andeutung, manehen schätzbaren Beitrag von O. F. Miiller und Pallas, wo nicht gänzlich übersehen, so mindestens doch nicht nach Verdienst gewiirdigt, auch findet man der von delle Chiaie nenerlich in seinen Memorie mitgetheilten Anatomieen fast nirgend Erwähnung gethan.

Hätte ich, als mir ein längerer Aufenthalt am Mittelmeer vergönnt war, die Grösse jener Lincken gleich erkannt, so wäre ich jetzt gewiss mit einer bedeutenderen Arbeit aufgetreten, ich hätte der Reihe nach die Hauptgattungen jener Annulaten auf ihre Anatomie untersucht, und die Zeit, welche ich damals zum Auffassen eines Ueberblickes ibber die Organisation der niedern Meeresthiere verwandte, erfolgreieher zur vollständigen Aufklärung jener Zweifel und zur Frweiterung unserer Kenntnisse in jenem engeren Fielde benutzt. So entschied ich 
mich erst in der letzten Hälfte meiner Reise für mein jetziges Lieblingsthema, nachdem ich vorher eine Zwischenstufe zwischen den Anneliden und Echinodermen den Sipunculus, so genau ich damals vermochte, durchgenommen. Der erste Kiemenwurm, welcher Gegenstand einer ausfühlichern Arbeit wurde, war eine bei Catanea entdeckte Pleione, doch konnte ich den hieher gehörigen Aufsatz von Stannius erst bei der Ausarbeitung wu Hause benutzen; auch hatte ich keine Nachricht daron, dass zur selben Zeit, als ich diese Studien aun Meere fortsetzte, das Gefisssystem der Arenicola abermals, und zwar von J. Wuiller beschrieben war. Meine Untersuchungen gingen also durchaus ihren selbstständigen Gang, sie waren unabhängig, aber eben darum auch nicht auf so viele l'unkte aufmerksam, als wenn ich ausführliche Beschreibungen anderer vor mir gehabt. Hauptsächlich bezogen sie sich auf die Arenicolen: die Anatomie der

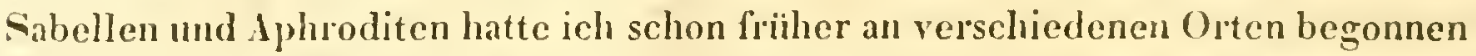
und fortgesetzt, die Bearbeitungr von Terebella ward in Italien mur angefangen, Limice, Onuphis, Cirratulus, Polynoe beobachtete ich lebend, gewann aber erst nach der Heimkehr Zeit in die Einzelnheiten ihres Baues einzudringen.

Wem ich nunmehr die Untersuchungen über die genannten Annelidengattungen bekannt mache, so habe ich allerdings, da dies Beginnen unter solchen l'mständen nie Anspritche auf Vollkommenheit machen konnte, etwas nicht belohnendes unternommen, indess möge man mir's nicht verargen, dass ich, obschon iiberzengt, fiir jetzt das Ziel nicht erreichen zu können, dennoch alles that, mich ihm zu nähern, und dass ich lieber eine Lincke vorliufig ansfïllen, und meine Arbeiten an H. Rathke's gründliche Monographie der Nereiden anschliessen wolle, als auf eine ungewisse 'Reit warten, in der das unternommene Werk zu beendigen verstattet wäre. - Je mehr ich mich bemühte, die liesultate der Zergliederung und Beobachtung von jeder Wahrscheinlichkeit und Reflexion zu trenuen, desto weniger konnte dabei atiurlich allgemein und apodictisch ausgesprochen werden, aber ich hoffe, dass gerade durch eine die Mingel blosstellende Beschreibung, kïnttige Bcobachter lcichter auf die wichtigen Fragen gefuhrt, und so der Wissenschaft auf kürerem Wege ihre Zweifel gelöst werden. 


\section{A r n ic o 1 a.}

I, iteratur: Oken in der Isis 1517. Heft IV. pag. 469.

Cuvier's Beschreibung im Auszuge. Isis. 1517. Heft IV. pag. 475.

Home. Isis 1518. Heft V. p. 57:2, ebenfalls ein Auszug.

Savigny, Systeme des Annelides. pag. 96.

Audouin et Edwards. Annal. des scienc. naturell. Tome 30. pag. 418. tab. 22.

Meckel, Vergleich. Anatomie. Theil 4, 5, 6 .

delle Chiaie. Memorie sulla storia e notomia degli animali senza vertebre del regno di Napoli. Vol. II. pag. 423.

delle Chiaie. Istituzioni di anatomja e fisiologia comparativa. Vol. I. pag. 227, 317. J. Müller. Ueber das Gefässsystem der Aren. carbonaria in Burdachs Physiologie. Bd. 1V. pag. 96 .

\section{Arenicola piscatorum.}

renicola piscatorum geliört zu den sehr allgemein verbreiteten Anneliden: sie kommt fast an allen Küsten der grïsseren Furopäischen Meere vor. Oken fand sie auf Wangeroog und den benachbarten Inseln der Nordsee, wo sie schlechtweg den Namen "Wurın" führen soll, I.each und Home beschrieben sie aus England her, Fabricius erwähnt ihrer in seiner Fauna Grönlandica, Cuvier bearbeitete die Anatonie nach Franzïsischen und delle Chiaie nach Neapolitanischen Exenplaren. Ich selbst erhielt sie in Harre (unter dem Nanıen $\mathbf{S}$ ando) in grosser Menge, seltener in Italien und Sicilien, was man vielleiclit den hier nur unbedeutenden Weclisel von Ebbe und Fluth zuschreiben darf. Denn, wie schon Oken benterkt, scheinen diese Thiere an liebsten auf solchen sandigen Stellen zu wohnen, welche nur zeitweise vom Wasser bedeckt werden, von wo man dieselben auch am leichtesten durch Ausgraben erhalten kann. Ihr Gebrauch als Köder zum Fischfange ist in den genannten Ländern allgemein. - 
Die Jrenicolen halten sich in Kähren, "Iuss und noch refer unter der Oberfliche, nuf, welehe didurch rntstohen, dass der Sand, in den sie hincinbohren, durch einen reichlich ausgeschwizten schlein, wie durch ein Cement, zusammengehalien wird, und sich der lorm ihres lib̈pers anpasst. Der Jugabe Oslers*), dass sie ihren ban mit dem Vorderende des liörpers aushöhlon, und sich spïter darin umkchren kïnnten, nö̈hte ich nicht geralezu widersprechen, wiewohl Okin wegen der linge der lähren an der II ahrheit der Beolachtung zwrilelt. Ils ich die Rähren der Onuphis tuhicola erhicht, hätte ich auch schwerlich vermuthen kïnnen, dass sirh der Wum in diesem schualen Raun umzum enden im Stande sei, und doch halue ich in dev Folge diesen Vorgang mohrmals selher

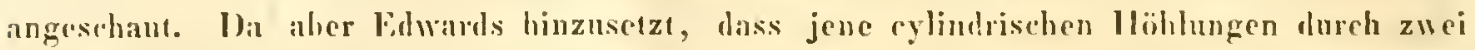
Finden nach aussen zu münden pflegen, so ist die Arenicola noch weniger genöthigt, sich diun unzukehren.

Vusere Irenicola hat ungefälur das Inschen cines dicken, nicht sehr langen Regenwmms, dessen vorderer Theil selur viel weiter als der hintere, und fast sackfinmig anfg(c)blillt ist **). lch find

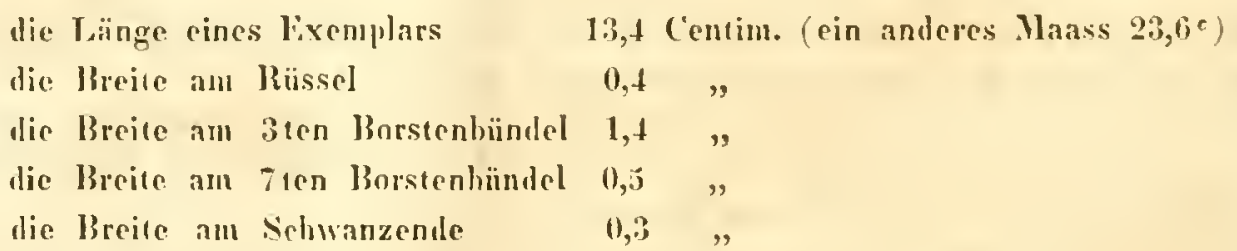

Der lï̈per grïsstentheils sehr dentlich geringelt trïgt Borsten und Kiemen, aber jene nur in den ersten zweil Dritheilen, diese allein im zweiten Dritheil der ganzen Länge. Lebrigons sind diese Dritheile schr ungleich, wie man aus folgender Tabelle ersicht

\begin{tabular}{|c|c|c|c|c|c|}
\hline erstes Irittheil (his zum Infang & $8, \mathrm{~S}^{\mathrm{c}}$ & 6,9 & 6,0 & 4,8 & 6,4 \\
\hline zweites Writheil (der Kiemen tagende Absehniti) & 8,9 & $7,1)$ & 6,7 & 7,0 & 5,9 \\
\hline drittes Drittheil (las Schwanzstiick) & 5,9 & 4,2 & $3, ?$ & 5,5 & 4,2 \\
\hline (iesimum länge & $23,1 i$ & $18, \pi$ & 16,$1 ;$ & 17,3 & 16,5 \\
\hline
\end{tabular}

wonach der kiementragende Absehnitt fast dutchgängig der längste, das Schwanzstïck aber das kürzeste ist.

So weit sich die Borstenreihe erstrecht, wechseln schmailere und breitere lingel so mit cinanler ab, dass nach 4 schmileren cin breiteres (ilied folgt, anf welchem stets die bewrgungs - und Alumungsorgane befestige sind. Mlit diesen grössern lntervallen übereinstimment fimlen wit im lunern den Jhgang der llauptgefïssiste. Die Bewegungs-

1) 3. Isis. 1836. Ileft VIII. pag. 381 .

") s. die subildung in den Am. d. sciens. nat. T. 30 . tab. 22. fig. 8. 
organe sitzen an den Seiten des Kïrpers auf den breiteren Ringen, und bilden hier zwei Reihen: die obere enthält grrade Borsten (soies subulées), die untere llakenborsten (snies à crochets). Jene setzen kleine, etwas plat gedrückte Bündel zusammen, die aus kegelförnigen Erhölungen hervortreten: die andern hingegen sind wie Zälune eines liammes zu Querreihen verbunden, und rigen nur wenig aus der Spalte der sie umschliessenden breiten Wülste hervor. Da sie an der Bauchfläche stehen, dienen sie wahrscheinlich am meisten leim Kriechen in den Rälıren, die andern vielleicht zum sifhwimmen und auch zur Fortbewegung auf dem Mcereshoden. An allen Exemplaren zälilie ich 19 Paare von leiderlei $\Lambda \mathrm{rt}$, aber die Kiemen trifft man allein an den letzten 13 liündeln dor obern Reihe an.

Die Kiemen lilden strauchartige, in Lelen blutrnthe, contraftile Büseliel, deren Stämmchen seitwäris nehen einander siehen, und vielfaels verzweigt sind; sie erscheinen stets hinter den obern Borstenlü̈adeln.

Der vorlerste weite Thlueil des Kürpers geht mit seinem Anfang in einen von l'apillen bedeckien Rïssel üher, an dessen Spitze die Mundöffung, und auf der Girenze dieses hervorstülplaren liüssels und des Leibes lemerkt man oben eine kleine Vertiefung, wie ein Täschchen. Fin algesetzter Kopf felult elıenso als Augen, Bïrtel oder Antennen; vielleicht muss man die Papillen, welche nach delle Chiaic sich verlängern und rerkürzen sollen, als eine $\Lambda \mathrm{rt}$ Tasiorgan betrachien. Der After, dem Munde rnigegengesetzt, nimmt die Spitze des Schwanzes ein, beide stehen senkrecht.

Auf dem übrigen Körper, besonders zahılrcirls am Schwanzende, sieht man grïnlich grane Wärzchea, aus denen wohl der heilgelloe Saft hervorquillt, weirher beiı Anfassen einer lebenten Arenicola die Finger so intensiv gelh färbi, dass man ihn nur mit Mülıe abwaschen kann, und ausserdem die Wände der Röhren zusammen'ittet.

Die Farbe des Wurmes ist ein schmutziges Schwarzgran, seltener fand ich eine ganz schwarze Varietït (die Arenicola carbonaria des Leach, ron Sarigny noch als eigene $A r t$ aufgeführt).

A nmerkung. Ausser der Arenicola piscatorum erhielt jch in Catania noch eine andere $A r t$, bei welcher mir anfänglich die von Ranzani in den Opuscoli scientifici Tom. I. pag. 110 beschriebene Arenicola clavatus einfiel. Allein bei naherer Prüfung seiner Figur (ebenda tab. 4) und seiner für die Aufstellung dieser Species angeführten Gründe ergiebt sich, dass die Exemplare des Bologneser Museums nichts anderes als die gemeine Arenicola piscatorum sind. Der Charakter des knotigen Schwanzes, auf den er lesonderes Gewicht legt, kann nicht in Betracht kommen, denn dies rührt von einer theilweisen Verwesung her, wobei die 
Muskelschicht und der mit Sand gefülte Darmkanal sich in einzelne, nur von der dauerhafteren Epidermis zusammengehaltene, Partieen getrennt hat. Unter meinen Spiritusexemplaren fand ich mehrere ron solchem Ansehn. - Die Cataneser Arenicola unterschied sich aber wesentlich ron der gewölinlichen durch die sammetschwarze Farhe und durch die viel grïssere Anzahl der Borstenbündelund Kiemenpaare: ich zillilte os l'arar Borstenhündel, von denen die ersten 11 isolirt, die ührigen 27 nit Kiemen zusammenstanden, und da das Thier nicht volstïndig erhalten war, mochten vielleicht noch einige Ilauptglieder fohlen. Ohwohl sie vicle Aehnlichkeit mit ber von Audonin und Edwards *) ahgehildeten Arenicola branchialis hesitzt, so wollen doch die Zahlen nicht stimmen, weil letzlere 32-3t l'aar Borstenbüschel und 19-20 l'aar hiemen zeigt. - Es könute der Fall sein, dass bei der A. branchialis diese Zahlen so bedeutend wechselten, aher hei $A$. piscatorum findet man sie doch selir constant. Dennowh will ich auf Grund dieses einen verstümmelten Exemplares beine neue, dritte Art aufstellen.
\end{abstract}

\title{
Inat, Muskeln und Betregungsorgane.
}

Nach lintfernung der Iaut, von welcher gleich die Rede sein wird, überzeugt man sich, dass die Körperwandung aus e̊ner sehnig glänzenden Längs- und Querfaserschicht hesteht, von denen jene nach innen, diese nach aussen liegt. Die läingsfasern erscheinen in schnılen, fast leistenartig herwortretenden Streifen, oder Bündeln, welche nicht in ihrem ganzen Verlauf parallel neben einander gelagert sind, sondern hin und wieler sich gahelig spalten, und durch diese Zweige in die benachbarten Bündel übergehen, wodurch ein sonst fehleudes System ron schrägen Fasem gewissernaassen ersetzt wird. - Die Querfasern dagegen sind zu breiten platten lingen zusammengefügt, und ihre Iücken stehn eben an den Grenzen der oben erwähnten Kïrperglieder; aus ihnen zumeist bestehen die fleischigen Kegel für die Harborsten und die starken Wüste, in denen die Kïnme der Hakenhorsten stecken. Nur an den vorderen Paaren, wo dic Kiemen fehlen, treten diese Wïlste fast gar nicht hervor. Die geraden oder IJar-Borsten, biegsam, fein, zllgespitzt, seidenartig glïnzend, bilden Bündelehen von $30-50$ Stïck, von etwa 3 Centru. Isinge, doch sind die hinteren anselunlicher als die vorderen. Lnter einer

*) Ann, des scienc. natur. Tom, 30, tab, 22. fig, 13. 
stärkern Vergrösserung betrachtet, erscheinen sie hohl, die Wandung zum Theil fein längsgestreift, in grössern Intervallen au untern Ende quergeringelt, die Wurel mehr lı̈̈utig als hornig und erweitert. Die Spitze hat das Ansehn einer halben Jeder, man unterscheidet einen dïnnen mittleren Schaft, an deu anf der einen Seite ein schmales Blättchen sitzt; dieses ist melur nach oben hin am liande ein wenig eingekerht, und an der Spitze wie eine Säge fein gezïhnelt, in seinen untern Theil erkenne ich schräge nach innen herabsteigende Linien. Auf der andern Seite des Schaftes stehen nur ein Paar winzige Zühnchen.

Der in die Leibeshühle hineinragende Theil des Borstenbïschels, wird ron einer höutigen Scheide umgeben und so zusamuengehalten; sie entsteht aus ein paar platten Muskelsträngen, wrlche an den Grenzen der ohern (weiter unten bescliriebenen) Lücke oder Rinne von der allgemeinen Längsschicht sich ablösen und in Fornı eines Andreaskıeuzes um die für das Bündel hestimmte Oeffnung sich inseriren.

Die Hakenborsten haben die Form eines schwach gekrümuten Lateinischen S, sind im Verhälıniss zu den andern sehr kırz, unıl ich habe bisher keine gesonderte Muskeln entdeckt, durch welche sie bewegt würden; während man dieselben bei jenen sogleich bemerkt.

An die Basis nänlich des in die Leibeshöhle hineinragenden Borstenhüschels setzen sich, sternförmig zusammenlaufend, $6-8$ und noch mehr lange, zarte, theils von den benachbarten Fasern der inneren Schicht entspringende, theils aus der iussern Ringfaserschicht entstehende, durch die Lürke tretende Bündel - einzelne der ersteren erstrecken sich wohl bis auf dic halhe Loinge eines S'egmentes - durch deren gemeinsanes Anziehen natürlich die Borsten hervorgedrïngt werlen nüssen; und durch die Wirkung eines Muskels, welcher von Nervenstrang, also der Mittellinie der Bauchfläche, ausläuft, treten hinwiederum die Bewegungsögane mehr in die Leibeshïhle zurück. Die Richtıng, nach welcher das Borstenbündel sich wenden soll, hängt von der Thätigkeit einzelner mter jenen Strängen ab. Meiderlei Borsten, zumal die hakigen, werden suit dem Abziehen der Oberhaut leicht entfernt, ein Zeichén, wie fest sie von ihr unschlossen sind.

Längs der ganzen Reilıe der obern und untern Borsten zeigt sirh in der Längsmuskelschicht cine schmale Lïcke, so dass hier nur die Querunuskellage die Wandung bildet; eine andere, noch viel schmülere Rinne befindet sich in der Mitte der Rückenund Bauchseite, daher die Längsmuskeln sechs an Breite verschiedene Partieen darstellen. Ausserdem hahe ich einer eigenthümlichen Anordnung zu erwälnen: es entspringen von den Rändern des Nervenstranges eine Menge ganz durchsichtiger, schmaler, wälurend ihres Verlaufes nirgends angehefteter, Membranen, welche an der erst erwïhnten Furehe der 
buern burstenbündel sich inseriren und aus feinen, ihrem Verlauf parallelen, Fasern bestehen; in vordesten Theil des lï̈rpers haher sie fast die lierm sehr langgezogener Dreiceke, weiterlin, wo die zum Geschlechtsapparat gehörigen Bhosen aufreten, werden sie hreiter, und ilıre Zalul entspricht hier den einzelnen lileinen hörperringen; mit dem Aufhieren del lismun jedoch nehmen sic wieder bald die erstere Form an, nur dass sie viel dichter als vorn hinter einander liegen: am hreitesten finde ich immer dic beiden Inserrionsstellen. Denkt man sich die Arenicola in lehenden Zustande, so müssen diese Binden den schweren larm wic ein parar stratle Wïnde unterstützen, und dieses scheint um so nothwendiger, als in der That wahre Scheidewinde, welehe in Sabella, Cirratulus 11. a. m. vorkommen und den Darm umfassen, in unserm Thier nicht durchweg zu finten sind. Nur in leun Sichwinzende und in dem vordersten, sachförmigen Körperstück stiisst min nuf Disscpimente, jedoch sind sic in ersterem nicht vollkommen geschlossen, denn ich konnte über dem Nervenstrang mit der Sonde durch sie hindurchdringen. Das uste dersollun schliesst zugleich vorn dic Jeiheshöhle, ist von den andern verschieden gehaut, und bedarf daher ciner näheren Betrachung. - Lnmittelbar nämlich vor deu ersten Borstenbündel entspringt aus der ganzen Peripherie der Liingsfaserschicht ein doppelter lireis son louden, jeder derselben breitet sich zu einem Blate aus, welches den Schind umfasst: wälırend aber die Basen der beiden Bläter an der Peripherie nahe hinter einandar liegen, stelen ihre Insertionsstellen am Schlunde veit ron einander ah, so dass zwiselien ihnen ein anschnlicher Maum cingeschlossen ist, von dem Ansehn etwa eizes in seirer Ixe durchbohrten Dopjellingels.

An der hintern Wand gu beiden Seiten des siblundes hangt ein lieuteleben, das in den elon beschrichenen kaum mündet, und hisweiten nach inaen eingestülpt jst: zwar frlaube ich in llarre cinen lingang aus demselhen in tren Schlund gefunden zu laben, spitcrhin aber konate ich diese Vermuthung, zu welcher anch delle Chiaie's angabe berechtigt, nicht bestïtigen, und es bleiht dahin gestell, welchen Zwecli dia Beutelchen laben. - llic beiden nächst folgenden einfachen Scheidewïnde befinden sieh an dem gten und 3ten Borsienbiuschel, und schr zahlreich stehen sie im Schwanzende.

Wis den ganzen Kïrjer fest umkleido. ist laujtsäch!ich rine feste Epidermis, von wllkmmener Durchsichtigkeit, ohne besundern Glanz mer Farhenspiel, we!che auf dem Rïssel die lindrücke seiner Papiilen anniums, und einc Strcele weiterhin der Oberhau heschilieter leptilien ihnelt. Donn man benerlit in ihr regelmässige, ein wenig emporgehulbene, lucitu Fldur, won foinen vertielten Streifen begrenzt, den Feidern haftet auf Jer untern Plïphe vine dunble Misso an. oftenhar ein Theil der son der Epidernis bedrcks'n I'igmentichich, mit walcher die rigentiohe Isederlatut vereingt ist. Im hintern 
gleichüissigen Alsschnitt des Körpers trift man, weil das Pigment sich nicht zu solchen Flächen ansammelt, auch keine so auflallende Muster in der Fipidermis.

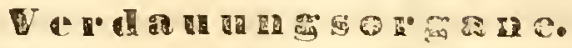

Der verdauende Kanal verlïuft fast ganz gerade ron vorn nach hinten, und ist mur in dem weiten sackförmigen Theile des Wurmes ein wenig hin- und ler-gekrümm; eben da hat er selher die grösseste Weite, nach beiden Enden nimmt sie ab. So wie sirh die allgemeine Muskelfaserschicht des Kïrpers in den Rüssel fortsetzt, und hier in die Muskelhatut des verdatenden lianals sich unwandelt, deren sehr viel zartere Fasern nach anssen in die Länge, nard innen in die Quere laufen, ebenso triot die Epidermis zum Rüssel hinein, um als Epitelium Schlund und Darm auszukleiden. Die Veränderung in ilhrem Wesen ist anfangs ehen nicht merklich, nur dass sie am Schlunde leichter, späterhin schwieriger al,gelöst werden kann.

Mlit den Namen Schlınd bezeichne ich denjenigen Abschnitt des rerdauenden Kanals, welcher von der oben beschriebenen Taschenfalte des Rüssels his zur Einmündung der beiden ansehnlichen, von allen Beobachtern erwähnten Bläsen reicht. Seine Wandung ist stïrker und gleichartiger als die des eigentlichen Darmes, seine Innenflïche gewïhnlich mit reichlichem schleim bekleidet, in dem ich wiederholentlich eie Menge mikroscopischer borstenförmiger Körperchen finde, welche unter starker Vergriisserung betrachtet, Bündelchen zusammensetzen, wie farblose Röhrchen aussehen, und an Synedern erinnern. Sollien sie eigenthüıliche Gebilde dieses Theiles der Schleinhaut sein? Denn weiter unten habe ich sie in Darm nicht henerkt.

A nmerkung. Ganz ïhnliche IJïrchen sind mir in dem Selılein der Fülller ron Actinia effocta begegnet und so zahllos, diss die ganze Innenfliehe dieser Theile daraus zu bestehen schien.

Zwischen dem 4 ten und 5 ten Borstenbïndel sü̈ndet in den hier etwas rerengten verdauenden Kanal jederseits von oben eine lïngliche gelbe Bínse ron etwil 1 Centm. Länge, durch einen kurzen feinen Ausführungsgang. Sie hat ungefïhr die Form eines bald nehr cylindrischen, bald mehr conischen Beutels, dessen unteres Stïck sichtlich dickwandiger als der spitze Zipfel ist, und nit einem Eichellecherchen verglichen werden lann. Der Inhalt dieser, nur theilweise durch ein Ligament an den Darn befestigten, sonst frei in die Leibeshöhle hängenden Blasen ist eine dickliche Flüssigkeit, und die Wandung aus welcher dieselbe - wie dies schon Meckel und li. Wigner ausgesprochen haben, - wohl 
zur Beförderung der Verdaung secernirt wird, ist fein gestreift. Am Basalende treten die Sireifen so stark hervor, dass mian sie füglich Falten otler Blätter nennen darf.

Ein paar ilhnliels gelegene Blasen hat neuerlich IJ. Rathke hei Nereis pulsatoria nacligewiesen, auch er hailt sie für Stellsertreter der Leher").

Gleich hintw der lïinmündungsstelle heginnt der anfïnglich stark erweiterte Darm: vielleirlıt darf man diesen sehr erweiterten Theil, welcher etwas hin und hergebogen ist, dem Magen anderer Inneliden rergleirlen. Der ganze Darm, sehr dünnwandig nnd durchsichtig, ist mit rinem regelmïssigen letz von Gefïssmaschen unstrickt, dessen Inorknung ich im nïchstfolgenden Abschnitt genauer beschreilen werde. Jede Masche umschliesst ein etwas hervortretendes orales Felıt, und durelizieht es mit feinen lederehen, was in lelıenden Zustande, da sich diese purpurrothen . Net\%e auf einem hochgelhen Grumle aushreiten, einen sehr schïnen Anhliek gew ̈̈hrt. Schneidet man den Darm auf, und lestrachtel die Innenflishe unter einer mïssigen Vergrösserung, so hemerkt man, dass jedtes Feld mit einer Menge kleiner Sückchen besetzt ist, welche in die Höhle dieses hanals hineinragen, denn man kann sie nit der Spitze einer Nadel hin- und herbewegen. lirst in lintern Tleil des Darmes hören sie gänzlich auf $" *$ ).

Solhen aneh diese Beutclehen die Function der Eseber übernehmen, mit welcher duch schon jene grossen Bhasen behaftet scheinen? Viel eher halte irh dafür, sie dienten zum Aufsaugen Jes Nahrungssitofies und wären als eine Irt Darmzotten anzusehen.

Je mehr mau sirh dem linde des Schwanzes näher,, um so engrr legt sich der Darm an die Kïrprerwandung; wenn aber Oken sich des Ausducks hedient, der verdaurnde Kimal ginge in die liande der Bauchhöhle über, so dauf man dies nicht wörtlich rorstehen; es greliang mir immer das Darmoho von dor Mluskelschicht zu trennen, und es whe grosse Mihe vollkommen albzuliisen. - Mie Ciestalt des lfters ist in verschiedenen Exemplaren verschieden; einige Male ragte die Mürkenseite üher die untere hinüher, und seine Oeflnung ersthien hammerförnig, gewöhnlich aber sahe ieh nur eine quere Spalte.

Die unmillelhare liefestigung des Darms bildet theils ein sehmales, auf seinem Rïrken verlaufentes Ioigament, theils eine Menge von ihm an die Muskelschicht gehender, durelı dïnne Membranen verbundener, paarigror Gefïssäste, theils die ilın umschliessenden Schecidewinde an vordern und hintern linde des Thieres: nichts desin weniger liegt er in dem sarbfömig crweiteren Thoile immer newh frei genug, um hier sich ein wenig hin-

") s. II. Rathke de Eopyro et Nereide commentationes Tab. II. Hg " $\%$.

*) Leo sagt com Regenwurm: Canalem cibarium prr totam longitudinem extrorsun el introrsum matelia lloccosa el thiva oblegit. 
und her zu biegen. Was endlich den Darminhalt betrifft, so besteht er fast allein aus Sand und Trümmern kleiner Conchylien, nit einer sehleimigen Masse vermischt, durchaus ähnlich dem Sipunkel, an welehen auch die Dünnwandigkeit des Speisekanals erinnert. In beiden ist er so durchsichtig, dass man die Contenta ganz deutlich erkennt, und so zart, dass an minder gut erhaltenen Exemplaren die Schwere des Sandes die Wandung durchreisst. - Die Ausleerungen erfolgen nicht selten; Savigny sagt, dass man an dem Unrath dieser Würmer leicht ihre Wohnungen erkenne, gleichwohl würde nur der während der Ebbezeit aufgehäufte in Betracht kommen, da den andern das Wasser fortspülen müsste.

\section{Gefiisssystem und Blutlauf.}

Das Gefïsssystem der Arenicola ist hiufiger beschrieben und ahgebildet worden als das irgend einer andern in Meer Jehenden Annelide; allein die Beobachter weiehen in so vielen Stïcken von einander al, ja sie widerspreehen sich in manchem so ganz und gar, dass man ohne einem derselhen Lnreeht zu thun, sich kein Bild daron entwerfen kann. Als sich mir die lang ersehnte Gelegenheit bot, dieses Thier in Havre zu untersuchen, war die so vieles berichtigende neueste Hlitheilung über seine Circulation von Johannes Müller noch nicht in meine Ilïnde gelangt, und ich hoffe um so eher, dass die Resultate meiner Arbeit der Wahrheit recht nahe kommen, da ich mit den seinigen in manchem übereinstimme, überdies aber den Tortheil genoss, den Wurm im frischen Zustande, wenn auch nur einige Tage, beobachten und zergliedern zu kïnnen. Indem ich also die Anzahl und den Zusammenhang der Gefïssstïmme nach der eigenen Untersuchung beschreihe, werde irh damit die Angaben der andern Beobachter zusammenstellen, um so jeder neneren Prüfung dieser Verhälınisse in die Hände zu arheiten.

Die Schwierigkeit der Untersuchung dieses Gefüsssystems liegt darin, dass Arenicola nicht im ganzen Verlauf ihrer Länge gleich organisirt ist, wie die Mehrzahl der andern Anueliden, dass die Gefïssstïmme in dem einen lbselnnitte des Thieres ganz andere Verhältnisse eingehen als in dem andern, dass man also nicht aus der vordern Hälfte auf die Bescliaffenheit der hintern schliessen darf, snndern mit grösserer Mühe als sonst alle Segmente durchweg prüfen und rergleichen muss. Lm die Darstellung anschaulieher z.u machen, erinnere ich daran, dass unsere Arenieola in drei grosse Alschnilte zerfällt: der vorderste trägt nur Borstenbündel, der mittlere Borstenbündel und Kiemen, der hinterste keines ron heiden, sondern vorzüglich nur Papillen. 
Jede Kieme erloilt ein oleres und ein unteres Gefiss, im Ganzen also haben wir 13 obere und 13 untere Pilare rom Kiemenadern. Dic umern sind sïmmolich Leste eines, den ganzen liürper durehziehenden, uncrlablb des Darmkanals und über dem Nerrensirang gelogenen, lliuptstammes - (ich will iln mit dem Nimen Vas ventrale principale, Il a uptbauchafiass, bezeichnen; Müllers Siamm B). Die obern hingegen

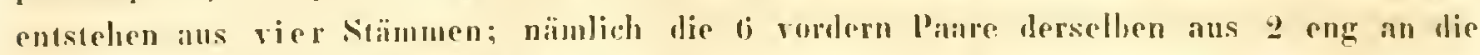
untere Pläche des Darmkinals solbst gehefteten Iängsgefässen, welche fast unmillelliar neluen einander, zu heiden Seiten der Mithellinie verlinfen, und häher als das V. ventrale liegen - (Vasa intestinalia inferiora, untere Darugefiisse), - die Z himem Piale der whern liemenadern endlich kommen aus ? Rü̈kenstïmunen: der eine gehört der Rürkenflithe des Damkanals an - (Vas intestinale superius, oberes Darmgefïss) - der andere hefindet sich dicht üher ihm, und bildet das starke Rückengefäss (Vis dorsale; Mïllers Stumm -1).

J. Miiller und Ilome lagegen leiten die ohern Kiementern alle vom Rüickengefïss, die untern rom Haupthauchgefïss her, Olien die obern von den Vasis intestinalibus in-

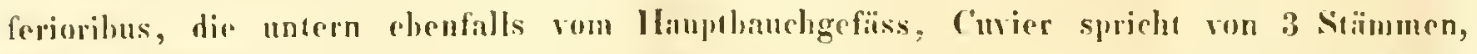
V. dorsale, V. intestinale superius und V. ventrale, die olsern kiemenadern sollen leste Jes V. dorsale, die untern Leste der leiden anderu sein. Fhenso sehe rariirt die Ingahe der Zahl der Kiemenadern: Ilone allein stimm mit der ron mir genannten ïberein.

Am Dacmkinal 1. h. an der lbheilung des verdanenden kanales, welche hinter der Finuaindung der beiden Bhasen herinnt, bemerkt man eil grossmaschiges starkes, denscellorn ganz umspinnendes Gefiissnez: es emstelu aus dem bbom und den untern

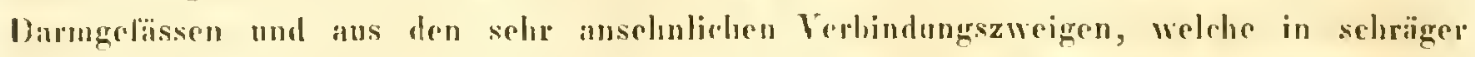

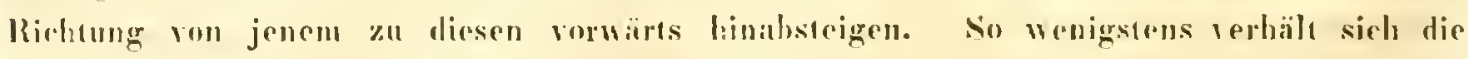

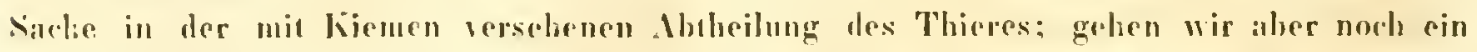
wenig curwärts, so stosson wir schon auf eine andere Anordnung: wir solien liee an den

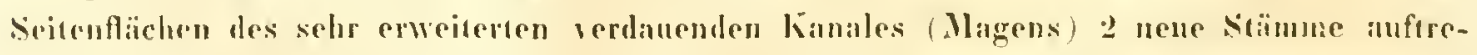
ten (Visat intestinalia latcriliat, seitliche l)armgefiisse), welche rechunklige

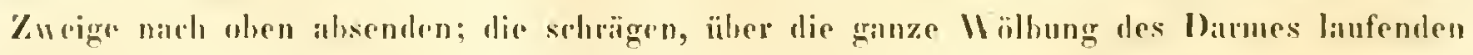

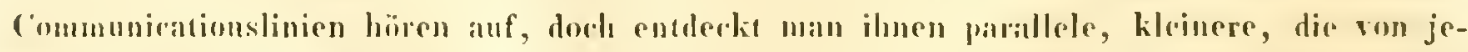

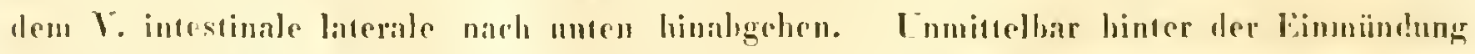

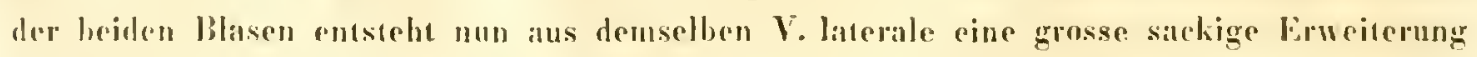
(1)armblublybälere; sie ist dureh einen nach hinten und unten gerielueten Gang mit dem Jauphandlygefïss verbunden, einen solehen Zusammenhang alher mit dem Rürken-

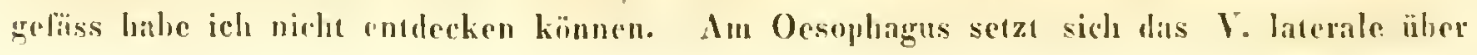


disse Erweiterung hinaus fort, obwohl viel dünner als vorhin, die Vasa intestinalia inferiora und das V. int. superius scheinen hier verselwunden zu sein, vielleicht verschuilzt das letztere nit dem V. dorsale, so dass in dieser Gegend des Verdaungskanals nur 4 Längsgefüsse sichtbar sind. So lange jedoch das obere Darmgefüss existirt, sielıt man aus ihu eine Reihe feiner Zweige in's Rürkengefäss treten; Mïller, weleher nur einen untern Darmstamm angiebt, glaubt eine äluliche Verbindung zovischen diesem und dem Hauptbauchgefïss, auch erkennt man deulich Zweige des letzteren, die zur untern Wand des Darmes laufen, sie scheinen sich aber zunächst in die schuale Liïcke zwischen den beiden untern Darmstämmen zu begeben. Eudlich in dem letzten Dritheil, deu sogenannten Schwanzstiick, konnte ich nur noch das Rü̈cken- und das IIupubauchgefäss unterscheiden; zwischen ihnen waren zarte Netze ausgebreitet.

Dieses sind die llanptstämme ler Arenicola, und so steht ihr Verhälthiss zum Verdauungskanal und den Jhmungsorganen. Wir wollen jetzt ihre Bezichung zu dem Nervenstrang, den Generationsorganen, den Muskwschichten und der IIaut betrachten; wohei es aufallen muss, dass hierin ein Stamm die Inuptrolle zu spielen scheint, das Vas ventrale principale.

Den Nervenstrang hegleiten zu beiden Seiten feine Iederchen - von Müller zuerst erwälnt und sehr bezeichnend Vasa nervosn-abdominalia genannt, - welehe aus den zu den Borstenbündeln gehenden Jesten des IInuphanchgefässes entstehen; da jedoch die Zweige derselben, deren gahelige Spaltung jene Gefässe herrorbringt, stirker als diese selbst zu sein pflegen, die Gefïsse auch nicht immer continuirlich verfolgt werden können, so darí man sie sich nicht als ansehnliche die ganze Länge des Thieres durlulanfende Stämme denken. Diese Beobachtung gilt namentliclı von den Aesten der 6 rordern, nicht mit Kiemen versehenen Borstenhüudel, in der Gegend der hintersten kommen die Ursprïnge der Vasa nervoso-abdominalia aus dem V. ventrale unmitlelbar. Wo Kiemen und Borstenhündel zusammenstehen, versorgt die Kiemenajer diese zugleich nit, und was von der versehiedenen Entstehung der obern Kiemenadern gesagt ist, gilt also auch für diese. Besonderer Erwähnung hedürfen daher nur die vordern 6 Bündel, unter denen die ersten vier ilive oberen Jeste vom Rückengefïss, die letzten zwei ron den Vasis intestinalibus inferioribus empfangen, die untern gehören sümmtlich dem V. ventrale prineipale an. Regeluässig hahe jeb, wenigstens am 5 ten und Gten Borstenhündel zwischen den obern und untern eine directe Verbindung wahrgenommen. Hinter den Borstenhündeln nänlich rom 4ten bis zun 10 ten Körpersegment liegen 6 zum Geschlechtsapparat gehörige Blasen oder Beutel, hinter jedem eine; zu ihnen sendet der Ast des V. ventrale, che er das Bündel erreicht, (aber nachdem er schon das V. nervoso-abdominale versurgt 
hat) eill feines Iederchen, welches eben sowohl als die Fortsetzung eine kanumartige Reihe von Seitensprossen treibt, deren Zweck - denn sie enden stumpf und sind nur kurz mir nicht einleuchtet; iibrigens gehören zu allen 12 Beuteln solche lï̈umchen. Nind diese Sprosscu des untern Borstenastes ahgegangen, so rerbindet sich mit ihm ein Communicationszweig des ohern Borstenastes. - In den Borstenbüschelchen nun werden theils deren lrsondere Muskeln, theils die Ungehung der allyemeinen Muskelschichten hedacht, doch erseheint dies nur spiitlich in Vergleich mit der ïheraus grossen Anzahl der Zweige, welche im hintern Theil des Wurmes, im Bereich der letzlen Kiemen und noch weiter fort zur lïrperwandung ahgehen, und bier unterhalb der muskulisen Querbinden ansehnliche Gurissnetze billen: sonderbarer II eise scheinen alle diese Zweige nur dem Vas ventrale principale anzugehïren.

Man hatte immer Home in Verlacht, dass er bei seiner kurzen Reschreibung dieses Ciefïsssystems die obere Seite der Arenieola mit der untern verwechsolt, weil er den Nerven ,über dem lä̈ckengefäss" gesehen habe; vielleicht heisst es in dem mir unhekanntrn Original, auf dem Rückengefïss", und dann liesse er sich noch leichter vertheidigen. benn min bemerkt, zmal im frischen Zustande, anf diesen Gefäss cinen Weissen, etwas grlïzenden Streifen, ihu ganz eng angehefted, su dass, wo das Gefïss sich ein wenig schbingelt, wic am vordern Ditmtheil, der Streifen sich mitschlängelt. An ihn setzen sidh die Ligamentasern, durch die das $V$. lorsale und zugleich der an dasselbe befestign Darm mit der Rückenwandung des Leibes veldunden wird; velleicht hat IJune rliesen für rinen Jerven grehalten.

So bin ich nun an den schwierigsten Punct gelangt, die linwicklung meiner Insicht, "ie in diesem so zusammengesetzten Gefïssystem die Blutströnung vor sich gehe. Meine lbeobachtungen an lebenden Exemplaren in llave reichen nicht zu ihrer lbegrïndung ais, weil ich bor zwei lahren noch kejnesweges anf alle die Fragen gekommen war, Wrelce sich beim längeren Sudium aufringen, überilies auch nur wenige Tage unter ungünsigen Lnstïnden an jenem Ort mir vergönnt warn. Zuerst makte jeh mich an un-

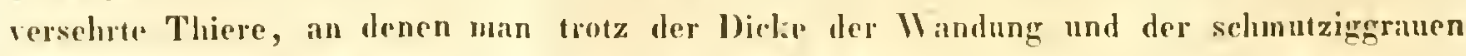
Farhe mit diner mässigen Lompe schon mancherlej wahnimut: ich erkannte die Vasa ner-

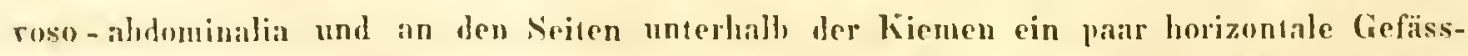
stammolien, wrlche bald mehr, bald weniger dentlich wurden, etwa in der Mitte der Segmente dureb einen Verbindungszweig zusammenhingen, und sich in zarte Geflechte ausbreitrten; las obere schickte cinen Zweig zur Kieme, einen andern zun Borstenbündel; (onn diesen llaupgrefissen habe ich späterhin an aufhewahrten. bxemplaren so gut als gar nichts mehr erkanut); auch bemerkte ich in Schwanztheil ohen das liückengefiss, und an jungen durchscheinenderen Thieren sugar dessen Fortsetzung zuischen den Kienen, wie 
sich's von hinten nach rorn contrahirte, wir aus seitlichen auf oder nherhalb des Darmes gelegenen Aesten (vermuthlich den ohern Kiemenadern) eine Blutwelle lineinstrïnte, und von der hinten andrängenden Woge im Rückengefäss selhst unitgenommen wurde. - Um melır zu erfahren, äflnete ich nun eine Arenirnla durch einen behutsamen Rü̈kenlängsschnitt, da fielen mir zun ersten Mal alle jene andere Hlauptstïmme in's Lnge und die Darmnetze mit den seitlichen Blutbehtiliern, ein überaschender Mnblick! Weil sich jetoch der Wurm heftig kriummte und zusammenzog, war auf eime ruhige sichere Beobarhtung nicht zu rechnen; ganz deulich erkinnte ich nur in der Wandung des Darmblutbehälters unregelmïssige weisse Streifen, :̈lnulich den Muskelbündeln in den Vorkanmern des Froschherzens; er contrahirte sich kriftig, und ergoss Blut in das Haupthauchgefïss. Die Dissepimente vorn, und namentlicls die beiden Beutelchen an dem ersten erschienen sehr reich an Aederchen, reichlich versorgt wuden auch die in den verdanenden Kanal mündenden Blasen. An den Vasis lateralibus und dem Vas rentrale bemerkte ich keine Contractionen, doch werfe ich mir vor, diese untern Theile gegen die obern zu selur vernachlissigt zu lıahen.

Da das Hauptbauclgefïss zu allen Kiemen untere Aeste sendet, die rolle Zalıl der obern jedoch nur durch Sumnirnng mehrerer verschieden gelegener Stïmme heranskomut, so glaube ich, dass die letzteren sich ergïnzen, und einerlei Bedentung haben, aber eine dem Hauptbaukhgefäss entgegengesetzte, dass dieses Blut in die Kiemen führt, jene die Vasa intestinalia inferiora, das $V$. int. superius und dorsale - es aus den Kiemen empfangen, dieses also venïser, jene arterieller Nitur sind. - In den Maschen der Darmnetze sammelt sich das aus ihren feinsten Zwrigen aufyenommene frischbereitete Blut, wird theils durch die seitlichen Stämme und die Darmblutbehälter in's Vas ventrale getrieben, theils wohl unmittelhar mit dem nach dem Darm strömenden arteriellen rermiseht; rermuthlich dienen auch die feinen Verbindungszweige des $V$. ventrale mit dem Darn zu einer solehen Vernischang. Ferner empfüngt dieses Bhut aus den Vetzen der Muskelschichten, und führt es mit dem rom verdaneuden Kanal gekommenen in die Kiemen, danit es von dort, der Emïhrung fälig, in die oberen Kiemenarterien und in andere Hautnetze ströme. In Scluwanzende, wo Kiemen fehlen, kann ich mir nur eine Irautathmung denken, und es mag die Secretion des gelhen sehleimes der Wärzchen wesentlich damit zusinumenhängen. - Die Norenstrang - Gefässe entleeren sich in die renïsen untern liemenäste und ausserden bekommt der Tervenstring wahrscheinlich arterielles Blut aus Hautnetyen, denn er liegt xiemlich oberflächlich. -

Zugleich findet im liiickengefäss die ('ontraction nach vorn statt, wäbrend unten im Hauptbauchgefäss eine entgegengesetze Richung der Strömung rorherrscht; so würden 
die vordern Borstenbiindel und ilure l'mgebung von oben her ernährt weresen, desgleichen der Schlundnervenring.

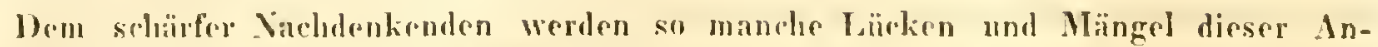
sicht nicht enterehen; auch machen mich bedentende Antoritilen selü̈chtern, wolehe das

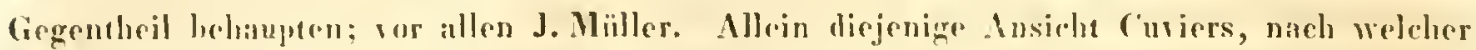
J. Mäller die Richtung der llauptströme als belannt vorausset\%t, scheint die ältere, später von ihm widerufene ${ }^{*}$ zu sein, und vielleicht hat Jome doch nicht das Oben und Unten verwechselt; lebende Arenicolen aber hatte J. Mäller bisher nioht fielegenheit zu untersuchen. Mit grosser Erwartung sehe ich nun den netresten lplocien von Mline Fdwards entgegen: die Mittheilungen welche das l'Instiut daraus lervorlıcht, zeigen, dass er sie sehr umfassend angelegt, und wïhrend eines längeren Iufenthalts am Mecre unternommen hat, und versprerhen viele wichigge und sichere Resultate.

So biel Wenigstens scheint ansgemacht, dass die lichtung des Blutstroutes im

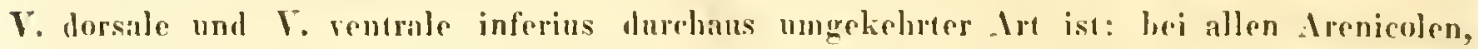
die ich älnete, liefen die obern und die unteru liemenäste einandep parallel, sclurïge hincrwärts vom Datrm zu den dthmungsorganen; es werden also die das kiemenblut zum Darm führenden dasselbe in den ihnen angahörenden llauptstämmen nach vorn treiben, im Gegentheil werten die Kiemenarterien aus einem von vorn kommendem Surome gespeist weren, wojl sie ihren lubalt nach hinten ergiessen.

A n merkung. Beide Jeste finden wir immer durch eine dünne Membran vereinigh, und die oheren pflegen ein wenig früles am Dam angeseres zu sein als die untern. Dre Curmd jener schusigen lichtung liegt dariu, dass allerdings, wenn der verdauende lianal griade ausgesterekt lïge, die In- und Shgangsstellen der

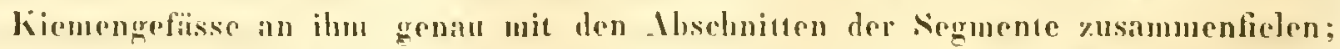
nun aber ist derselbo in dem vordem weiten Theile des Thieres ein wenig hill- und herecelogeren, also verkïrn, und somit werden jene stellen nach vorn grerïclit.

Dass aloer die rerschiplene sirömung des Blutes mit einer entgegengesetgen Bedenung der stämue ichunden soi, lehrt auch die farbe: bei lixemplaren, welebe ich lebend in spiritus geset\%, fand ich nach drei stumlen das llauptbauchgefiss fast schwärz-

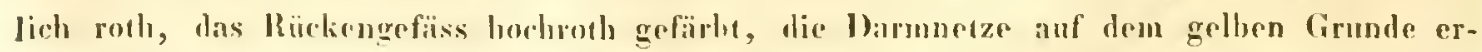
schienen lebhafier ats das llauptbanchgefoiss. - Mas dunklere Blut halte ich für

9) s. Meckels vergl. Anat. Thl. 5. pag. 59. 
das mehr venïse - (denn ron einem vollkommen getrennten lireislauf kanri nicht die Rede sein). -

Selon wir ron diesen Beobachtnngen ab, so finden wir doch anch mehr Lehereinstimmung mit fer Circulation anderer Kiomonwirmer, wrun das mehr ateriplle Blut nach vorn strömt; ich glanhe, dass auf diese Rirhtung der Shhlundring und seine Gehirnganglien, so schwach diese Theile ath entwiekelt sein mïgen, cinen wesentliehen linfuss haben.

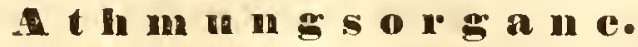

Die Zahl der liemen hahe ich sowohl hei kleinen als grossen Individuen bestïndig gleich gefunden, jederseits 13, Oken und (uvier sprechen ron 16, delle Chiaie *) ron 15 Paaren, Miiller bei seiner Arenienla earhnnaria von 14 liemenaderparen. Sie nehmen nach der Mitte hin an Unfang \%n, und hilden niedrige Biisehel mit mehreren (S bis 12) quer nebencinandersichenden stark rerweigten Stämmehen, welche sich wïhrend des Lebens bald sehr lebbaft zusammenziehen, bald wieder ausdehnen, und dunkelroth im gefïlten, graulich sshwar\% im leeren Zustande aussehen. Als ich dieses Phänomen zum erstenmal anselbaute, glaulhe ich, wegen der Schnelligkeit, mil der os geschieht, dass sich das Blut in den ganzen innern laum der Zweige ergösse, und aus ihu anf eimmal in die Kiemenrenen gepunpt würte; ich schnilt also, mu darüber in Gewissheit zu koumen, einen Zweig ah, und brache ihn unter das Mikroskop; fast alles Blut war herausgeflossen, doch gelang wir's an der spitze des Zweiges noch einige Blutkügelehen in einem Gefässgefle der Wandung wahrzunehmen; Weiler erkannte ich dunkel gefürbte ringförmige Furchen in der ganzen Lünge des Zweiges, offenbar die Grenzen der eigentlichen Wandung selbst, denn die sie bekleidende fubblose Oherhaut untersehied ich daron deutlich. Vielleicht laufen in jenen Furehen cinander hegegnende Halbkreise von Gefïssen. An Spirimsexemplaren suchie ich rergeblich nach Gefïssspuren, desto sichtbarer waren an den emtrahirten Kiemen jene Furchen, wodureh sie glisderartig ringesehnürt wurden ${ }^{*}$ ). Was mich aher hesonders in Erstaunen setzle, war das Erscheinen von eiähnlichen Körperchen in den Kiemenstïmuen selhst, also müssen dieselben lohl sein. Zn meiner grossen lirembe las ich in der so genauen liearbeitung der Nereiden durch II. Rathke,

*) Die Abbildung delle Chiaies in seinen Memoiren zeigt nur 7 liemen- und 80 Fusspaare und jst, wenn sie $A$. piscatorum vorstellen soll, unvollständig.

**) vergl. Leuckart. Ueber die äusseren Kiemen der Lmbryonen von Rochen und Hayen. pas. 37. 
dass auch er zu gewissen Zeiten in den Athmungsorganen dieser W ïmer Fier angetroffen late, dies Vorkomuen alsu aurh sonst begriundet ist. - Itel,rigens ist das erste Kiemenpaar oftuals so likin, dass man es leicht übersicht; man muss es an tten Borstenbündel suchen, das letre an 19ten.

\section{Ge nerationsomane.}

So wenig man die beiden in den Darm mündenden Blasen in das Bereich der Geschlechtswerkzenge zn ziehen herechtigt ist, so gewiss scheinen die an der Seitenwandung des Kïrpers gelegenen Sïcke dahin zu gehören. Oken bildet 2 Paar ah, Home und Cuvier geben deren $5 \mathrm{an}$, ich hahe jedoch immer 6 gezühlt, nur ist bisweilen die Grösse des hintersten l'aares so unledentend, dass man leicht darüber linweggrht.

Nlle liegen in der untern schmalen Liïche der Eäingsmuskelschicht rom tten bis 10ten Borstenbündel, sind länglich runde Blasen, an vordern Theil etwas schmäler, am hintern etwas erweitert, mit einem Stück ihrer Seiterfliiche an die Leibeswandung gehefiet; und münden durch eine enge Spalte, unterhalb und etwas hinter den ohern Borstenbiindeln auf der Bauchflïche des Wurmes. - Thre Wandung ist dünn und farblos, in der Regel zussammengefallen, ihr Inhalt ein graulicher oder gelblicher Schleim, in welehem ieh im Monat Juli Jierchen entdeekte, und dies prinnerte mich sogleich lebhaft an die im Sipunculus vorkommenden zwri Blasen, deren lnneres auch zuweilen mit lierchen erfüllı ist ${ }^{*}$ ) uml deren sonstige Verhältnisse mit diesen so sehr übereinstimuen. - Werden aber, wie ('urer vermuthet, in diesen Sïrken dis Fier gehildet? Schwerlich: vielmehr scheint der Ont ihrer lintstehung die Banchhöhle zu sein. Sie sehwimmen hier in einem dicklirhen trïhen Fluidum, und zwal in so ungeheurer Masse, dass sie hinten fast den ganzen liaum zwischen Dirmu und Muskelschicht ausfüllen; nur in den vorderen durch die grossen Querscheidewïnde algesperten Segmenten, obsthon sie aucl eine trülse Flüssigkeit enthalten, lantte ich die Vierelien nicht wahrgenommen. - Ich suchte also in dem zweiten Dritheil meiner Irenicola nach Ovarien lange genug vergellich, his mis endlich die auffallende stïrke mancher Gefässiiste verdïehtig vorkim, welche, wie hereits ohen erwähnt,

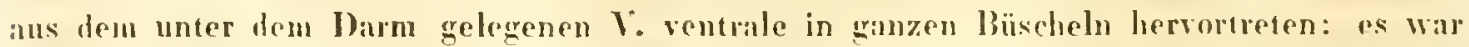
lofermilend, dass bei allen, noch so rorsichtig geïlneten bixemplaren cine Inzahl dersellon an deou andern linde nielit hefestigt will, sondern frei herablhing: auch bonnte

*) s. Müllers Archiv fur l'hysiol. IS3-. Heft 2. pag. 2i5. 
ich mir durenaus nicht erklären, warum in diesen, durch nichts besonders ausgezeichneten Alsschnitt des Kïrpers, die Gefässe so bedentend vermelurt sein sollten. Nachdem ich also ein paar solcher Aestchen vom Darm alggelöst, brachte ich sie unter eine 110 fache Vergrösserung, und erkannte nun, dass einige an uanchen Stellen dicker, an andern dünner waren. Es erschien um das Gefässchen eine zarte, häutige, knospige Masse geschlungen, welehe mit den entleerten Ovarien der Pleione ïbereinstimute, und ich glaube, dass dies die ursprüngliche Bilılungstätte der Eier ist. - In frischen Arenicolen werden spätere Beobachter diese an Spiritusexemplaren angestellte Betrachtung leicht und mit Sicherheit prüfen können. - Deunach wäre es nicht unstatthaft in jenen Blasenpaaren befruchtende, männliche, Organe zu sehen. - Den Weg aber, auf dem die Eierchen aus der Bauchhöhle in's freie Wasser gelangen, hahe ich erst sehr spät gefunden; indem ich nämlich die Epidermis der Bauchfläche abzog, und die Wülste, in welchen die Reihen der Hakenhorsten stecken, näher untersuchte, entdeckte ich zwisehen ihnen eine Menge Eier und sah cine Lücke, durch welche sie aus dem Cavum des Körpers durch die Längsnuskelschicht hindurchschlüpfen können.

\section{ye re ns yste m.}

Das Nervensystem der Arenicolen ist, da sich ron Gesichtsorganen und Fühlern keine Spur zeigt, und die Muskellagen minder stark und zusammengesetzt sind, auch viel weniger ausgebildet als in andern Anneliden. Ich sehe einen mitten auf der Bauchsrite verlaufenden Nervenstanm, der aus zwei, durch eine elastische, schwach glänzende Scheide rerlundenen Strängen besteht, sich nach hinten zu verschmïlert, nirgends deutliche runde Ganglien, sondern nur längliche, im contrahirten Zustande mehr zusammengedrängte, Inschwellungen bildet. Vor der doppelten, die Leibeshöhle vorn schliessenden Scheidewand, weichen die beiden Stränge unter einem ziemlich spitzen Winkel auseinander, jeder an die Körperwandung seiner Seite geheftet, um den sogenannten Schlundring zusammenzusetzen. Da nun aber der Schlund, un welchen dieser Ring in schr geneigter Stellung läuft, viol enger ist als der Durchmesser der dortigen Körperhïhlung, so ist die Untersuchung dor etwa daselbst entspringenden Nervenfäden, weil sie vermuthlich gar leicht zerreiss'n, überaus schwierig; mir ist es nicht gelungen, $Z_{\text {weige des }}$ Schlundringes, die an den verdauenden hanal träıen, uit Bestimmtheit nachzuweisen, wohl aber sieht man vou Nervenstrang selbst während seines Verlanfes eine doppelıe leihe von Fäden rechtwinklich abgehen; sie: begeben sich sogleich unter die Schicht der Längsnuuskeln und lassen sich bis vor die Basis der Hakenborsten verfolgen. Ueber ihre genauere Verzweigung kann ich nieluts 
berichten, da üherhaup die Yerven der Arenicola viel zarter und sehwerer zu anterscheiden sind als in andern Wïrmern; nur der Hauptstamm ist auf den ersten Blick zu erkennen.

Oh der Schlundring bei dew Mangel von Fühlern und Augen einen einfachen wahren Gehirnknoten bilde, ist sehr fraglich. Der vordere Theil des Schlundringes nümlich ist derulıassen ron Muskelbündeln überdeckt, dass man dureh sie hindureh seinen Verlauf nicht deutlich wahrnelumen kann, und wenn man sie atıl̈sen will, in der Regel eine Partir des Markhalshandes mit zerstört. Doch halie ich wiederholentlich nahe der obern Mittellinie des Kürpers jederseits einen weissen Knoten erkannt, der sowohl mit dem gleichnamigen als mit den Schenkeln des Sehlundringes in unmittelbarer Verhindung zu stehen scheint. Aullallend ist ihre Gestalt, die ich an besten einem in der Mitte vertieften fast durchboluten lin̈̈̈pfehen vergleiche; nur einmal habe ich von ihnen auslaufende Fïden benerkt.

Len $\left.{ }^{*}\right)$ spricht zwar auch bei dem Regenwurm von einem über denı Oesophagus liegenden Ganglion, lildet aher zwei getrennte kinoten ah, und auch Cuvier erwilhnt bei der Arenicolin zweier knoten.

\section{T e e b e l a.}

Pallas. Niscellanea zonlogica uber T. (Nereis) conchilega pag 13i, rab. IX. fig. 17- 22. Savigny, Systeme des Annelides.

delle Chiaie. Memorie sulla storia elc. Vol. 111. pag. 168.

dete Chiaie. Istituzioni di linatomia etc.

Auf der Girenze zwischen der Gattung Irenicola und Sahella (Cus, oder Amphitrite Lam.), doch dem innern lhau nach niher mit jener verwandt stehen die Terebellen. Sie bohren sich nicht in den Meereshoden hinein, sondern wohnen schon in freien Häusern, indem sie auf Sieinen und Mluschelschaalen ihre kähren aus Sandkürnchen und Conchylienfragment'n hauen. Wit Hülfe der weit ausstreckharen Fühler werden diese Matecialien zusammengesurht, und durch den aus dem körper ansyeschwitzten Schlein ziemlich fest verhunden; auch ungeben sich die Fühler selhst theilweise mit ïhnlichen Rührehen, so dass das ganze Gehiiuse des Thieres etwa wie ein Stern mit einen stirken Stiel aussieht. -

") de structura lumbrici. pag. 3C. fig. VII. c. 
Die Fühler sitzen am vordersten Kürpersegment, das man, obgleich andere Sinnesorgane fehlen, mit dem Namen eines Kopfstückes belegen mag, und zwar auf dem hintern Rande seines obern weit vorspringenden Lappens, und bilden einen mehr oder weniger dichten Halbring. Sie kïnnen theils durch Einrollen, theils durch Contraction bedeutend verkürzt werden, - ihre grïsseste Länge habe ich bis auf 5 Centim., also elsen so lang oder noch länger als den Körper gefunden, - und dienen ausser dem ehen crwähnten $Z$ weck, wie die Fühler der Hỵdren und mancher Actinien, auch zur Ortshewegung. Dies gesehieht dadurch, dass die dicken gekriiuselten Ränder der auf ihrer untern Fläche bemerkharen Rinne sich fest anlegen, der zwischen ihnen befindliche Luftraum durch stärkere Wälbung des Fadens ausgelelunt wird, und der ganze Apparat nlso wie ein Saugnapf wirkend, den Ort festhïlt, gegen welchen hin der Körper nachgezogen wird. Auch abgeschnitten bewegen sich die Fühler noch einige Zeit hindurch lebhaft.

Der Kïrper zerfällt in eine grosse Anzahl ron Ringen, deren vordere auf der Bauchfläche eine Theihe mittlerer scharf begrenzter fleischiger Schilder zeigen. Dieser Kürpertheil, den Voigt in der Lebersetzung des Régne animal mit dem Namen der Brustringe bezeichnet, und welcher an den Bau der Sahellen und deren fleischige Bauchschilder erinnert, trägt zwei lheihen von Borsten: obere haarförmige, gerade, und untere hakige, ganz ähnlich wie in Arenicolia, nur mit dem Unterschicde, dass letztere in doppelten Kämmen stehen. Jene setzen etwas quergedrückte Bündel zusammen, sind überaus fein, an dem olern Ende schwach knieartig gebogen, und mit einem schmalen Randhlättchen an der Spitze versehen; diese nur kurz, und die Kämme mit den Haken einander zugekehrt. Während jene bald hinter den Brustringen aufhören, setzen sich diese in dem übrigen Theil des Körpers weiter fort, werden aher immer unscheinbarer, bis man sie am Schwanzende kaun mehr zu erkennen vermag.

Diejenige Art, von welcher das üher die Anatomie dieser Thiere gesagte, entnommen ist, mag vorläıfìg Terehella multisetosa benannt werden.

\section{repella maltisetosa. n.}

Der Wurm gehört unter die Abtheilung der Terebellen, die Savigny simplices nennt, bei denen der Stirnlappen ungetheilt, und die Anzahl der Kiemenpaare drei ist.

Der vordere, weite und aufgetriehene Theil des Körpers zählt 18 Segmente: in seiner Mittellinie unten läuft eine Reihe fleischiger Bauchschilder, von denen die hintersten 
dje schutilsten sind. Das erste hildet die Lippen für die Mundiffnung und den Stirnlappen ohen. Dann folgen dic 3 kiementragenden Segmente, deren rordere zwei an der Seite mit einem Fleischbuckel rersehen sind; das dritte zeigt scton einen Büschel von Haarbursten, iblher der sclmale Wulst unter demselben enthïlt noch keine Hakenhrorsten. Die nächsien 1.1 Segmente, welche noch Bauchschilder hahen, und hinter ihnen 7 andere

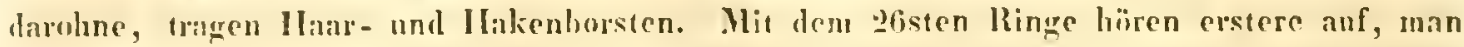
findet nur letztere trit denen ihnen eigenthümlichen Querwïlsten, und statt der Bauchschilder eine Biuchrinne. - Die Kiemen sind ïstig und haumförmig, das erste l'alar ist dils grïsseste.

Lnsere Irt stimnt in viclen Stücken mit T. Medusa (Savigng) ïherein, untersclueidet sich aher ron ihr dureh die grössere Anzahl der Borsteubüschel (nönlich s.?, wïhrend jene nur 17 besitzt), durch die geringere Menge ilırer Körperringe (bei unserer ctwa in, hei jener 90) und durch ihre Kleinheit (T. Nlsdusa misst iiher 9", unsere Int e. 5 (entm.). Auch habe ich keine schwarze Striche am Thorax bemerkt.

Dic Anordnung der Muskeln entspricht durchans den Arenicolen, auch jene handartigen, rom lerrenstrnng zu der obern Reihe der Borsten hinülierlaufenden, Muskellinden fehlen nicht, sind aber mehr in Form einzelner Bündel entwickelt und stärker. Zwischen der allgerneinen Muskellage des Kï̈rpers und der Fepilermis findet sích, hesonders stark in hintern Theil, eine in FIocken alblöshare Schiclit, bestehend aus dem Corium und dem daraus algresonderien ohen erwilinten Selicim. Die llählung des rorn selir emeiterten Leilies wird, wie dort, nur an einigen Stellen durch vollkommene Scheidewände in Fächer getheilt: an einem derselten entderkte ieli auch einmal die eigenthïmliehen, hei srenicoia rorkommenden Beutelchen, die ütirigen Dissepimente treten auf his zu dem dritten Paar der zu den Cienerationsurganen grehïrenden BTasen und ganz hinten im Schwanzende. Wis sie auflü̈ren, wird der lharmkanal seitlich von starken, sehnig glïnzenden, senkrecht strhenden, dreieckigen Membranen gehalten, die nit ihrer liasis durt, mit ihrer Spitze an der Leibeswandung ansizen, und den Darm theilweise lekkeiren: ancl hefestigen iln pinige l'asern an die Rücken- und Bauchflïhe. Aber die Bündel der Löingsmuskelsehicht treten in Arenicola stärker herrur.

In rerdauenden Kanal ist die Mlulieilung des Schlundes sclir kurz, im ührigen herscht auch hier die grïsste Lehereinstimmmg mit jener . Inoclide, wir nehmen dieselhe starke Erweiterung und lisegung in Infange walir, dieselhen erhahenen, und oralen Fel-

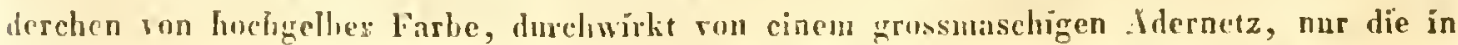
ihn mïndenden zweil Blasen hahe ich nicht gefunden, und man hemerkt da, wo der sehnigglänzeule Ueberzug des Darms leginnt, dem entsprechend, eine siel deutichere Inlage 
zu zelliger Einschnürung in seinem Innern. Dies geschieht etwa im 19ten Segment. Von einenr wahren liüssel ist keine Sjur rorhanden, viehmehr erinnert die Mundbildung schon an Sabella, wie sich denn auch an eineın der ersten Körpersegmente mancher Arten ein llaIskragen zrigt, hestehend in zwei fleischigen Lappen, welche freilich noch vollkommener bei Sabella Ventifabrum erscheiren.

Man kann sich in vieler Beziehung Terehella, wie eine forn mehr zusammengedrängte und redkürzte Arenicola vorstellen. So schrumpfen die dreizehn kiemenpaare des Sandwurms hier auf drei (nach Sarigny hei T. cincinnata Fabro anf zwei, und bei T. cristata Fabr. und T. ventricosa Bose gar auf eines) zusammen, desto höher und baunförmiger wird ihre Gestalt und das rarderste Paar scheint durehgängig das ansehnlichste. Bei T. cirrata S. ersclicinen die athmungsorgane als starke Quasten. Ihre Stellung ist in so fern von Her dortigen abweichond als sie näher an die Mittellinie des Rückens (Cuvier sagı bereichnend „sur le col"6) und ganz nach vorn gerückt sind, übrigens sind sie jenen analog gebildet, die Stïmme und Meste theilen sich meist gabelig, enthalten je zwei Gefässe, und ziehen sich sehr käftig zusannien.

Leider bin ich nunıehr ausser Stande, nit Schärfe den beiderseitígen Ursprung der Kiemengefässe anzugeben, da ich unr die Iloffnung, diese sn liäufig begegnenden Anneliden zu Ende meines Aufenthalts in NeapeI rulhiger untersuchen zu können, durch ungünstige äussere Umstïnde betrogen wurde. Was icli aus meinen ersten beobachtungen an frischen Individuen, und aus spätern an Weingeistexemplaren sorgfïlig unternommenen zusammenstellen kann, ist folgendes:

Unter dem Darm bemerkt man einen Löngsstann, der, nach seinen Aussehen und seiner Lage zu urtheilen, dem Vas ventrale principale (Müllers Stanm B.) zu vergleichen ist; lange Aeste gehen ron ilım zum Darm empor und andere nach unten zum Nervenstrang. - Auf dem Darm liegt ein suässig starkes liückengefäss, das von ihm Zweige erhält.

In der Stelle, an welcher der Sclilund in den weíten Theil des Darmkanals übergeht, gewahrte ich, dass jederseits ein halbringförmiger Gefïsshogen von unten über das Rückengefïss hinaufstieg; heide biogen rereinigten sieli zu einem kurzen ansehnlich dicken hanal und lieser spalteie sich vorn gahelig in zwei leste, jeder derselben wieder in drei, nicht gleichzeitig, sondern hinter einander trervortretende Zweige, welehe zu den Kiemenpaaren laufen. Der Ursprung jener Gefïssbogen sind zwei starke unter dem Darm dicht neben einander gelegene Längsgefüsse, rermuthlich ven Vasis intest. inferioribus der Arenicola analog, und dann wären jene Zweige Kiemenrenen. Die Bedeutung von Kiemenarterien kann ich, da iclr directe Beobachtungen über die Circulation nicht angestellt hahe, 
vorlaufig nur den Adern gehen, welche ich von dem llaupthauclugefiss nahe der Körperwandung gegen die Kicmen zu hinaufsteigen selie. Den Witheilungen von Liwards zufolge, (l'Institut. Oct. 153i. p. 340), wïrde das Hanphlauchgefäss arterieller Vatur sein, indem es Blut aus den Kiemen empfingt, das auf dem Darm laufende Gefäss venöser $N_{\text {atur, }}$, indem es das Blut durch unregelmässige Contractionen nach vorn und in die Kiemen treilut durch sein oberes Ende (ovtremité anterieure) soll das liückengefäss sein Blut empfangen. Die wesentlich nothwendigen genaueren Angahen felilen, und man ersieht nur, dass hier die Richung der Blustrïme von der in den Eunicen gänzlich ahweicht.

delle Chiaie ist zwar ausführlicher als I'allas, hefriedigt alıer auch nicht: Er hat sowohl Kiemenvenen als Kiemenarterien gefunden, doch sollte heiden ein Gefässring angehïren (der um den Schlund liegt), und in den sich anch die ddern der Fühlfiiden ergüssen.

A nmerkung. Die ganze Stelle hei delle Chiaie ist mir nicht klar geworden, er (rückt sich folgendermanssen aus "): Nelle Anfitriti ho ravisato, che il sangue de' cirri anteriori e delle loranchie si riunisca in due resiche oppure in unil, ad $\bar{\Lambda} e$ che vi si faccia un circolo sanguigno aortico ed enterico. - Sollten dies etwa zwei von einander verschiedene Zirkel sein, oder ein und dersellse? Weiterhin redet er von den Terebellen, als oh diese son seinen Amphitriten verschieden wären, und beschreibt in's besondere die Inordnung ihrer Gefässe, whne jedoch auch hier so ausführlich zu sein, dass man sich ein deutliches liild von der (irculation entwerfen kinn.

Suriel steht fest, dass delln Chiaie ausser dern Rïckengefins, welches sich vorn in das llerz fortsetzen soll, und rineul Bauchgefïss, zwei seitliche stïmme annimut, aus welchen er vorzugsweise die barmnetze ableitet. Dagegen ühergeht er ein paar stämmchen, wetehe den Nervenstrang in die Mitte nehmen, mil Stillschweigen. Wa sie ehenfalls durch Aeste mit dem Haupthanchgefiiss zusammenhïngen, so entsprechen sie vollkommen den Vasis nerroso-ventralihus der Arenicola; andere Zweige des untern wie des ohern Ilauptgefïsses rersorgen die Muskelschicht der Kïrperwandung. - Endlich auf dem hintorn Throl des Darmes hab' ich wiederholentlich zwei Stämue liemerkt; da der eine das Vas dorsile vorstellt, würde dinn der andere dem Vas intestinale superius analogr sein, doch uIu darüher zu hestimmen, bediuf es noch gründlicherer Nachforschungen und Vergrleichungen.

†) 1. pag. 318 . 
Der Nervenstamm, weleher sichtlich aus zwei eng rerbundenen Strängen besteht, umgiebt den Schlund mit einem ziemlich engen llinge und scheint von dem der vorigen Gattung nicht durch hesondere Verhältnisse abzuweichen.

Um zuletzt auf die Gencrationsorgane zu Jommen, so sprielst sieh auch hierin die Uebereinstimmung mit dem Sandwu'm in hohem Grade aus. Die gelblich weiss gefürbten Vierchen fïllen den Raum zwisehen Darm und Wandung des Körpers aus. Den Ort, au dem sie sich lilden, hat bereits Pallas entdeckt, und es ist wunderbar, dass in ten rergleichenden Anatomieen diese wichtige Angahe mit Stillsehweigen ühergangen wird. Nach ihı liegt auf den Batuhbinden ein flaches, hinten (am 9ten Ringe) in zwei Schenkel auslaufendes Organ, welehes unit kleinen Körnehen (granulis) gefültt ist, nach aussen zu münden scheint, und oflenbar das Orarium bedeutet. Die Mïndıng habe ich nicht finden können, das Organ aber ist unstreitbar vorhanden: es sieht weisslich aus, dic Oberfläche ist dureh hervorspringende Buchten und Wülste ungleich, mit einem Gefässnetz übersponnen, und sein Inhalt eine Unzahl kleiner Eierehel. Aussen unter einigen Borstenbüscheln der vordern lhinge, fand ich eine winzige l'apille und an ihrer Spilze eine Oeffnung; durch diese, glaube ich, gelangen die Eierchen aus der Bauchlsöhle in's Freie, in die Bauchhöhle aber werden sie nach meiner Vermuthung durch das Bersten der Ovarienwandung ergossen.

An merkung. Die Furehen, wodurch das beschriebene Organ so Iappig aussieht, gehn sehr tief, und stimmen mit der Anzahl jener Segnente des Körpers üherein; die Zartheit der Wandung verhindert mich aber mit Sicherheit zu behaupten, diss das Ganze ans einer Reihe hintereinander liegender getrennter Säckchen besteht, wie ich vermuthe.

Während wir in Arenicola sechs Paare seitlicher nach aussen mündender Blasen erwähnten, begegnen wir hier nur dreien von diesen wahrseheinlich befruchtenden Organen. (Pallas giebt vier an). Sie sind etwas platt gedrückt, langzipfelig, von dem darin enthaltenen Schleim grau oder gelblich gefärbt, und da er sich an den beiden Rändern anzuhäufen pflegt, sieht man in der Mitte hïufig einen durchscheinenden hellen Streifen verlaufen. In ihrer Form besizen diese Organe, deren Spizen sich his über den Darm, und zwischen die Kiemengefässäste zu krümmen pflegen, eine noch grössere Aehnlichkeit mit denen des Sipunkels als mit drenicola. Beide Würmer aber zeigen eine ligenthümlichleeit, welche mir bisher bei andern Anneliden noclı nicht begegnet ist. Inden iclı nämlich diese Thiere anhaltend in einer Schaale mit Mecrwasser heobachtete, bähten sie von Zeit zu Zeit ilıren Körper auf, ein Act, der lei Arenicola au hintersten Kiemenpaar legann, und dann weiter nach vorn fortschitt, wïlrend ich ihn an Terebella fast allein im vordersten weiten 
lärplertheil bemerkte: dabei weclselte anf eine merliwürdige Weise die Färbung der letzteren; die weissen Fleckclien auf dem bramnen Grunde verimlurten ilure Gestalt, und der Grundton wurde bald holler bald dunkler. - Vinige Arten dieses Genus rullen sich, wenn man sie aus Iler Röhre zieht, spiralförnig auf, was sie wiederum den Sabellen näher führt.

\section{S a b e l l a.}

Kriftiger und gedrungener gellaut als die Terehellen sind die meistentheils präehtigen

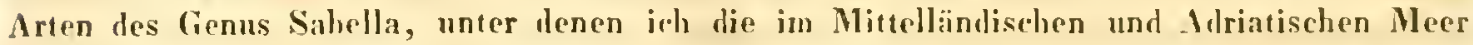
nicht selten rorkommende s. unispira (Navigny) zum Gegenstand ıneiner nälıern äussern und anatomischen Besclureilung machen will.

\section{Sabella unisuin.}

Pallas. Miscellanea zoologica. p. 116. - Anatomisches -

Savigny. Systeme des Anuelides. p. 80.

delle Cljaie. Istituzioni di Anatomia e fisiologia comparata, p. 229. 318

Der in Verhältniss zu seiner Länge schlanke, cylindrische Kürper ist durchweg in gleich gestaltete, schunil. Ringe getheilt, und nur am Schwanzende schnell zugespitzt. Ich fand hei verschielenen in Neapel gesammetten Exemplaren:

Anzahl der Ringe 236 Länge $2,3,2$ cent. Broite 0,8 cent. Länge der grïssesten Kieme 4,2

15,3

0,5

5.2

159

14,8

0,8

5.2

mehr als 150

9

$(1,5$

3,5

Man ersieht also nus diesen Zahlen, dass unsere Sabellen auf zweierlei Weise ihre Grösse erreichen: durch steigende Anzahl ihrer segmentr und durch dusdehnung derselben: immer waren die letzten Ringo die kürzesten. Wïhrend man in andern Thieren dieser Klasse gewohnt ist, die Rückenfläche mit Kiemen oder Schuppen bedeckt zu sehen, ist sie luer mit nichts dergleiclıen besetzt und ganz glatt, lie Bauchfläche hingegen auf besondere Weise ansgezeichnet durch eine lieilse quer oblonger starker Fleischplatten, welehe eine mittlere Laïngsfurche in zwei Iialften theilt, und tiefe Einschnitte von den vorhergehenden 
und nachfolgenden absondern. Ilure Anzahl entspricht genau dien Segmenten, und sie setzen sich seitlich fort, um an den Bändern des K̈̈rpers ïhnliehe krhahenheiten oder Wülste für die Bewegungsorgane zu hilden. Diejenigen Platten, in welehen die untere Reihe derselben steckt, sind beinahe quadratisch, aher ahgerundet an allen Feken, und an der oberen liante ein wenig ausgeschnitten, - deun hier treten die Ifarborsten heraus.

Ueber diesen viereckigen Sehildern liegen schmilleve, lü̈here, an den Seiten ausgesclwweifte, mit einem etwas abgrgrenzten keulenfirmigen Theil versehene, in welchein die Jlakenhorsten stecken. - Diese den rorigen heiden Gatungen entgegengesetzte Anordnung der Bewegungsnrgane, wonach hier die Hakenhorsten die oberen, und die Haarhorsten die untern sind, erleidet nur in den ersten acht Kïrpersegmenten eine Ausnalume, wo wiederum das Gesetz der Arenicolen und Terebellen eintritt. - Auch trägt hier eine weniger getheilte l'late heiderlei Borsten, es sind die fleischigen Bauchschilder dieser Stelle durch lieine unittlere Furche lialhirt, und die seitlichen W'̈̈lste wachsen in dem Maasse an Breite als die Bauchschilder daran abnehmen. - Was vorderste Segment umgieht cin mehrfach eingeschnittener, aus zwei Uälften bestehender, zurïckgeschlagener llalskragen, dessen grïsseste Lappen anf der liauchfliche bemerkbar sind, und dieser trägt zugleich das erste Paar der Borsten. Was die form der Bösten anlangt, so finde ich die haarfirmigen sümmtlich an der Spitze ein wenig geschweift und mit eiaem schmalen Flossenhlättchen verselıen, wie in Terebella, die andern lanhen eine kurz s förmige Gestalt, welehe aber hinten in rinen wagrechten Schwanz ausläuft, den Theil, mit dem sie festsitzen; der vordere Schnalıel ist zugeschärft. An ilnen bemerke ich noch lotiznntalliegende, an einem linde verdickte siticle, welche sich nit dem andern an sie zu inseriren scheinen, und dann wie llebelarme wirken kïnnten.

Fon der Basis des ehen besehriehenen Ringkragens ungeben treten die Kienen hervor, zwei pritchtige aber unsymmetrische Büschel, sleren Länge, wie man aus den oben

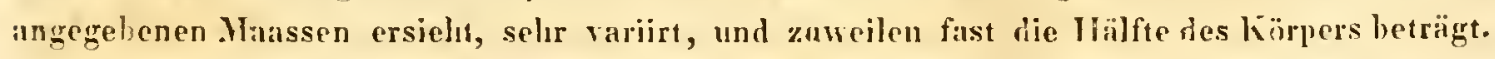
bie liäschel bestehen aus einer Reihe langer, ringelwcise orange, oder rostgell, weiss und violett, auch bloss orange und weiss gefärhter, grefiederter wolliger läden, welche auf dem Rande cines nufrechtstehenden knorplichen Blatt's ringefïgt sind. - Mas Blatt der bleineren lime beschreiht einen einfachen niedrigen llallicylinder, an deun aber doch anch der obere Rand lïnger als die Basis ist und Anlage zur spirale verräth, das andere, ron selumal vierseitiger form hildet eine wirkliche, rasch in die Ilöhe steigende Schrauben-

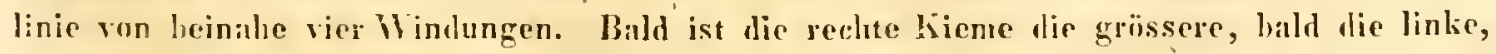
im ersten Fall ist sie, (wenn wir von den lingsten Endstrihl, der immer nehen der Mittellinie des lïickens steht, au־gehen) ron links nach rechts gewunen, iu zweiten Fall ungekelart, es entsteht also die Spirale ron der Bancliseite her. Die Zalal der Strahlen 


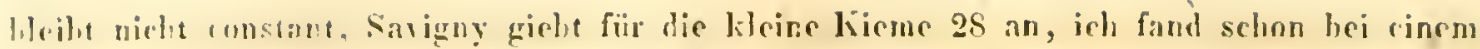
jungen Individuma! ̈̈her 311.

Fs ist aber belsamnt, dass diese Lnsymmetre bei viclen andern Sabellenarten gar nicht rorliommt.

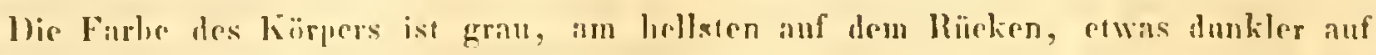

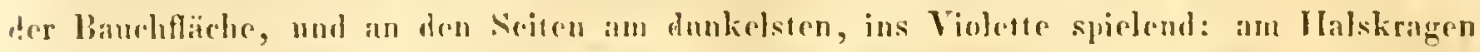

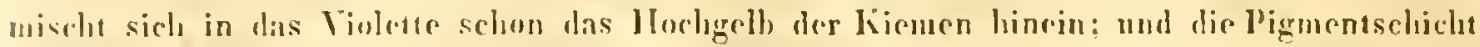
erreiclut hier rine ansohnliclue stïske.

Im lehenden Zustande fülıl sich der Wurm fest, nher sehr schlïpfrig an, was von

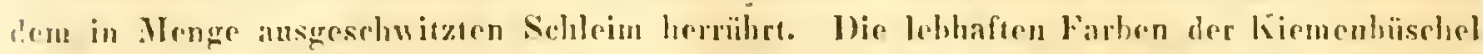

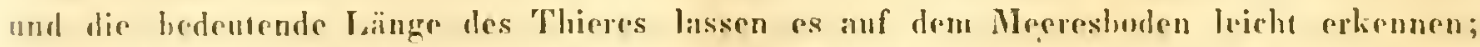
lavi der Innäherung oder starken Bewegung des Ruders pflegten sich diese Wïrmer plïz-

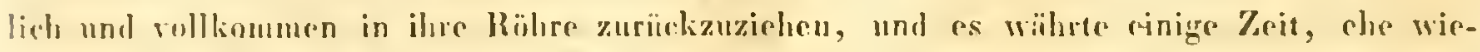
derum die Splizen der hiemen sichubal wuden, noch lïnger, che sie sich ganz entfalteten,

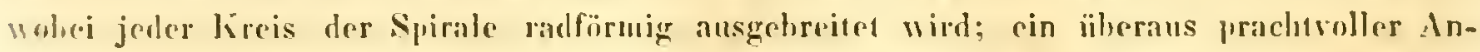
hlirk! Ohwohl ich das IIasser in rinem Becken alle 5-6 Stunden wechsele, gelang zares doch schen, meine Sahellen einige Tage zu erbalten; ungestïrt steckten sie stundenlang mit hallem Leibe aus der Bähre hervor, nhe sich oder die Kiemen merklich \%u heweren, mur kinz vor ihrem Tode pflegern sie manchual diesclle ganz zu verlassen und

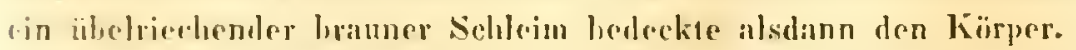

Withrend das Gelı̈use der Terehellen aus Sitndliörnchen und Conchylientrïmmern

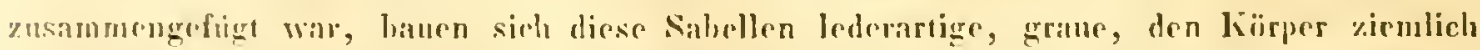

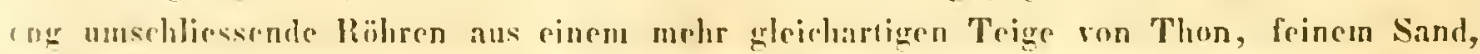

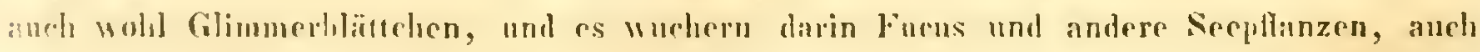

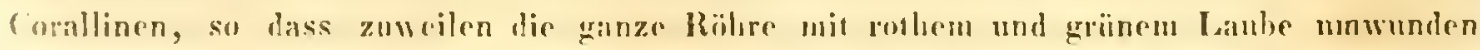

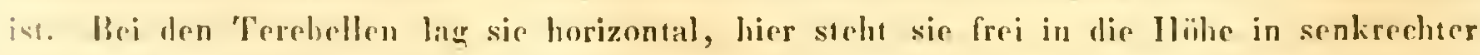

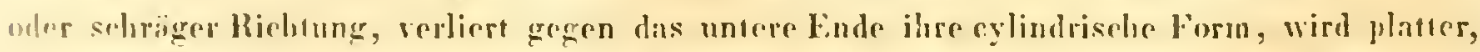

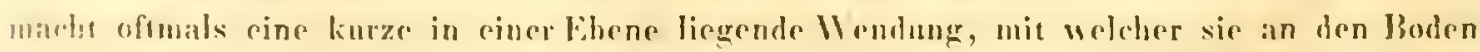

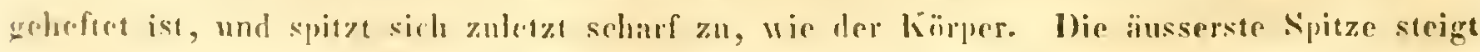
lisweilen wieder in die llähe. - An heider linden findet man die Rahre ollon, die lnnen-

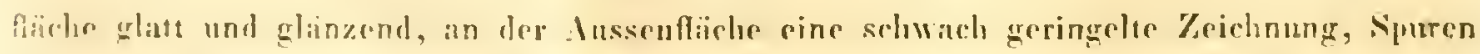
der fort und fort linzulommenden Insïzze, die Wandung ist olun rewa dremal so diek, als unert. - Trotz jener Glïte deg Wandung im Innern vermag dieser Wurm sich so

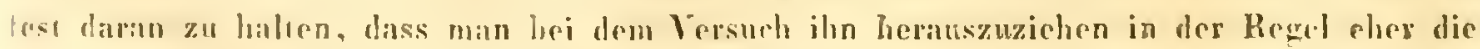

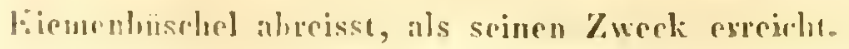


In Triest und Fume fing ich Sabella nnispira nicht sclten, in Veapel, wo sie das Volk Fiocehe di mare nennt, brachten sie uir die lischer zuweilen in grosser Anzalıl, aher bei Catania spähete ich rergeblich danacl. Savigny gieht auch den Ocean als Fundort an.

Den Leih umgrebt eine feste Hatut, sie überzieht weiter den Halskragen, setzt sich fort ïher die Kiemen, jeden strahl einzeln belileidend, wohei sie cinen eigenthümlichen Schimmer annimut, biluet dann innerhall der kiemenbläter einen kleinen kranz, weleher in 2 Fühler oder (irren auf der Rückenseite endet und tritt so in den verdauenden Kanal: unan kann an ihr Epideruis, Pigmentlage und Corium, lesonders deutlich an den fiemen, unterscheiden.

Die Mundäfluung liegt vorn zwischen den Basen der Kiemenblätter, ist unbewallnet, eine einfache ewas lervortretende Rihre, und fuhrt in die erste ththeilung des Darmkinals, wclche sich nur dadurch von dem ïlrigen Theil unterscheidet, dass sic anfangs ein wenig dickundiger, zwar eingesclü̈rt, aber nicht spiral gewunden ist. Vou sten Körperseguent an, also da, wo die Borstenreihen wechsoln, beginnt der schimulenfïmigg fortlanfende, wenig engere Alsschnitt des Darmes. Jie Dissepumente, welche den rerdiuenden Kanal umfassen, sind vollkommene Sicheidewïnde, gehen aus von einer die Leibeshöhle auskloidenden Membran, und enteprechen der Anzahl der Körporringe; sie bestelien aus Muskelfasern, und dienen vermuthlich auch zur lirweiterung des Darmes.

Diese Monge ron (2uerwänden, das enge Inliegen des Dames an der Körperwandung und die Dicke der letseren, verunchrt durch die von der Ringfiscrschicht gebildeten Banchschilder und Seitenwülste, erschweren die Contersuchung an lobenden oder frisch getödteten Thieren ungemein: in der Reucel verlet\%t man leci den ersten Sichnitten den Darmkanal und die Gefässstämme, aus denen nun fortwïhrend die braungrün gefärhten Contenta und das Blut hervordringen, und das Wasser trïlen. So sebwebe ich noch gegenwirtig in Zweifel, weniger über die Zahl der Haungefäse als über deren Verbindung und Zusammenhang namentlich in der vordern körpergegend, wo die IIandung fast knorpelhart wird, und die Organe auf's engste unschliesst. - Oftenbar muss die Circulation hier eine ganz andere sein, als in allen denjenigen Inneliden, welche ihre liemen auf den Seiton des Leibes tragen, und wo eine doppelte Blutströmung stattindet; die in jedem einzelnen Sroment vor sich gehende - ron den Athmungsorgangn zum verdanenden Kanal und den anliegenden Theilen und umgekehrt nach jenen zurück - und die Bewegung ron vorn nach linten. In der Sabella, Jeren Kiemen nur an dur Spitze des Kärpers sitzen, wird diese loztere Richtung des Blutfusses die vorhorrschende sein, die andere seitliche verliert ihre Wichtigkeit mit dem IVegfillen der Organe, von welchen sie abhing, und dient nur zar Vertheilung des ernährenden und zur Fortleitung des aus den Speisen frischbereiteten 
Fluidums. Vidlleicht aber steht auph, sofern man aus der Farbe etwas schliessen darf, die blublddung auf rimer niedern stufe, desn während fast in allen andern Jnueliden das Bhut roth ersehcint, unterscheidet es sich hiç nur wenig ron des Farbe des selır flüssigen

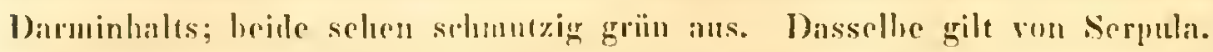

Zurörderst knmme ich hier auf die Kiemen und deren Bat zurürek. Sic kïnnen wrder mit den kiemen der Areniculen und Terelellen, norls mit denen der Jereiden oder liuniren verglichen werden, sondern haben in ihrer Structur etwas gitnz cigenthümliches, was melır an die Jorngebilde crinnert.

Wir haben schon ohen angedeutet, dass die Jiemen ats sehr langen, auf der liante

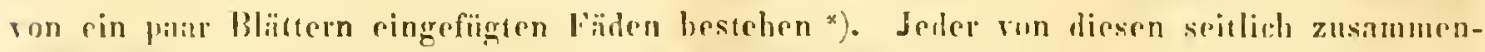

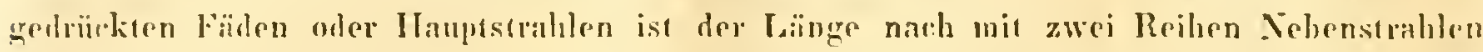

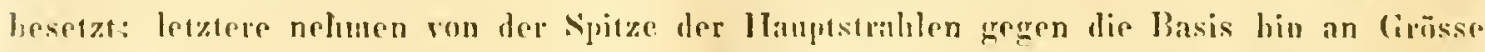
zu, sind sichtheh gegliedert, mit einem doppelten sïmmehen lieserzt, oft versehiedenartig gewunden bler eingreollt, und alle sehen nach der inneren Seite ler Kieme. Jie Jiluptstrablen, welkhe in der whersien Windung der grossen Spirale ebenfalls nur ganz licin und fist ohne Vehenstralilem auftecten, werden an ihrer Basis durch eine weiche Jatut relouden, simb zwa schr hiegsam, aber doch ron einer hornigen Tectur und so consistent, dass uari on ihnen Epidemis und Pigmentschicht entfernen kinn, olne sie selhst zu rerletzten; sie bestehen aus einer Reihe dicht hinter rinander stehender Sohridewinde und

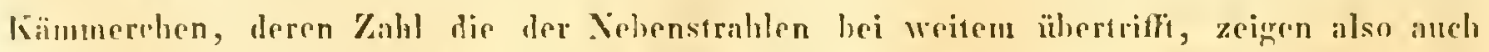

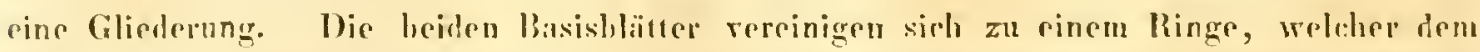
Vordertheil des übrizen K̈̈rpers anfgrestreift und an ihn lheils durch die alles ïherziehende

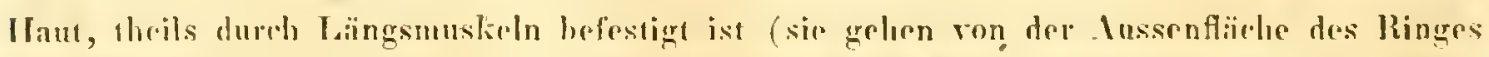

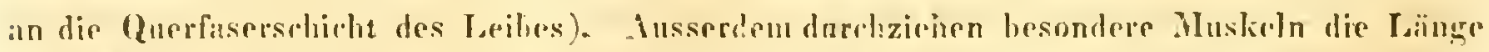
Jer Blïfrer, und sie lewirken wohl dess Jusamunenollen der liemen, soliald sich die Saluella in ihe enge Rohle zurükzieht. - Zwischen der Maut und diesen Muskeln hemerkt man rin gan\% rigenthiimlielies, sohr galles, fast schwammiges Cachilde, dessen lerdeutung

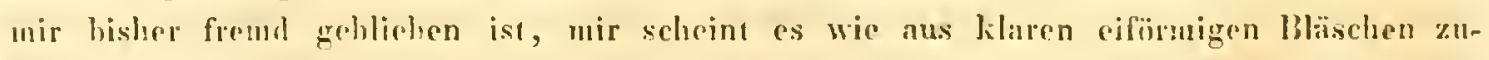
sammengesetzt, und ron Gefïssen durchzogen.

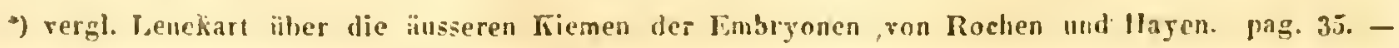
T.enckart hat in len Seilenfasern der Lïnnentäden zwei Geläse entded, an meinen Exemplaren kann ich dieselben nich nachwejsell. Anch machem ich ron einem. Fiemenfaden die llaut be hutsam abgesehah, gilang mir's nieht sie antzutinden, viehnehr sah ieh nur, dass er duch 3 längsrippehen in + längstïcher genbeile war, dicse viederum in Querfïcher zesticlen, und in den einzednen häumeden hin und wieder runde kingelchen, wie Lludiügelchen, lagen. (Die Vergrössermug burug 175 mal im Durchmesser). 
Längs der Basis jedes Blattes rerläuft in demselhen ein Kanal für ein aus dem Kärper tretendes Gefäss ron bedeutender Stärke, ron dem eine kammförmige Reihe langer Zweige für die Kiemenfïden entspringt. Vergeblielı aher suchte ich dort nach einem zweiten Gefïssstanm, und ich kann nicht umlin, nuf eine in Cette gemachte und an Serpulen wiederholte Beohachtung zu verweisen, und künftige Untersusher un deren Brïfung zu bitten, wonach es schien, als ob die Bluthewegung in den einzelnen Kiemenstrahlen auch nur in einem Gefässe stattfünde. Nachdem ich nämlich diese Thiere rollkommen ilure Büschel latte entfalten lassen, lionnte ich mittels eirer nur mässig seharfen Lonupe walırnehnıen, wie in den einzelnen Kiemıenstralılen das grasgrüne Blut lïngs der Mittellinie in die Höhe stieg und sich ehenso wiederum zurückzog; wäre es auf einem anderı Wege zurïckgekehrt, als auf dem, auf welchem es emporfloss, so hätte das Blutsäulehen sich an der äussersten Spitze des Fadens umbeugen müssen, es hätte in einem Moment die Basis blutleex werden müssen, während die Spitze doppelt ( $d . h$. in einem zwiefachen Säulchen) gefüllt war. - Immer jedoch hlich der Kanal an untern Ende voll, und die Spitze allein erschien bisweilen farlifos; Tïuschung konnte hiehei nirlit stattfinden. Der Kienenfaden fülte sich nicht auf einmal, und ruckweise, sondern allutillig, und in die untern Strahlen trat das Blut eher aIs in die oberen. Sollte dies nur eine Stïrung der Circulation sein? Dann hliche es doch auffallend in hohem Grade, dass solehe Störungen ohne äussern Anlass so lange anhalten können, - denn es verging darüher wohl eine Viertelstunde, - und dass sie nichı nur an einem Individuum, sondern an allen füufen, die ich in Cette erhalten hatte, hemerkt wurden, sowohl an Sabellen als an Serpulen.

Die Flimmerhewegung an den Athnungsorganen der letzteren habe ieh sehr deutlich wahrgenommen.

Bei der Verfolgung der Gefïssstïmme des ührigen Körpers habe ieli mehr an älteren Weingeistexemplaren als an friselgetödteten herausgebrach. Löst man hehutsam die Muskelschichten der liüelenflïche ah, so sieht man auf der Innenseite der Membran, welche die Leibeshölile ausklèidet, jederseits oberhalh der Borstenbündel einen starken Lüngsstamm im Zickzack rerTanfen; aus jedem oberen Winkel der Zickzacklinie tritt ein Querast für die obere Seite, ans jedem unteren ein Querast für die Baucliseite herror. Jene gehen nahe den Dissepimenten, also längs den Grenzen der Segmente, diese mehr in der Mitte der letzteren; ein dritter $A$ st begiebt sich geradezu in das Innere des Kïrpers gegen den Darm hiu, und alle verzweigen sich vielfach, und hilden inastomosen. Wir ich mich wiederholt üherzeugt hahe, sind es die Fortsetzungen dieser zwei stimme, welche in die blätter der Kiemen tretend, dort die oben beschriehenes leieht in's Iuge fallender Gefässe zu den eimzelnen Strahlen ahsenden. 
An der Stelle nin, wn dirse Stïune ans dern Yepihe in die Kiemen treten, sendet jeder rinen .Ist nach innen, und durch Verrinigung beiter entstelt ein Rückengreäss, wolehes ich wenigstens nuf dem vordern geraden . Whsclinitı des Darmkanals eine Strecke verfolgen konnte. Dir Discrpunente, von Jenen dersellee suwie die zu seinen Seiten gelegenen (writer unten uäherthesprochenen) Schläuche umfasst werden, strotzen von Ailernetzen, und ihr Lrsprung ist sowohl von dem Vas dorsale als den längs der Körperwandung verlaufenden Zickzackstämmen herzuleiten; desgleichen finden wir zu heiden Seiten des Riickengefïsses ein besonderes beutelfärmiges Organ, welches fast nur aus einem Convolut von Gefässchen zu bestehen scheint und vernuthlich mit den heiden von delle Chiaie angrgehenen Blisen der Branchialarterien einerlei ist. Es nimmt die Lünge des zwriten Körpersegmentes ein, und empfängt sichtlich auch Zweige rom Vas dorsale.

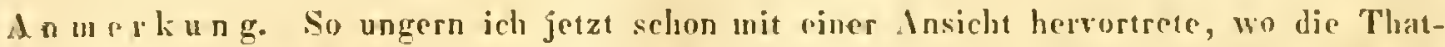
sachen noch so selir der Lntersucliungen an ledsenden Thicren heelïrfen, sche ich mich doch der Vollstiindigkeit wegen dazu genöthigt. Mir schoint, dass die (irculation der Sabellen in mancher Art ïhulich wie in Ilirudinen vorgeht: Dis Bhut fluctuirt aus den Zickzackstïmmen nach den Kiemen, und kelor von dort, der Ernährung fïhig gemacht, zurück, um das mittlere Rückengefïss anzufüllen. Ans ihm gelangt es dtirch Anastomosen wirder in die seitlichen Zickzackstiimuse.

Ausserdem alier kinn ich noch einen unpansen stamm auf der Bauchseite nachweisen, neleher zum Vurschein kommt, sobald man das Lingeweide entfernt hat: er giebt in jedrm körperringe einen Zweig zur rechten und zur linken ab, an denen mir ihre

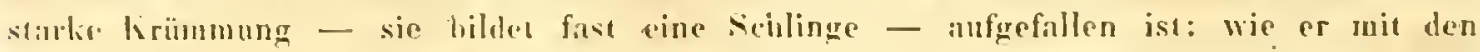
rmdern Theilen des diefüsssystrms zusiunmentrïngt, ist mir entgangen.

dolle (hiaie hält das Banchgefüss für sine Vene, ohne weitere Grunde anzugeben, und dir andern stämme für Irterien.

Das llauptstück de's Vervensystems hestrlat in zwei ron einander ganz getrennten stimmen, welche nicht zu Ganglien anschwellen, atber in jellem sirgment durch einen dop-

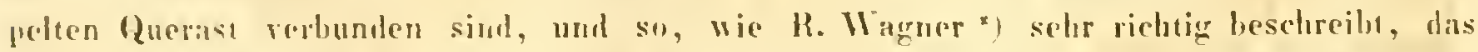
Ansehn einer striekleiter behalten. Xach vorn nehmen dic stränge ledeutend an stärke zal, die Verbindungsïste rürlien näloer zusammen, und der sorderste uhertrifft die uilrigen durch seine Dickr. Jier sichlundring scheint when durch kein llirnganglion gesschlussen. IVenn ather Viviani das Terrensystem überhavpt nicht tiaden tonnte, so hat dies seinen

* Vergl. Ana II. pag. 3=1. 
firund wohl darin, dass es rersteckter als sonst, und fester eingesenkt in der selir festen Muskelschicht des Banches ist.

Lim das Xerrensystem genau zu erkennen und zu rerfolgen, muss man die, die Bauchhälıle auskleidende Membran ahlösen, unter weleher es lirgt, vad um con Terlatıf der Nerrenäste zu sehen, auch die Eängsmuskelschicht. Ist letzteres geschehen, so stïsst man auf die Quermuskellage, und hier bemerkte ich wenigstens zwei, durch Dicke ausgezeichnete Strcifen, welehe in jedem Scgment ron jedem der beiden Haultstränge entspringen, und für deren Aeste zu halten sind. Auffallend ist es, dass jene Verbindungsfälen der Stränge nicht, wie etwa die Ganglien, in der Mitte, sondern an des Grénze der Kïrperringe erscheinen.

Ueher dem Geschleclutsapparat schieht noch manches Dunkel. Man bemerkt zut beiden Sciten des Schlundes zwei grosse, durch die Dissepimente mit umfasste und eingeschnürte Sïcke, welche im Sten Körperringe, da wo die Borstenreihen ihre Lage wechseln, Jlind anfhören, und vorn durch rinen sehr engen Kanal zu mïnden seheinen. Ich hin der Ansicht, dass sie den an Arenicola und Terebella nachgewiesenen Blasen entsprechen, und also wahrseheinlich befruchtende Organe sind. In den iiłrigen Kanmern des Körpers habe ich zur rechten und linken des spiralförmig gewundenen Darms in jedem Segment eine zähe, hochgelhe, bei wohlerhaltenen Evenplaren compacte, Masse gefunden, welche den Raum zwischen Darm und Körperwandung genau ausfülte und den Abdruck der Damwindungen zeigte. Mlit einer scharfen Nadel rermochte ich nur einzelne Fäden aus ihr herauszuzichen, theils feine Gefässäste, deren stämmehen man besonders an der untern Seite hineintreten sab, theils Muskelfasern, aber eine hesondere Membran und deutliche Eierehen, gelang mir nicht an allen Spirituseremplaren bachzuweisen; jedoch an einigen derselben, und auch an frisclien fand ich sie in eben diesen Räumen nicht nur bei Sabella, sondern auch bei Scrpula. Eine Oeflnung, durch welche sie hinausschlüpfen liönnen, scheint in der Spalte der Wülste für die Iakenhorsten gestcht werden zu miissen; oft sah ieh dieselben überaus daron angescliwollen. 


\title{
C i r $\mathbf{n} t \mathbf{u} \mathbf{u} \mathrm{s}$.
}

So wenig dasjenige genügen kann, was ich über den innern Bau der Gattung Cirratulus mitzuheilen vermag, da ich sie nur nach Spiritusexemplaren untersucht habe, so füllt es doch in einiger Hinsicht die Lücke aus, welche bisher in der vergleichenden Anatomie der Anneliden an dieser Stelle bemerkt wurde.

\section{Clrontulus camarckí.}

\begin{abstract}
Annales des sciences naturelles Tome 29. pag. 4117. - Tome 27. pl. XV. fig. $1-4$.
\end{abstract}
Diese. Irt wurde von Andouin und Edwards dem zu lihen so genannt, weleher das als Lumbricus cirratus von Otto Fabricins beschriebene Thier zuerst von den Lusuluricis tresnte, und zu einer eignen Gattung erhob. Was ihn dazu vorziiglich hewog, waren woht die selır auffillenden langen Fäden, welche auf der Rückenseite des Wurmes stehen. Im vordern Theil des Kä̈rpers trïgt jeder Ring ein Paar, weiterhin schicbt sich zwisehen je \%wei soleher segmente ein nacktes, noch mehr nach hinten habe ich drei, aueh rier dergleichen eingeschohen gefunden, und am ïussersten zugespitzten Schwanzende verschwinden die Füden gänzlich. Un so zahlreicher stehen sie auf dem tien linge, den sie mit rince ganzen Querreihe treselzen, so dass man hier cin wahres Lahyinth erblickt. Sie sind evlindrisch und schr dinn, oftinals oben etwas verdickt, 1-4 Centsm. bang künnen gelsrïluselt, und spirallïrmigg eingerollt werden und befanden sich bei den von mir beobachteten Individuen in hestindiger Bewegung. Viefleicht tragren auch sie zal der stirken Schlciunsehicht bei, mit weleher sich der Körper in sehr kurzer Zcit zu hedecten jflegt, unindestens sah ieh sie bei dieser lirscheinung sich häulig um den Leib schlingen. II enn sir einestheils lehhaft an die henachbarte Gattung Ophelial erinnern, se mag man auch andrerseits an die Cirren der Terehellen und deren emsige Thitigkeit denken. that mian diese lialden num als Cirmen oler als kiemen zan betrachten? Audouin und VAwards wollen die den Ilalhring bildenden kiemen, die auf deu Rieken vor und hinter ihnen einzeln stehenden (irren nennen, des Gebrauches wegen; eher sollte man sie umgekelirt beyeichnen, weil so einfache Athmengsorgane nie auf cinem dinzigen Künperringe vorzukommen pflegen, sondern in der Länge des Leibes. Cebrigens herechtigt uns anch nichts, einen Lntersedred in den Kamen anszudrieken, weil mir beiderlei fïlen von 
gleicher Beschaffenheit scheinen; auffallend war an denen des Rückens die Lnbestimmtheit ihrer Stellung, einige niiherten sich mehr der Mittellinie dessellen, antere weniger, bald standen sie paarig, bald abwechselnd, immer aher nicht so unmittelbar tiber dem IBorstenbündel, dass man sie mit den Cirren der Extremitäten, wie sie bei Amphinome, Aphrodite u. s. W. vorkommen, vergleichen könnte. - In jedem erkennt min zwei Längsgefässe, welche sich in kleine Zweige verïsteln; vielleicht dienen sie elen so zur Athmung als zu den andern oben besprochenen Zweck.

A n merkung. In dem von delle Chiaie (Mem. Vol. III. tab. XLV.) abgebildeten Lumbricus filigerus, einem gewiss sebr nahe verwandten Thier, sind die pararigen liückenfïden vorhanden, aber die auf dem Nacken stehenden fehlen.

Der Körper ist eylindrisch der Gesammtform nach, genau genommen aber vierkantig, der Rücken gewölbt und breiter als der Bauch, daher bilden die Seitenflächen mit der Banchflïche stumpfe Winkel. Er ist in schmale Ringel getheilt, und die Lünge rueiner Exemplare ühersteigt nicht 5 Centm. bei einer Breite von 0,3 Centm. Jedes Segment triigt zwei Paar kleiner Borstenhöcker von ïhnlicher Beschaflenheit, nur dass die darin steckenden obern Borsten schnal, fein, spitz und farblos aussehen, wïhrend die untern etwas gebogen, bräunlich und an der Basis dunkelbraun gefïrbt erscheinen. Die letziteren sind von den Nadeln (acicules), welche man unter. den feinen obern Haarborsten versteckt findet, nicht wesentlich verschieden, es stehn ihrer $4-5$ neben einander, und ich sehe in diesen, nur wenig hervorragenden Kä̈nmen den Uebergang zu den IIakenborstenreihen der Terebellen, Arenicolen u. s. w.

Minder breit als der hintere Körper sind diejenigen Segmente, welehe vor dem Ilalb-Gürtel von Fäden liegen, unten weniger von ihn gesondert als oben, wo sie eine tiefe Furche alggrenzt. Das vorderste, an dem man jedoch keine Angen oder sonst irgend etwas characteristisches bemerkt, lïuft in eine Spitze aus, welche die nach unten gerichtete Mundöifnung ïberragt und entspricht einem Kopfstïck. - In der Schwanzspitze. liegt wie gewöhnlich der After. - Die Farbe des Thieres ist ein ganz helles Fleischroth mit schwachem Schiller, aher einige Male erhielt ich anch grauschwarze Individuen; eine ähnliche Varietit haben wir oben bei Arenicola angeführt.

Die fast farhlose, ein wenig bïuliche Olerhant ïherzieht die Rüekenfïden so fest, dass man beim Abstreifen die letyeren regehnïssig milnimmt. Lnter ler hesonders stark entwickelten Quermuskellage des Körpers finden wir die Längsmnskeln in sechs Particen getheilt, vier mittlere, und zwei seitliche zwischen den Borstenbündeln, deren liewegung auf die gewöhnliche Weise hewerkstelligt wird. 
Der ganze innere Raum der Loiheshiblue ist mit einer eigenen Membran amsgekleidet, wie in Salellat, welche eine Reihe ron Fïchern hildet. An diesen sidheidewänden liegt die Bildungsstïte der Eier. Betrachtet man nämlich ein solclies Dissupiment nuter dem Nikroscol", so enteckt man an ilwin ausser den sich kreuzenden sternfirmig laufenden und (irkelfasern, gekrïuselte, an einzelnen Stellen mehr erweiterte Schläudhe, in denen kleinere und grössere tïrchen sich hefinden. Au vallreichsten sind sie in den von mir untersuchten Exemplaren an der leripherie, weshalb anch gleich auf den ersten Blick die Dissepimente hier dicker als in der Mitte erseleinen.

Lange galt Sabella für die einzige Annelide mit spiralförmig gewundenem Jarmkanal, derselhe Fall tritt auch bei Cirratulus ein, und die ron den Scheidewänden umfassten Windungen folgen einander ehen so rasch, und liegen so nahe an einander, wie dort. Gegen das Ende hin wird der Darm beträclutlich enger, scin Infangscheil ist gerale, eine starke fleischige, aher nicht mit Kiefern hewaflnete Pharynumasse.

Auf der Rückenseite des rerdauenden Kanals Jiegt ein dïnnes Lïngsgefäss, welehes ich nur mit Mühe rerfolgen konnte, es sendet Meste snwohl an ihn als an die Muskellagen ab, die ron vielen anastomosirenden Serpentinen ïherzogen werden: wahrseheinlieh entstclit hier die eine Reihe von Adern, welehe zu den Rïckenfäden gehn, die andere aus deu viel ansehnlicheren doppelten Banchstamin.

Der Nerrenstrang bildet nicht eine Strickleiter, wie in Sabella, sondern gleicht dem der Nereiden: cinen Sithlundring lionnte ich erkennen, ob er aber ein Hirnganglion zeigt, war mir nicht mebr mäglich zu entschriden.

\section{- il i i c e.}

Inter den schlanken aher Ineh kräftig gebauten Anneliden, deren körper in seiner

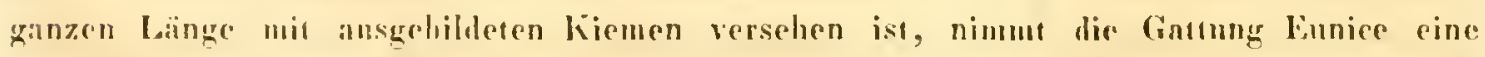

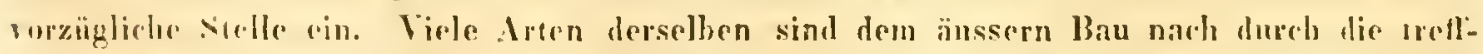

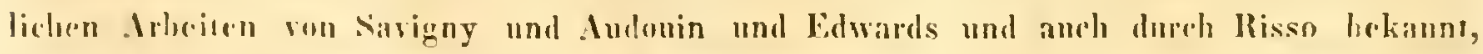

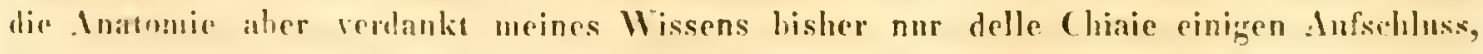
"relcher scine kunice gigantea zu zergliedern begonnen, und ron einer verwinden Giltung 
Diopatra (hej ihn Nereis cuprea) etwas ausführlichere Mirheilungen gegreben hat; auf Jetztere werde ich besouders zurückkommen. Wemnach beschrïnt sich die gan\% literatur fül dieses Gienus anf:

Savigny. Sysleme des Annelides. pag. 48. - Leodice.

Annales des sciences nalurelles. Tome 28. pag. $\$ 12$.

delle Chiaie. Ilemorie. Vol. II. pag. 3s9. tab. XXV'II. XXVIII.

Risso. Histoire naturelle des prineipales productions de l'Europe meridionale, IV. p. 421.

\section{Eunice Harsin.}

Die ron mir untersuchte $\mathrm{Mrt}$ ist, wenn man nicht zu viel Gewicht auf die Zahl der Hinge legt, diesellye mit der unter diesem Namen von Audouin und Edwards besehriehenen, und der Jeodice fisciata des Risso, zur grösseren Sicherheit aber setze ich doeh die genatere Beschreibung meiner Art hieher.

Der Kopf, rorn zweilappig, nicht sch tief eingesdunitten, trïgt 5 gegliederte Antennen, welche in Gestalt eines flachen $V$ gruppirt sind, und 2 schware Augen. Die ïussersten und zugleich vordersten Antennen sind bei einem kxemplar siebengliederig, die darauf folgenden zwölfgliederig und länger, - auswärts von ihrer Basis sizen die Augen - die mittelste, fast die längste neungliederig, alle mnilchweiss nit braunen kingeldien, doch variben die Zahlen bedeuteud bej andern Exemplaren. Die Gliederchen

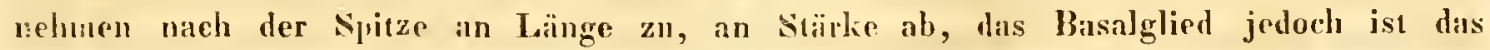
böchste und unten plötzlich rerdünnt. Dep kopf ist kupferbraun, an den Lappenrïnderu opmlweiss, mit mitterem weissen R̈̈ckensireif umd elıenso gefürhter $V$ förniger Zeichung, welche 5 braume linge trïgt, für die Ansïlze der 5 Autennen.

Der eylindrische etwas platt gedrïckte Körper zerfïllt in gleichü̈ssige, schmale vegmente, ron denen nur die vordersten besonders ausgezcichuet sind.

Das rrste ctwa so ling als die drei folgerden zusamuengenommen ist cin platter, an wordern hande seitlich pingelierbter und unten etwas gesebweifter ling, in den der Finf sich soweit zurü•lizielıen liann, dass man von den Augen niclus walınimun. Jurch rine seichte, nicht ganz herumlaufende Querfurche zerfält dieser lhing in zwei ungleiehe Hälften, von denen die hinterc, ausserordentlich schmale auf der Rüekenfliche zwei wie die Antonnen gregliederte (fïnf- oder sechs- und mehrual) geringelte Fïden trägt, - und von Edwards als selbststïndiges Segment gezïhlt wird, obschon es nicht vollstïndig $10 m$ vorhergehenden gesondert ist. - Die Anatonie spricht für Edwards Ansicht. Die beiden 
darauf folgenden Körperringe tragen an den Seiten nur ein schwaches Borsienhïndel und zwei Cimen, erst hein nïclsten treten Kiemen hinzu. Die ganze borstenreibe erhelt siclı alluailig indem die Kvermititen aun dritten Segment, tief unten, fast anf der Bamchseitr, am vier:en etwas höher, am folgenden noch höher stehen, und so fort, his otwa mir dem serlisten Segment diejenige Srellung erreicht ist, in welcher unan diese Organe die ührige Iainge des Thieres durchlaufen sicht.

An diesen ïhrigen Segmenten finden wir seilliche Vorsprünge, an Jeren Basis blen die Kieme mit ihrem ("irus sitzt, mol ans deren Spitze das Borstenbündel hervortritt, ihrn gehört der untere (imus an. - Jener, der ohere, ist schlank, gleich lang mit der kiene, spit\% znlaufend: in melirere, weder ganz regelmissige noch immer vallstïndlige llingel gertheilt, und bildet mit der kieme ein Ganzes. Die Kieme hat die Form einer halhen Federfahne; ats einem Stanufaten tritt nämlich nach diner Seite, (der äussern) eine dinfache Roihe, nach ohen zu an Jainge abnehmender, Jebenfiiden, welche an Dicke dem Stiumm wenig nachgeben, und von denen sich der Cirrus durch seine Pïbung und Stärke. unterscheidet, denn er glïnzt und schillert stïlker opalartig, und trägt feine loraune

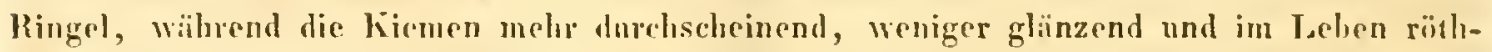
lich, nacls dem 'Tode weiss sind. Die Inzalıl der Xebenläden steigt sehr sehnell, an der vordersten hieme erscheinen nur 2-3, an der nïchsten 4 , an der folgenden b, dinn herrschen eine Zeit lang die Zahlen 6 und 7 ror, und sie erhähen sich bei dem Individum, an dem icls die Besclureibung gemacht, bis auf 8 . - An andern aber finde ich sogar liemen mit 13 Xebenfiden, mol es scheint die Menge derseben mit dem Mlier zuzunehmen. litwa vom Infange des zweiten kërperdribbeils an schwindet wiederum ihe Zalh] und sinkt rasch bis anf 3, gegen das Ende hin tritt sogar bloss 1 Vehenfulen auf, welcher ebenso lang als der Stumufaden wird; noch weiter vergeht auch er, und zuletzt bleibt allein der Cirus ïhrig. - Man sieht zumal an ten hinteren Kiemen sehr Jeutlich, wie sie aus der basis des cirrus herorspriessen. - Lner dem Mikruseop erkennt man in den einzelnen Zweigen 2 dunkle Reihen von Quevweigen, welehe ans 2 Idingslinien spriessen, - jeh halte sie für die Gefiisse der Kieme. Contraction konnte ich an olen Athmugsurganen diess' Wurmes nir bemerken, sie unterscheiden sich dadureh wesentheh von denen der Irenicolen und Plrionen*).

In des lorsprunges unterer llälfe sitzi der untere, dem ohern ganz uabihliele (irrus; scine Spit\%e tritt war\%enartig aus einem loggligen Basalgliod lorvor, an dron

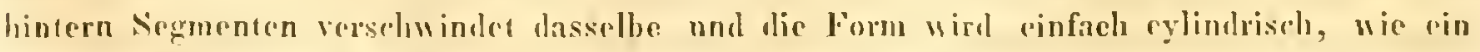
Finger. J)e bänge dieses (irrus lecträgt etwa cin brubeil des obern, seine farbe ist

•) s. meine Abhandlung. Pleiones carunculatae Auatome. Regiomonti. 1537. 
ganz weiss und von Ringelung keine Spur vorhanden. Endlich die beiden einzelnen Cirren unten am After sind denen der Kiemen ähnlich, und kïnnen unter den Bauch gekirümmt werden.

Das Borstenbündel nun, ron rorn nach hinten zusammengedrïckt, besteht aus rerschiedenen Tlicilen, den eigentlichen Haaborsten, die das heroragende Miischel hilden mud len Videln (acicules. Siarigny), welche nicht melır als drei, viel stärker als jene,

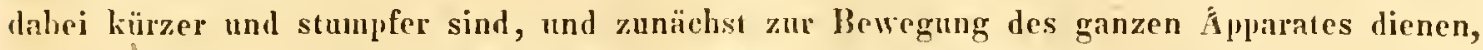
indem sich an sie gerade die bewegenden Muskelstränge inseriren. Die feinen Borsten, welche sich um diese Jehel gruppiren, sind zweierlei Art, ohere zarte, einfach zugespitzle, und vntere, an denen man bei starker Vergrösserung ein eigenes, eingelenktes Endglied erkennt, wit scharfom etwas gezahntem Rande. Auch hier sah ich in der Borste, wic bei Arenicola einige schrïge Striche an der obern Spitze.

Gar prächtig ist die Fïrbung des Kärpers. Jedes Segment ist kupferroth, von desu benachbarten auf der Bauchfläche durch zwei metallischglïnende gelhe Querstriche, auf der Rückenseite hinten durch einen ähnlichen, rorn durch eime schmale, nur in dex Mitte und an den Seiten erweiterte, weisse opalisirende Binde getrennt. Das 5te, zuweilen auch das 4te, 5te und 6te Segment finde ich ganz weiss, überhaupt scheint die Zeichnung etwas zu variiren. Zugleich glïnzt diese Eunice mit dem lebhaftesten Farbenspicl, violett, grün und feuerroth, wie der schönste edle Opal, und die Ursache desselben ist zweifelsohne eine mechanische, - denn es hört nach dem Tode, ja nach langem Aufbewahren in Spiritus nicht auf, - die Furchung der Hant. Geht man behntsam zu Werke, so findet man unter der Epidermis ein wahres mit Pigment hekleidetes Corium, heide zeigen das Phänomen, iber jene in stärkerem Grade, und aif heiden Flïchen; die Furchen, welehe man hier schon mit ciner starken Loupe erkennt, kreuzen einander, und dazwiset... bemerkt man bei bedentenderer Vergrösserung eine Anzahl kleiner heller Flecken, wie Spaltöfnungen. - Sowohl Oberhaut als Corium sind sehr fest, und eng mit einander verbunden.

In Muskelsystem ist an den allgemeinen Lagen nichts besonders auffallend, die inneren Längsmuskeln aber zeigen cinen stïrkeren Glanz als die Querumskeln, welche nach aussen liegen. Die ron beiden gebildete Wandung des kïrpers besitzt eine zumal in rordern Theil sehr hedeutende Dicke, nur an den Seitenflächen, wo die Borstenbündel lervortreten, verliert sie dadurch, dass die Iüingsmuskeln grossen Theils als einzelne Strünge zur Bewegung jener Extremitïten verwindt werden, merklich an ihrer Stärke, es entsteht eine Lücke. Aehnlich wie in Irenicolin finden sich auch Querbinden, die vou Nervenstrang bis zur Fussreihe hinüberdaufen, in jedem Sogment rorkommen und viel dentlicher als dort aus gesonderten Bändeln besiehen. Durclischneidet man die Leibes. 
wandung um zu deon verdauenden Kianal zu gelangen, und legt man die beiten Hälften aus einander, so macht sich auf der Innenseite derselloen die Theilung in segmente auch

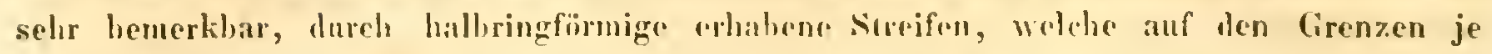
zweier Abschnitte stehen, und ron welchen die Dissepinente ausgelien.

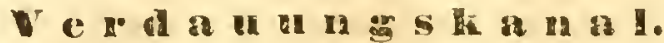

Vief zusammengesetzer als in den friblier beseluriebenen Anneliden ist hier der

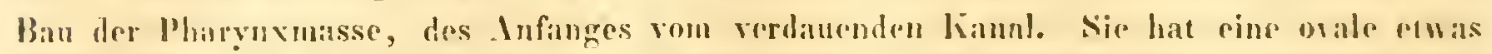
platlegedrüclite form, und besteht ans cinem hreiten, untern Theil und eincm schmalen,

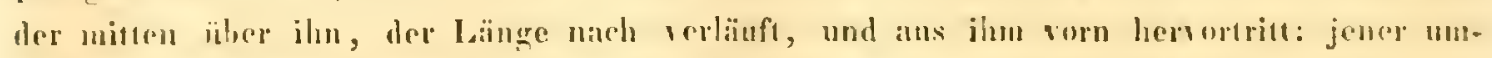

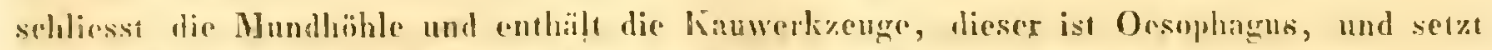

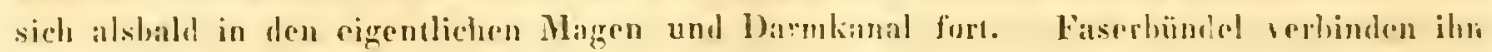
mil dem untern mechanisch zu eisem gemeinsimen finzen, sowoht an seinen seiblichen Rindern, als auf sciner Unterfliche; dennoch untrrscheidet man ihn atuf den ersten Blick dureh seine Erhabenheit und den Mangel an Glanz, withrend der untere, breiture und flachere Theil denselben schimmer hesitzt, welchen die Lärgsmuskeln des Kiorpers an sich haben. Dort erkennt man tine schwache Jängsstreifung, hier ist alles aus Ringfasmen zussanmengresetzl, dock bilden dieselben, nicht vollkommene lireise einer kbene, sondern

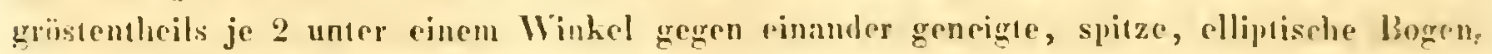
Belrachiert man dis zuletzt beschriebene Stück son der Banchitiche, so bemerkt man daran einen milleren herodretenden Rä̈cken, ron der iibr:gen Masse dureh zwei seitliche

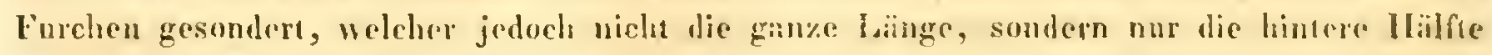

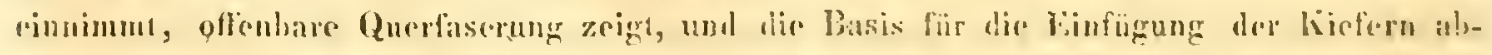

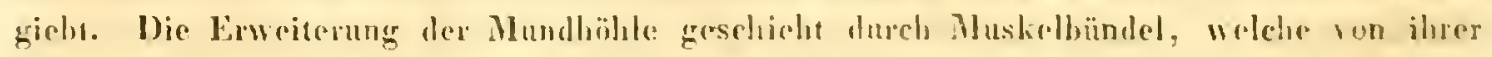
Wandung an die Mandung des liöpers gehen, theils auf der Rücken- theils imf der Baucluseite. Vordere bis an dwen Rand der Mundïllinung tretende stringe, und hintere won den ä̈ssersten Jicken der Planynxmasse an dis bite Segment sich hefestigende müssern

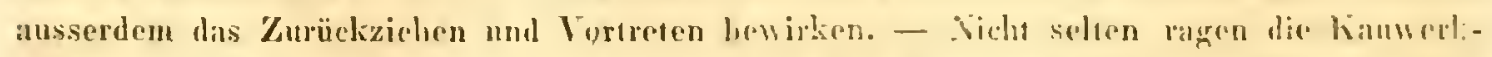

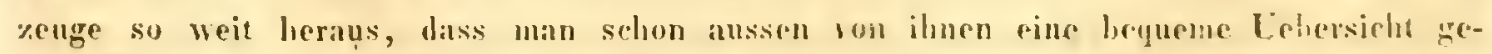
winnen kiann. - Dis Verengerung endliel wirl dured dir oben heschriebenen bugen- und

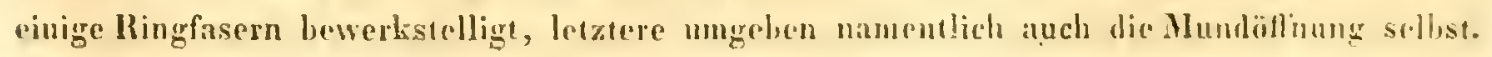

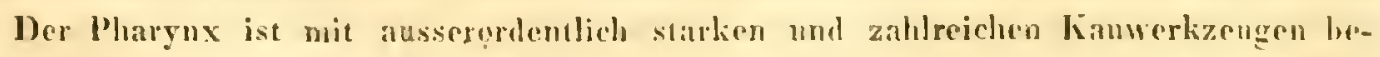
wallnet, wolche in rinem aus zwei unsymmetriscinen Hailfon zusammengesetzten Zirkel stchen, (indem sich auf der linken secite cin stïck mohr befinden. Hauptsïthlich zathen 
wir vier Paar Kiefern, von denen Edwards das eine, mit seiner breiten Flïche auf dem Boden liegende, mit dew Namen Unterlippe hezeichnet. Es ist das grösseste und stärkste ron der Form eines schmilen Dreiecks, dessen Spize linten im Grunde der Höhle steckt, und dessen etwas ausgeschweifte huchtig gezahnte Basis roun hinansragt; heide Stiieke grenzen in der Mittellinie an einander (in ihrem vardern Theil) sind vorn grantich weiss, linten seluwärlich und dort wenigstens ganz kalkhaltig. Durch eine Läicke hievan getrennt, nehmen $3 \mathrm{Paar}$ wahre Kiefern die sciten ein, zwei dersellsen wirken borizontal, 1. H. mit ilurer breiten Flïhe gegen einnsuler, diss dritte steht auf seiner hohen Kante vor den andern heiden, und kann die llähle nacl aussen rersperren. Es ist halhmondfürmig gekrünmt, an dem sehneidenden Rande seharf gezilhnelt, und kalkhart, weisslich, wie das rorige, die Basis mit der es wurzelt, mehr hornig und spitz zulaufend. Die beiden andern, am meisten nach hinten, besizen eine ansehnlicle Iä̈nge und liegen so dicht ühereinander, dass man dass obere Stïck, einen einzelnen Ilaken, fast als einen algelösten Theil der untern Platte betrachten kann. Letztere gleicht ungefähr dem Lïngsdurehsebnitt eines oben zugerundeten (cylindrisehen) Kegels, triigt einen innern gross gezahnten Rand, ist binten tief ausgeschnitten, und scheint mit dem schlanken, unten loreiteres Ifaken an einem gemeinsamen Grundstïck zn articuliren. Um diesen Zirkel ron Kiefern auch oben zu schliessen, geht eine kleine Reilhe, von vier winzigen, ganzrandigen Stïckchen, von dem reehten halbmondförmigen Kiefer zmm linken linuiber. Was num endlich das unsymmetrisehe, unpaare Stïck anlangt, so kann man nicht sagen, dass es der rechten IÏ̈lfte ganz fehle, aher man erhlickt es da nur angedeuiet. Zieht man niimlich den hallomondförmigen Kiefer ron der hinter ihm liegenden Spitze des breiten, aun Längsrande gezahnten Blattes, ein wenig ab, so entreckt man einen schmalen, sehwarzen Stiel an derselben Stelle wo links ein einzelner gezïhnelter kalkiger Kiefer eingeschoben ist, dessen Basis dem-Stieleben ähnelt; es ist also auf der recluten Seite bloss die Lamoder Selineidefläche desselhen nicht entwickelt.

Aus dem Pharỳn (weleher, wie wir oben gesehen, rüsselartig hervorgestiilpt werden kann) geht es aufwärts und nach vorn dureh eine Längsspalte zum Oesophagus, weleher

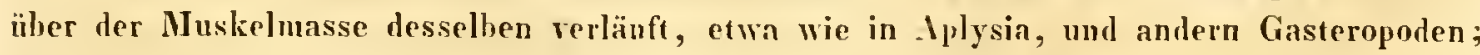
er setzt sich fort in den mit welligen Längsfalten versehenen Magen, dessen Cardia zumal durch ein pair seitlieh stark hervortretende Rüeken verengt ist, und dieser in den Darm. Alwechselnd erweitert und zusammengeschüirt verlïuft der Darm dureh die ganze Länge des Körpers, üherall gehalten durch Dissepimente und Ligamentfasern der Rückenseite.

Sehr aufiallend war mir der Umstand, dass die in die Nundhöhle hineintretende, also schon dem Epitelinm entsprechende Epidermis noels ein lebhaftes Farhenspiel zeigte, ja sogar noeh eine Strecke hinter dem Magen war dasselbe nicht ganz versebrunden, 
und es gelang fast eben so leicht das Liptelium aus dem Infang des verdauenden Kanals zul schälen, als die Oherhau von dem Corium abzuzieln.

\section{Ce c i is s y s te m.}

Im Gefiisssystem kann ich, da ich nach Spiritusexemplaren untersuchte, nicht alles Init gleicher limwisheit behaupıen, sehe mich aher genöthigt von der Beschreibung, welehe Jelle Chiar bei der gewiss nahe verwanden Gallung biopatra gegeben, in vielem alzuueichen. Srine barstellung ist folgende: Ausser ciner Anzahl kleinerer verzwejgter Arterion, wetche die fleischige Mundunsse versorgen, motstelien aus cinem, den schlund ungeherden Gefässring dyei Lüngsstüune: Die Lorta und die beiden Kiemrnarterienstimunc; letziere verlaufen auf der Bauchseite, erstere hingegen nimut die Mitte drer Riickeruseite ein. libenfalls lïngs dem obern, mitteren Theil des Kïrpers grolut die Venis "avil, welche ihre Aeste zu den Kiesnen linsendet, und in der Gegend des Koppes mit zwei andern Venenstimmen (vene ventrali) anastomosirt, deren Bhut hellgrün sein soll. Dit sich von jedem Kiemenarterienstamm zwei Aeste in die Kiemen begehen, von der lena eavi nur einer, so erhälı also jede Kieme drei Gefiisse - sie hilden eine gemeinsehaftliche Spirale und gehen auch an die aberen Cirren - die Adernetze aher, mit denen der Darmkianal ungehen und die Bauchmuskeln hedeckt sind, erhalten ihre \%weige theils aus den Lestrn der hiemenarterien und der Aorta, theils ans den Venen. Jine eigenthümliche Anordnung beschreihn delle Chinie an der Aorta: sie soll nämlich larze, anfangs: in runde, weiterhin in nierenförmige Blasen blind andende lianälchen alssender, und aus dem erwïhnten Gefïssring unten entspringen, olwohl sie spïter, nach seinen eigrnen Worten lïngs der Oberseite des 'Thicres verlïuft, demnach müsste sie rine logenwendung von unten nach qhen machen.

A n merkang. Weil delle Chiaie ausdrücklich sagt, in den kiemen circulire gränn's und rothes Blut und vorher von den Vone ventrali, whe doch mit den kiemarn-

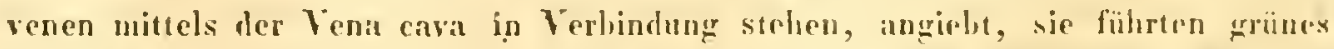
Blut, so muss man schliessen, dass a unter Vene hranchiali Cidfissw verstanden, die venöses biut zu den hiemen hringen! und unter Artrgie hrandhiali das Gegentheil.

Allerdings begegnet im Grffisssystem manthes von der gemeinhin angronommenen Norm abwcichende, so vor allem ein doppeltes liiickengefins. 
Nachdem ich meine Eunice von oben her der Länge nach aufgeschnitten, und lie Riickenlagen der Muskeln von den Dissepimenten getrennt hatte, bemerkte ich, lass mitten auf dem Darm eine Reihe gelhlicher, an den Rändern oft schwarzrother B]ïschen Ferlief, welehe an manchen Stellen krenzförmig zu je vier gruppirt waren; unter einer scharfen Loupe entdeckte ich die Verhindung derselhen nach vorn und hinten dureh je zwei dünne Fäden, und dass die rechte und linke llälfte der kirenzchen getrennt war, und es unterliegt keinem Zweifel, dass dieses zwei Gefässe sind, deren Blut sieh an den Stellen, wo IIauptäste abgehen, jedesmal an den Einschnürungen des Darmkanals, gesammelt und enagnlirt hatte, während die zwisehen inne liegende Strecke des Kanales hlutleer war. - Die Gefässe der Pleione, die ieh friseh untersucht, sahen naelı dem Tode nicht anders aus; auch bestïtigten mich in meiner Ueberzengung ein paar kleinere Exemplare, hei denen die beiden Rïekengefässe auf dem starkgefïllten braunen Darm continuirlich zu erblicken waren. In jedem Segment tritt neben der Scheidewand ein Hauptast jederseits zur hieme, vor deren Basis sieh etwas geronnenes Blut zu sammeln pflegt, und vertheilt kleine Aestehen an die Bewegungsorgane und die benachbarten Theile; dureh andere Zweige stehen die Rückengefässe mit dem Darm und den Muskeln des Rüekens in Verbindung.

Yorn, wo der Oesophagus die Pharynxmasse verlässt, also im 7ten Segment, weirhen die beiden Stämne ein wenig aus eiunder, un sieh dann zu vereinigen; aber nur anf kurze Zeit, denu schon in der hintern IJïlfte des Oesophagus theilt sich dieses Gefïss anf's neue.

A nmerkung. Diese letzte Theilnng ist wahrseheinlich gahelig; zwar gelang mir's an den beiden Exemplaren, an weldhen diese Stelle möglichst gut erhalten war, die Fortsetzung des Stämmehens rollknumen nur anf der linken Seite zu verfolgen, und zwar auf der Grenze von Oesophagus und Pharynrmasse, doch er- . kannte jeh auf der entsprechenden rechten Seite die dentlichsten Spuren eines ähnlichen, nur weniger gefüllten Gef̈̈sses, an deutliehsten hinter dem Kopf, wo es denselhen Zweig ahgah, wie das vollstïndig erhaltene; weiter nach hinten sah ich nur gesehlängelte Bruchstïcke, und auch die Spaltungsstelle selbst zeigte keinen sichern Umriss eines Ueherganges atus dem Stämmchen in einen Ist iler rechten Seite. Bei Inneliden nämlich, die einige Zeit in Weingeist liegen, zerhrökekeln leicht die schwiieheren Adern. - Im Gehirn scheinen die äussersten Zweige dieser ohern Gelïsse Inastomosen mit den untern einzugehn, desgleichen hinten an der Pharynxuasse. 
An der untern Flïclie des Darmes giclot es nur cinen Gefissstamm - Vax ientrale - in welchen eine Menge von Zweigen mündet, einer hauptsïchlich an der hinern Grenze jedes Segmentes; nnd hier tritt seitlich nach atssen ein starker Zweig hersur, der jedesmal an sciner Basis eine anselnnliche blasenartige nach Ldwards sich contrathirende Erweiterung bildet; jedoch endet sie keinesweges blind, wie delle Chiaie ablildet, sundern derselbe Zweig setzt sich aus ihr fort, linft schräg nach vorn iiher die Breite seines Srgmentes, erreicht das Dissepinent, in welehem ohen der gleichnamige Zweig der Rückengefässe forlgeht, und versorgt die Kieme, die Orarien, und die Mnskeln der allgemeinen Körperschichten und der Bewegungsorgane. Vorn an Jinde des Plarynx liegen die Urspriinge der für die vorderen Segmente hestimmten Zweige dicht lintercinander, wäluend die Zweige selhst büschelig auseinanderstrahlen. Der Bauclsstamm aber setzt sich zwisehen der untern Flïche des Oesophagus und der ohern der Pluarynxmasse fort, und billet hier ein Gefïssnetz, in welehem man ausserdem noch zwei seitliche, ilure Zweige gegen die Rückenstïmme hinsendende, Niern unterscheiden kann. - Auf dem Nervenstring endlich habe ich zunächst dem Schlundring ein Vis nervoso-abduminale erkannt: weiter nacle hinten aber war es durelo das Ablösen des Darns zerstïrt. In einem lessern Exemplar lag auf dem Nervensirang ein dunkelrothlonuner gliederweise ein-

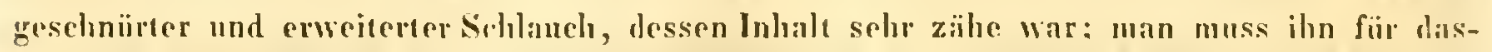
selbe Vas nervoso-ventrale hilten, wenn er nicht noch in hesonderes Bezielung zul den Generationsorganen stehen solle. Zarte Zweige traten seitlicis aus ihu hersor und wanden sich nach den Kiemenästen des Vas ventrale, der Hauptstamm selbst üherderkte so ganz den Xerrenstrang, und war ihun so eng verbuuden, dass es mir unmüglich wurde, ilu unverselurt divon za trennen, dass man vielmehr vermuthen kann, der Xersenstrang, Werile von seinem Blute umspiilt; allein an Schlundring hemerkt man doch eiue deuliche Gefïssteraweigung und wird daher nuf die Annahme besonderer Giefisswandungen zurürkgefülırı.

Vit man in den Kiemen Gefïssiiste von zwei llauptstïmmen antrifti, so hahen diese wohl sellost eine entgegengeselzte Bedentung, unıl ich halte das Bauclugefäss wegen der

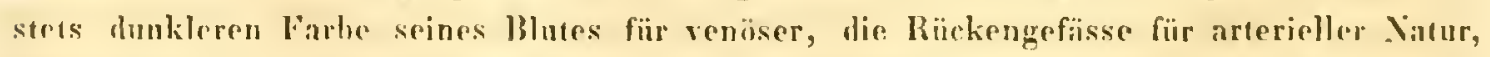

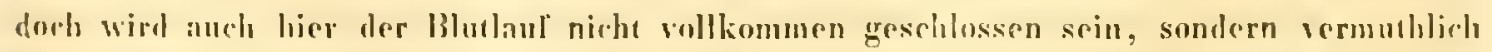
in den Darmenetzen und dem Vas nerroso-ventrate gemisclutes Blut circuliren. Oflimbar ist die scitliche strönung in den dinzelnen Ringen die üherwiegende. 
Der sehr ansehnliche Nervenstrang - aus, zwei durch eine Scheide verhundenen Schnüren bestehend - lässt in einigen Exemplaren denticher, in nnderu minder deutlich länglieh runde Ansehwellungen erkennen. Im vierten Kärperseguent spaltet er sich, um den Schlund oder vielmehr die Mundötfinung von beiden Seiten zu umgrhen: nachdem aber dic Schenkel des Ringes schon aus einander gretreten sind, werden sie noch cinmal durch eine Brücke, ein paar querlaufende Fällen, verbunden. Die Schenkel sind am Ursprung derselben etwas angesehwollen und senden einen Nervenast ab, dann setzt jeder seinen Bogen fort, nach aussen und innen noch zwei Zweige an die vordersten beirlen Segmente schickend und an Dicke merklich abnehmend, und stïsst mit dem andern in Gehirnganglion rusanmen. - delle Chinie hildet dasselhe herzförmig ab und sagt, dass aus ihm auch einige zu Rückenganglien anschwellende Füden entständen; soviel ich aber aus der ganzen Beschreibung entnehme, ist sein Gehirnganglion der vorderste Knoten des Bauchnervenstranges, aus dem die Ringschenkel hervorgehen, und sein ,gruppo quadrigemino di gangli dorsali"s der Gehirnknoten, weleher ja jmmer vor oder über der Mundhöhle liegt; es fehlt seiner kurzen Beschreibung an Schärfe. An den wenigen Exemplaren, die mir zu Gehote standen, schien das Gehirnganglion zweilappig: auf der Grenze der beiden Jappen sah ieh den Anfang des Fadens für die mitulere Intenne; den Ursprung der für die nndern bestimmten Fäden véruochte ich nicht sicher zu erkennen, weil hei lem lbliisen der Muskelmasse des Kopfes, in die das Gehirn cingesenkt ist, disselbe verletzt wurde, aher dic üheraus kurzen Augennerven - man kann sie nur Erhahenheiten des Giehirns nennen - sassen nahe den äussern liändern der Lappen.

Bei keiner Annelide hale ich so deutlich den Infang eines eigenen Nervensystems für die Verdauungsorgane nacluweisen kïnnen als gerade hier: offubbar entspringen aus dem initteren Theil des Gehirnganglions (etwas nach hinten und unten) zwei zur Oberseite des Schlundes laufende Fäden, sie vereinigen sich hald zu einem gemeinschaftlichen linoten, und trennen sich wieder, um iher den Anfang des Oesophagus an beiden Seiren herab zu laufen; sie begegnen einander dann auf der Unterflïche dieses Theiles, und geben an die muskulöse Jharynxmasse einen aus ihrer Verbindung entstelıenden Zweig ah, urn längs den Seiten des Oesophagus ihren Gang fortzusetzen: weiter lube ich sie fiir jetzt nicht verfolgt.

Aus den Knoten des Nervenstranges sollen nach delle Chiaie bei Nereis cuprea kreuzformig je rier Zweige entstehen; bisher habe ich nur zwej erkannt. In sinen sonstigen Verhälınissen bietet er nichts besonders dar. 


\section{Wortorlanxungsorgane.}

Gewöhnlich war ein grosser Theil der Fächer mit losen Fierchen ron aussernedenthieher Kleinlseit erfült; ihr Vorkmmen äusserlich an den hiemen lïsst mich remuthen, lass sie durch einen Gang in der Yïhe des Borstenlüschels ans der Leiheshöhle in's Freie gelangen. Für Orarien aher halte ich diejenigen kïrper, welche man unterhall des Basis der Borstenluisehel, wn die Längsmuskelschicht des Rïekens aussetzt, seitlich von Darm antriff. Sie waren weiss, gelappt, ziemlich dickwandig, in einigen erkannte man rundliche thsonderungen, wie Kimmen ron lierehen, und deutliche Gefïssierzweigung. Das in die Bauchböhle hineinragende Rorstenbüsshel pflegte unmiltelhar auf ihnen auf zu liegen und einen Eindruck zu hinterlassen, der diese flichen, in dem ïussern Ulmiss etwa wie ein Fïcleer gestalteten Organe quer in zwei lliiffen theilte, so daks sie zweiklippig oder zweihlättrig wurden.

Lange genug hahe ich mich vergehlich nach mïnnlichen Organen mmgesehen, his irh sie endlich in den liinglichen Blasen gefunden zu haben glaube, welehe noch üher den Berstenstielen, seitlich an der Grenze der Läingsnuskelsehicht des Rückens liegen. Thre Cirïsse iihertraf ein wenig die der krweiterungen der Bauchgefïsskiemenäste, sie waren strotzend voll von einer dunkelbraunen zïlien Flüssigkeit und verriethen im Aeussern viele Aelinlichkeit mil den won Il. Rathke in den Nereiden gefundenen Organen. Uebrigens halbe ich in den vordersten sigmenten beiderlei Generationsorgame vermisst.

Dis Wadhstum scheint hej den Eunicen sowohl durch Vergrögserung der einzelnen Segmente als dureh Vormelurung ihrer Zalul zu erfolgen. Diesellee Lnzahl ron Scegmenten, nämlich 172, faud iels in zwerien an Länge sehr verschiedenen Individuen, denn das eine unss 17 , das andere uher 22 ('ontimeter; in einem dritten betrug die Zahl der Segmente 152. hei einer Länge von 11 Centimeter (und einer Breite ron 0,3, wogegen das son 17 (ent. - 0,5 hreit war); aher bei Funice (Leodice) opalina und atnennata differirt dieselhe nachs saviguy, namentlieh bei der leszeren um mehr als 100. Da die letzen Gilieder selur fein sind, und diese Thiose durch heftige Contractionen - wie ich das selber einigemal angeschaut - leicht einen Theil roun Selwwanzende verlieren, so muss man hei der Zälılng gensu darauf aclıten, dass die Exemplare rollstindig sind. -

Funice Harassii wohnt nach Audonins Angahe in Sandröhren, die sie sclber zu hauen scheint, die meinigen erhicht ich mit mehreren andern Anneliden son Fischern, ohme 
näheres darüber zu erfahren; die grössten Exemplare zog ich aber selbst mit Schwämmen aus der Tiefe des Meeres herror - im Guarnero von Fiume, am Ufer der Insel Veglia.

\section{(1) Il I h i s.}

Ein den Eunicen verwandtes Thier, welches jedoch durch seine Kopfbildung wieder sich merklich von ihnen unterscheidet, hat den Ferren Audouin und Edwards Veranlassung gegeben, ein neues Genus Onuphis daraus*) zu machen. Alle Individuen der Art, welche ich zum Gegenstand meiner Beschreihung mache, erhielt ich allein in Palermo, wälırend meines dortigen Aufenthalts im December 1835 und Januar 1836; sie können wegen der Einfachheit ihrer Kiemen, wegen der Substanz der von ihnen gebauten Röhren, und einiger anderer Gründe halber nicht zu $O \mathrm{nuphis}$ Eremita von Audouin und Edwards gezählt werden, sondern stimmen vielınehr mit der Nereis tulhicola Müllers ïherein und wenn gleich der Beiname nicht mehr bezeichnend genug ist, weil das ganze (ienus in Röhren zu wohnen scheint, so will ich ihn in prägnanter Bedeutung gehraucht wissen und nichts daran ändern.

\section{Gunluis tubicola.}

Mlüller. Zoologia Danica. Tom. I. tab. Xvil1.

Der Kopf trügt 5 ungeringelte Antennen, von denen die änssersten die kleinsten sind, die mittleren haben die I,änge der folgenden 7 Segmente zusammengenommen, und geben der unpaaren mittelsten wenig nach; er ist klein, hreit-oval, läuft nach vorn in zwei cylindrische, etwas zngespitzte Fortsätze aus, die lidwards auch Antennen nennt, und unterhalh ron ihnen in 2 runde Jappen - erstere entsprechen den Kopflappen der Eunice. - Die heiden kleinen dunkelrothen Augen stehen seitlich und hinter den mittleren Antennen.

Auf den Kopf folgt ein unbewaffnetes Segment, welches die senkrechte Mundöffinung enthïlt, mit dem zweiten beginnt die Reihe der Borstenhügel, doch sind dieselhen in den

•) Ann. des scienc, nal. Tom, 28. pag. 22j. 


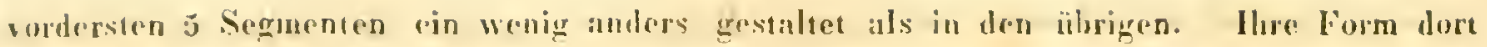

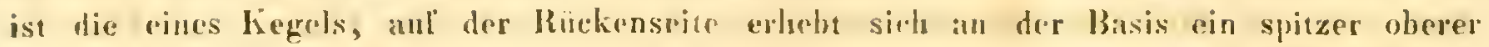

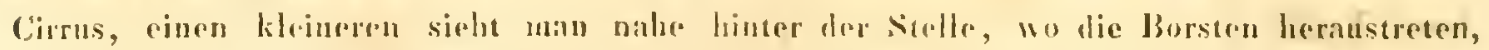
und nuf der Batuchseite arscheint rin unterer, eluntills nur kurzer ( irrus. Jed letztere nimut immer mehr an Jsinge al, an lBreite zu, his er in sechsten sigument \%u cincm rundlichen, von vorn nach binten zusanumengedrïckten Wulst umgewandelt ist, auch vre

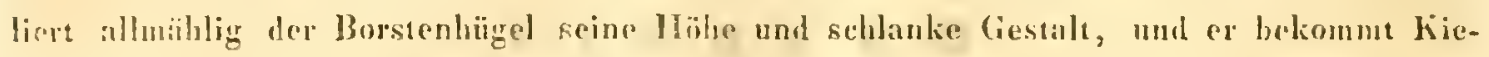
menfiblen \%u tatereli, won der einfuchsten form.

Fun den selur feinen Borsten laufen einige in eine einfache Spitze aus, andere sind mit cincm schutilen l'lossenblïtchen versehen, noch andere endich verdicken sich :u dem

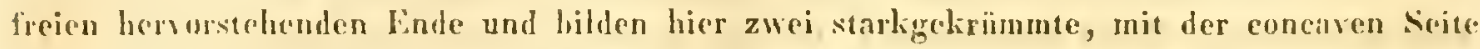
ciundor zugokehre Inken. - Sie entsprechen den hewallneten Borsten der Funicou. -

D) Sclswanzglied ist, wie bri Eunice mit zwei unteren Cirren versehen.

Dir beiden hïckenumsheln der lä̈ngschicht scheinen mir verhälnissuässig schunaler als hei lunice, zumal am hinteren Ende, im ̈̈hrigen Muskelsystem herrseht grosse Leberrinstimmung mit jener, wie üherhapt in der ganzen übrigen Mnatomie.

So sind die hiefern im Pharynx jenen selu analog gebildet, nur dass alle diese 'l'heile lior viel zarter, die läinder der seitlichen grossen Bogenstüclie in ihrer ganzen Jange gezähnelt sind, und vielleicht in den kleinen Jiefern eine Abweichung eintritt, die norl einer nälieren Entersuchung bedirf.

Das Gefisssystem lonnte nicht bis in seine Feinheiten verfolgt werden, weil diese an sich schon liknen Thiere in Weingeist zu sehr grelitten hatten. - Mber Rückenge. firsse sind in hintern Theil zwei vorhunlen, an lebenden Thicren sah ich sie durchschimmorn, duelı sehien es, als ob die sin̈mme am mobnten linge selon zusanmengestossen waren. Das einfache Bauchgefiss triggt an der Basis seiner liemenäste sohr ansehuliche Haxige liwerterungen; das Vis mertoso-ventrale lian mir cinfach vor: an der Vertheilung der Gefitsse um den Pharyax herum ist nichts hesonders aullallendes und abweiehendes zu finden. Dasselbe gilt von Nervenstrang und den Dissepimenten. -

Die Fier, welehe in Verbälniss zur Grisse des Thieres ansehnlich sind, salı ich lose in der hinteren llälfe des Körpers liegren, abor in so gedrangter Masse, dass sie an den Wïmlen des Darmes in einem Weingeistexemplar thachkugelige Findrücke hinterlassen hatten. In den vorderen Abschniten dagegen fand ieh zu beiden seciten des verdauenden Kianals knospig aufgeniebene Kärper won kreileweissur Farbe, unterhall, der Borstenlöndel ansitzend: sie entsprechen ohne Zweifel den weissen lappigen Organen dieser Sitelleu bei lunice, und sind Orarien, deren Eier nocl nicht ihre lleife erlangt haben; wit mir's denn mehrmals aueh bei Eunice begegnet ist, dass das Lusreissen derselben von 
ihrer Bildungsstätte linten früher als vorn erfolgt war. - Die vernuthlich befruchtenden Organe hafteton an derselhen Stelle, wie dort, nümlich üher dem in die Leiheshähle hineinragenden Borstenbündel. In demjenigen Judividum, in velebem ich in den hintern Segmenten nicht mehr die compacten Ovarien etiennen konnte, weil die Eier bereits daraus hervorgetreten waren, sah iel diese sonst kleinen, melir hinföruigen Organe anss'rordentlich angeselwollen, und strotzent ron ainer dicklichen weissen Flüssigkeit. Wiese niedliche, wenn gleich mit weniger bracht Farben spiclende Annelide, ist hellfleischrotl gefürbt, und wohnt in durchscheinenden hornigen Rïhren, welche das Anselun von Fedrerkiclen haben. Sie sind gerade oder in der Nitte ein wenig gekrümut, schlank, an beiden Enden offen, an den einen mehr erweitert als an dem andern; die Ränder der Oeflinung pflegen gekerbt und gespalten zu sein. Die längste mass 8 Centm. in der Länge und ; 6 : in der Dicke, an dem weitesten Fnde. - lhre Substanz lässt sich leicht mit Jen Messer schneiden, olıse jedoch zu spalten, und besteht ans mehreren selir feinen Hornlagen, in whlchen min unter dem Mikroseop Streifchen von verschiedener Richung erkemt. In wrichsten ist dic innerste Schicht. Sie bildet an den Ausgängen der Rähre eine sonderbare Vorrichtung, wodurch das in das Innere sich zuriekzichende Thier vor Ingriften gresiclert wird. Sie kleidet nämlich hier nicht viberall die Wand des Tubus aus, sondern ist nur sackntig an einzelnen einander gegenüherliegenden l'unkten, hefestigt, so dass je zwri lase heralhängende IJïlien, wie cin paar Klappen zwar den Ausweg erlaubeu, aher rin Findringen rou aussen nicht gestatten. Solcher Klappen zähle idh an jeden bude zurei his drei hintereinander, und die Spuren der schon verschwundemen - denn dic Rähron müssen mit den Alier wachsen, - nimm man an den lablbuondfömigen Zeichnungen in der Wandung derselben walır.

So sitzt demn die Onuphis sicher in ilırer Röhre, oft Viertelstunden lang, ohne sirlı zu rühren, hisweilen salı ich sie nicht allein ihren Kopf mit den langen Intrunen, sondern auch cinen Theil des Vorderleibes linausstrecken. Der Bewohner ciner z Centul. iangen

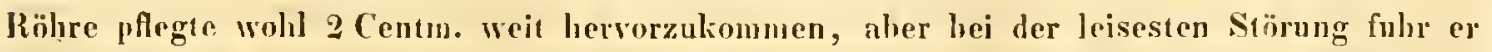
rasch zurïk. Wer solle vermuthen, dass sich in diesem engen Raum das Thierchen umzuwenden vermag? Lnd dorli habe ich diesen Vorgang oftmals mit rigenen Ingen angesehen: es wandie laıgsam den kopf nach hinten und dann arfolgte schnell das Umbelıen des Körpels, so dass nun der Kopf zur Schwanzöflinng des Tubus hinaussalı. - 'Trotz dieser Baweglichkeit und dem Schutz des Gehäuses fand ich doch verstümnelte Exemplare; vielleicht mag diese Verstünmelung weniger äıssern Feinden zuzuschreiben sein, als dem Bewnhner selbst - bahen wir doch von den Eunicen, denen dieser Wurm in allen Stïclien so ähnlich ist, sehon oben erwähnt, dass in Folge lieftiger Contractionen das lintere Ende abbriclit. 


\section{A It I o d i t e.}

Withrend ich in Cette vergeblich einige andere Anneliden zu erhalıen hoffer, deren Anatomie ich in Italien zu studiéren begonnen, brachten mir Ansternfischer in ziemlicher Anzill Aphrodite lysstrix, mir un so ingenehmer, da ieh diese Gattung lisher vernachliissigt hatte, und hegierig war, den innern Bau eines äussertich scţon so sonderhar gestaltelen und hewatlietẹn Thieres nähẹr kennen zu letnen;

\section{Aphodite liystrix,}

Synon. Ilalithea hystrix. Savigny, Systeme des Aunelides. pag. 20.

Hermione hystrix. Blainville.

Aphrodile liysurix. Annales des sciences naturelles. Tome 27. pag 406. - pl. 7. Fig 1-9.

Ceber die Inalomic der Iplorodile aculeata:

Swammerdamm. Bịbel der Natur. pag. 356 .

Gunner in den Drontheimer Gesellschafisschriften. III. 5I,

Pallas. Miscellanea zoologica pag 79. lab ril.

J. 12 Treviranus. Teitschiff fiir die Physiologie. Bd. X pag. 157. tab. XI. XII. XIII.

Wenn ich hier die äunssere Beschreibung dieser hinlänglich scharf characterisirten Irt noh rimnal wiederhole, so geschieht es melur der Vollstïndigkeit wogen, als einiger Zusätze halher.

Der Kärper hidde din selur lang gezogenes, an heiden linden stark versclamïlretes Oval, nähert sich jedveh bei einigen Individuen, welche wie schon kidwards bemerkt, inch aus andern Grïnden eine eigne Yarictït auszumachen scheinen, der gestreckteren form der Implinomer.

Iünge des kï̈rpers . . . . . 6., 6,5 Centm.

Grïsseste Breite......... "

Gr. Breite ohne die Borstenstiele . 1,3 ",

Der Leib ist ohen mit frei lingenden Schuppein hedecki, und hestelut aus 33 Segementen, sowohl bei grossen als kleinen lixemplaren; zwishen die vordersten ist theilwrise der Kopl eingeschuben. Zụ den Seilen stehen zwei Raihen lorstenhiugul, deren erstes 
Paar, durch eine Lüche von den hinteren gretrennt, so unuiliclbar an den Rändern des kopfes lervortritl, dass man es leicht für einen Anhang desselben halten könme.

Die Schnpen sizen auf dem 2ten, 4ten, 5ten, Tten, 9ten, 11ten u. s. w. 2lsten, 23sten, 25sten, 28sten, 31sten Segment, also mit zweimaliger Ahweichung von der heihe der ungeraden zahlen, im ganzen 15 Paare. - In der Aphrodite aculeata tragen die mit Schuppen nicht versehenen linge, Kiemen und Rü̈ckencirren, in unserer Art finde ieh zwar die letzteren, suchte jedoch nach jenen kanmartigen Hautvorsprïngen, welchen man dort den Jamen liemen ertheilt hat, rergehlich, und eben so wenig thun ihrer Savigny, Audonin und Edwards Erwähnung. Bei allen meinen Weingeistexemplaren habe ich ahermals anfs genaueste nachgesehen, aber erfolglos. Allerdings könnte diese Organe die ungewölınlich hasse Farhe des Blutes und vielleicht ihre Kleinheit der Beobachtung entzogen halien, wozu noch kounmt, dass die grosse Menge Schuntz, welehe an den Borstenluändeln zu klehen pflegt, die Untersuchung dieser Theile erschwert, aber es ist nicht gut glaublich. Bemerken wir doch anch in der Reihe der Euniceen einzelne Gattungen ohne liemen, die übrigens wenig von den andern versehieden sind.

Die Bewegungsorgane sind sehr ausgehildet und mannichfiltig; so finden wir in den schuppentragenden Segmenten zweierlei Borsten der oheren Reihe, die einen in Form eines Vächers gruppirt, ror der Basis der Schuppe, dahei etwas gekrümmt, dunkelhlond, am obern Lnde zugespitzı, ungefähr 0,8 Centun. lang; die andern, auswärts von diesen, ans len Borstenhügeln selbst herrortretend, wahre Stacheln von 1,5 Centm. Länge und an der Sprize mit Wirierhaken versehen. Jederseits stehen fünf Widerhaken, ahwechselnd, lie untersten sind die grössesten, die obersten die kleinsten; die Farbe ist bei diesen Stacheln dunklex, der Gilanz metalliseher, die Dicke beträchtlicher als hei jenen Borsten.

In den sehuppenlosen Segmenten trïgt der olere Borstenhïgd nur e in Bündel hellblonder, sehr feiner und biegsamer Ilaare, von 0,6-0,8 Centrn. Länge, sie sind leicht gehogen, viel zahlreicher als die vorhin beschriehenen, und haben hiinter sich die Rückencirren.

An allen Gliedrrn übereinstimmend finden wir die, an Farbe und llärte, den langen Rückenstarbrln gleichenten Borsten der unteren, mehr hervortretenden licihe von Hiigeln oder, hezcichnonder gesprochen, Kegeln. Die Spizze dieser Borsten ist weder gan\% einfach, noch so stark lewaffnet als in jenen, sondern läuft gabelig in zwei Zinken von ungleicher Länge aus. Sie stehen nur zu dreien oder vieren, und messen 0,9 Centm. Mlit Ausnal:me der ror die Basis der Schuppen eingefügten Borstenfäeher, sind alle Bündel nit stirkin Stielen oder Sarde!n rerselın, an sie heften sich die bewegrnden 
Mluskelv, anch hier umgieht ein ltäutiges Bentelchen den in lie Leibeshöhle hineinragenden Theil der Bündel; wie in lunice, Arenicola, I. d. a.

Auf der Cuterfliolın der letzigenannten Kegel, eine Strecke von der Oeffnung dersellen entferm, sitzen die kloisen Bancheiren, in Form eines kur\%en fleischigen Futens; dagegen sind die Rürkencirren wohl noch achtmal so lang, sehr sehlank, an der Spitze gliederartig eingeschnür, wie mit einem lïnglichen Kn̈̈pfehen versehen, unl erhelien sirh auf einer algestumpft konisehen Basis. Jene begegnen an allen Seguenten, diese nur an den ron Schuppen entlü̈ssten.

Der kleine Kopf trägt eine unzaare mittlere und zwei sehr viel ansehnlichere, ghate, fein zulaufende Antennen (ron etwa 1 Centm. Länge, wis die lä̈ckencirren) den einzigen perlmutterglänzenden Aussentlueil dieses Thicres. Zwischen den Füllern sitzen vier schwarze Augen, nirht unuittelbar auf der Oberflïhe sonilern zu je sweirn auf einem kurzen, stumpfen Stiel. - Die vorderen Augenpunkte übertreflen an Unf:ng die hintern.

Der Kopf üherragt die anf der Axe senkrecht stehende Mundïfnung, an der idh jedorh den Kiranz von Tentakeln, welchen die Fraziisisehen Beschreiber angehen, nirlut bemerken kamn, nur die Liinge des Baucheirrus roun nebeniunstehenden ersten segment fillte selir in die Augen.

Zu spuit leider hin iclu anf eine Eigenthïmlichkeit dieser Aunclise aufuerksam geworden, welche, wie es seheini, auch sonst übersehen ist. Sowolul anf der Banechtlïethe nämlich als an den untern Borstenkiggeln und rorzüglich an ihren Spitzen entleckie irlo

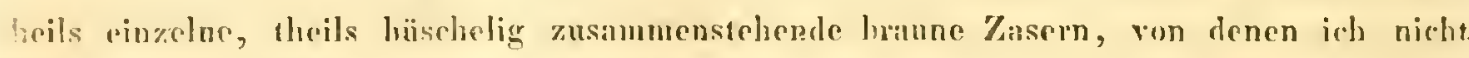

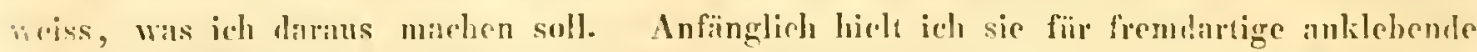
is äperehen, da sie aber so fest an der Oberhant hingen, dass man sie nur mit Mühe entternen konnte, whole ich zweifelhnfe. Bei mikroskopischer Untersuchung ergah sich, diss diese Zasern hrame durchseheinende rylindriscle Röhrohen sind, einige sprangen mehr lervor, theilten sich ein- und mehrfach galbelig, andere blieben kürzer, rerstricken sirlt und lisorlien wie Wurzeln liings der Oberllïele fort; manche ron den längeren ir-

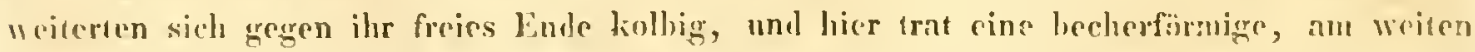

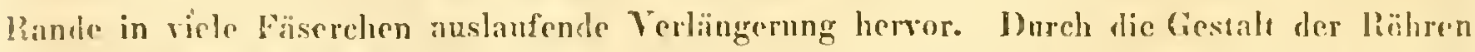
im Algemeinen wurde ich an die Wolnungen der Meyonelli diaphna erinnert, vielleichı sind es in der 'That Polypen, die sich rorzugsweise gern anf diesem Thicre ansickleln, atber andrerseits scheint dir Banchfläche ein unruliger Aufenthalt. bine Lochlingswolunng kleiner Anneliden ist die Mphrodite aculeata; sie resstecken sich dort unter dem 
schiitzenden Filzgewebe des Rückens. Unserer $\Lambda$ rt soll es gïnziich feh?̉en, und doch kanı ich sichere Spmren davon, zwar nicht wie dort schön glänzende rerstrickte Hinare, aber doch einzelne weissliche Fasern, nachweisen, welche an der Spitze ter oheren Borstenhügel eutspringen, und zuweilen quer über zur andern Seite gehend, wenigstens eine schmale Binde darstellen. Ja an einen ganz jungen Exemplar, welches nach allen Merkmalen diese und keine andere Art ist, war es unmöglich freiliegende Sehuppen zu erkennen, weil der ganze Rücken mit einem festen Gewebe, dem eine Masse Schmutz nnliaftete, überdeckt war. Das Vorkommen oder Fehlen desselben scheint also bei Aphrodite hystrix nur eine Altersverschiedenheit zu sein.

\section{Selnuppen, Fant, Muskein.}

Um mich näher üher die Sehuppen auszulassen, muss ich gleich ron der Bekleidung des Kï̈pers sprechen. Die oherste Haut desselben erseheint glatt auf der Oher-, nuehr runzlig auf ter Bauchseite, und etwas rauh oder feinwarzig an den nutern Borstenkegeln, ihr fehlt aller Schiller, alles Farbenspiel: an sich ist sie farh]os und durchsichtig, nur das ilur anhaftende l'igment verleilut ilır den schumtzig braungranen Ton, welcher dieser Art eigenthiimlich ist. - Wenn man sie an der Rückenseite aufschneidec und zu beiden Seiten zarücklegt, trillt man, nicht wie in vielen andern Würmern z. 13. in Arenicola gleich auf die deutiche Ringmuskellage, sondern auf eine Membran, welche min leicht für das Corium zu halten genpigt ist, indessen üherzeugt mich die miliroskopische Untersuchung dawon, dass Querfasern darin vorwaltend sind, aber durchwelt ron andern kreuzenden, so dass man in ilır zunächst ein Analogon der sonst fehlenden IRingmuskelsehicht suchen muss. Die Ilaut und jenes Blatt sind mehr oder weniger fest an einander geheftet, und weun Treviranus angicht, dass zwischen ilunen ein Zwischenraum stattfinde, so muss man dies wolll der Aufhewahrung in Weingeist zuschreiben, wobei sich häufig auch bei andern Thieren z. B. den Sipunkeln, die Epidermis ron ihrer Unterlage ablöst. Ias Caritum hahe ieh als eigene Schicht nicht ablösen können, es muss also sehr dïnu und entweder mit ihr oder der Pigmentlage verbundru seiu. - Zu beiden Seiten der Mittellinie des Rüekens schimmern zwei mässig breite Längsmuskeln durch, eine Lücke treunt' sie wälırend ilıres ganzen Verlaufs durch dir Kinrpellänge. Jeder ron ilnen ist in eine Scheide geschlossen, deren oberes Blatt die beschriebene quergefaserte Rückenhau, und deren nuteres die den Kärper innen aus- 
kleidende Memban bilde, beide aber beriiluren unmittelbar cinander in der die Lailngsmuskeln trennenden strecke, und man erkennt wegen ihrer Durchsichtigkeit hier deutlich den darunter befindlichen Darmkanal. Zwei andere Längsmuskeln der Räickenfläehe wift man lïngs der Basis dew ohern Borstenhügel, seitlich von jenen; sie werden überdeckt zunäiclst ron fïcherartig ansgehreiteten Querhündeln, welche an üussern Rande jener mituleren Längsmuskeln entspringen, aussetdem alber von der die gesammen Muskellagen umbiillenden жweiten Membran. Denken wir uns ten Darmkanal und alle andere Organe der Banchlähle entfernt, und üherblicken wir so dir ganze Muskulatur dor Aphrodite, so finden wil auf der Baurhseite eine ganz ïlntiche Anordnung in den Membraneu, aber nur ein Paar Längsumskeln und mehr ron einander entfernt als dias mitlere Pair der whern Seite. Vou innern kaude dersellien entspringen zweicilei Quermuskeln, die einen laufen horizontal zur Basis der unteren Borstenkegel (von dere Banchhöhle aus gesehen: üler den Lïngstunckeln liegend), die andern steigen zur Rüclenflïlse empor, befestigen sich an den soitlichen Längsslinden und theilen das Innere des Loilos in Kimmern. Den fächerartigen wheren Quermuskeln entsprerben eben solvhe untere, rom änssern Rande ler Banchlïngsmuskeln entstelende. Fs liedarf in der That einiges sundiums, um sich üher den Bau der allgemeinen Muskelschiehuen unserer Aphrodite zu unterrichten, und eine Schlwierigkeit, Welche dasselbe noch erböht, ist, dass bei Wringeisievemplaren am häufigsten diese Theile des Organismus verdorben sind, die Enden der Striinge reissen alb und man finded ein Conrolut nur theilweise noch

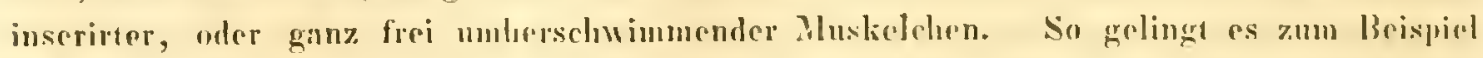
selten die Bündel, wodureh die livermitïten bewegt werden, an allen rollständig nichzonsisen, und dieses ist wohl der Grund, warum sic Terviranus an Iphrodite aculeata

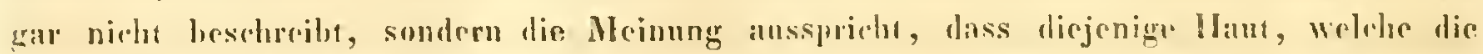

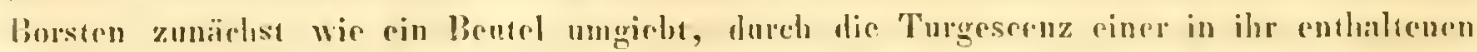
Flisstigkeil diese Orgame hewrge, eine Vorrichtung, Welche meines Wissens nur dru Fichinodermen zukmumt. - Namentieh an den vordern Borstenbüscheln habe ich die zur

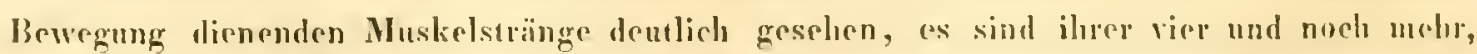

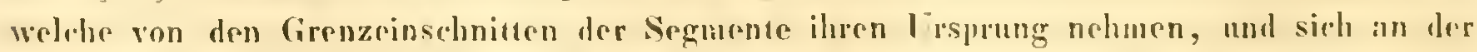
Satlel (acirule) frestsetzen; das Burstenbündel, (wenigstrns die langen Stachetn und die

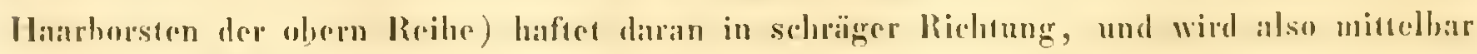
durch diesen Hebel bewegt.

Ferner sprish Treviranus ron den in den Zwischenraum zwiselon der ersten

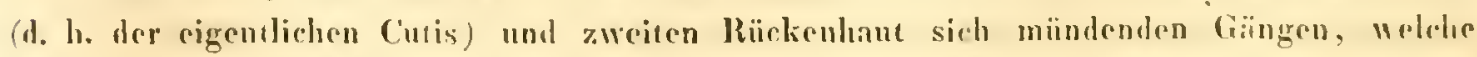
z.wisehen den abwerhse'nden Füssen liegen und da hinein Wissor füluren sollen, er spricht 
von einem Zusammenhang dieses Zwischenraumes mit der inneren Batrehhöhle, und ich wollte gern die nüheren Verhïlınisse dieser Gänge und Verbindungen kennen lernen. So sehr mir daran gelegen war die Stellen, an denen die Eier die Leibeshöhle verlassen, aufzulinden, so wenig gelang mir aus der ïussern Untersnchung der Wandungen das gewïnschte Resultat zu erbalten. (Ich muss hinzusetzen, dass alles dies an spiritusexemplaren vorgenommen ward). Nunmehr versuchte ird künsiliche Mittel, ich schnin einen Spalt in die IIant, und wollte den angeblichen Zwischenaum zwisehen ihr und dem mächst untern blatt mit Luft aufblasen so lange, bis dieselbe durch jene seirlichan hianïle entwiche. Dies führte zu nichts: es gelang nicht einual eine solebr Möhlungr zwisclsen beiden Blättern nachzuweisen. Darauf älisete ich dic Spitze eines untrun Borstenkegels so tief, dass die eingefülute Canuelle in das Cavum abdominis hincintagre, umschnürte diesen 'Theil fest mit einem Faden, und injicirte mit Laft von nenem. 1)er Jepib sehwoll ïheraus an, immer wollen keine Bläschen ins Freie entweiclian, ich setre meine Operation fort, er dehnte sich noch mehr aus und - es fillten sich die Rüchenschuppen dernaassen, dass sie wie Blasen anzusehen waren.

Früherbin hate ich beim Alstreifen der Haut diese Schupren immer mil alyezogen, und sie für blosse Duplicaturen derselben gehalten; nummehr gab ich genauer Icht, und bemerkte, dass bei diesem Abziehen allerdings ein oheres Blatt fer Schuppo mitging, dass aber nicht bloss ein unteres Blatt zurïckblich, sondern drei, rines, dir dem oberen entsprechende untere Hälfte, das zur wahren Hixut gehörte und zwei andere, ebenso wie jene miteinander verbundene, welehe rine llïhlung in sich einsihlosscrn. Die Communieation der Ilöhlung mit dem Cavum des Leibes war dureh die Lnjection bewiesen. - Auf einigen Schuppen sassen winzige Vebenschüppchen auf, deren Carum mit dem der grossen communicirte.

Da ich an lebenden Aphroditen die Schuppen nicht aufgehlasen geselien habe, so las ich im Suammerdamm nach, den Treviranus als Gewähsmann dafür angiebt, fand aber, dass auch er nur todte Exemplare zu zergliedern Gelegenlecil gehaht, und dass der Gebrauch der Scluppen als Schwimmblasen von Aclian und Rondelet erzällt sei. Ob die Blasen gar nichıs mit der Respiration zu seballen haben, wïrde man nun freilich an frischen lixemplaren untersuchen müssen, und anderseits ob nichts den Kiemen iilulichrs rorlianden sei. Erhehungen gewahrt man allerdings auf der Rückenflïche jedrs Seggments, aber sie rühren nur von den dasunter liegenden roluminösen Anlüingen des verulauenden lianals ber, welche die IInut aufureiben, mul dies wird noch mehr markirt durch die inmern, die Grenzen der Segmente einschnürenden Dissepimente, und durch 
ciue eigenthümliche Vorrichtung, wornach in der zweiten allgemeinen (Faser-) Menbran gremule diese Girenzfurelien consistenter werden. Jedesmal nümlich erseheint hier ein horniges Schildchen, welehes als eine durchlïeherte Platte, wite rin sieh, nach innen rorragt gegen die Mnsketsehicht, und natirlich durch seine Festigkeit die Wirkung der. Dissepimente und Querstrïnge erhöhen muss, denn durch die Lü̈cherchen treten Muskelfasern.

\section{F}

Der verdauende Kanal der Aphrodite zojehne: sich eben so sehr dureh seine Beselablenteit ror dew andere Inncliden ans als vieles von dera hisher heschriebenen. Er

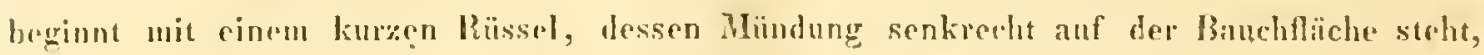
und an den aus dem bezirk des Nerremringes ein pane Muskelbündel treten, er erweitert sich diun etwis, und wird hier abermals und zwall von vier starken Huskeln umfinszt, deren zwei ron der Rüblen- und zwei von der bahelwand Jes Leibes mul zwar aus den lä̈ngsunskeln entstehen. Jenn sowohl die oheren (mittleren) als die unteren Läng:smuskeln spation sich ungefülir im bten Segment in 2 Strïnge, einem innern und einen iussern, die letzteren bilden die ehenhesclurebenen Dilatatoren und zugleich Betractoren. Dilhinter liegt win kurzer Vormagen, der Gestalt nach ïusserlich kium zu unterscheiden, und sodtun folgt ein Mochnitt des verdauenden šanals, den man füglich mit dem Magen vieler Insecten vergleichen kann, jellesfalls aber als den eigentlichen Magen bejraclaten muss. Eo hat die form eines seitlich sehr stark zusammengodrücken, rom hreiteren und ewwas buckliwhen, Cylinders mit eomvexem lizicken, filhle sich hart und knorplich an, unt zoigt einen seidenamigen Schimuer. Die seitenflïclen sind mit foinen weissen, ron oben nath unten liufenden, etwas gekrümuten, mil der convexen Scite gegen binander gekehrten Linien gestreift, nur die niuleren derselben erscheinen gerade. - Iber Magen setzt sied in den zweimal so langen, gerade zom Ifter rerdanfenden, varn etwits zipfelig erweiterten Iarm fort, in don hekinntlich aine doppelte liephe sehr ansehnlieher hinder Siicke mïndet. In zïhlte jhrer 21 bis 22 , und mit Iusnahme der vordersten . Ihschnitte, welehe den sidhlund und Anfing des Magens ungeben, und der hintersten, in denen sich der Darm schon bedruteml rerengt hat, gehört jedem scerment cin laak an.

Fis sind weite riellipplige und luchige Beuel. welche durch einen engen Hids

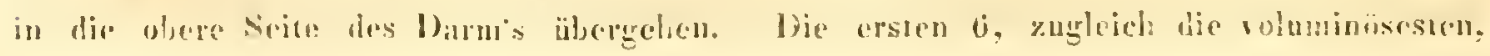


liegen zu beiden Seiten fast des ganzen Magens, sind am meisten getheilt, und laben wegen der bedentenden Länge desselben (e. 2 Centm. in cinem Exemplar), auch viel ansehnlichere Hälse als die übrigen, die in denselben Segmenten in den Darm münden, in welchen sie selber sich befinden. Die Hälse der beiden rordersten liegen so nahe zusammen, dass man sie leicht für einen nimmt.

Uchrigens scheint es, dass nicht die Grösse allein, sondern auch die Lappentheilung der Beutel mit deu Alter zunimmt, denn bei jungen Exrmplaren wird es leichter sie aus ihrem Versteck hervorzuziehen als bei alten, wo die rersehiedenen Zipfel sich dermaissen zwischen die cinzelnen Muskelbündel der seitlichen- und Dissepiment-Yagen geschoben haben; dass die Köpfe derselhen ansser der Bauchlöhle zu liegen scheinen, und sich wie Riegel ror die winzigen Oeffinungen schieben, durch welche ihr schmaler linls mit dem grossen Bentel communicirt.

Dass sie aber ähnlich den äussern Kiemen der Amphinomen gehaut seien, wie Treviranus anführt, lann ich nicht finden, und dass anf diesen Theilen sich zahhreiche frine Gefïssnetze finden, (solle auch wirklich auf irgend einem Wegre frisches Sicevasser in die Bauchhöhle dringen), ist, glaube ich, noch kein hinreichender Grand für die Annahme, in der Wandung jener Blindsïcke werde die sonst gewöhnliche Respiration d. h. die Wasserathmung hewerksteligt; die Adernetze könnten ja bloss zur Ernährung dieser Organe und zur Blublereitung und Ahsonderungen dienen, wie in andern mit liemen rerschenen Anneliden. -

Oefinet man den verdauenden Kanal und untersuclit dessen einzelne thibilnngen nïlier, so bemerkt man zwischen dem Rïsselschlunde und dem grossen Magen eimen Weinen ovalen Mbschnit, auf dessen Boden sich cine Menge dünner, zienlich hoher, paralleler Bläter crheht, weshalb ich ihn oben mit dem Namen Vormagen hezcichnet habe. In der Schlundwandung sind Ringfasern rorherrschend, der lingang zu diesem Theil, welcher durch zwei seitliche Wülste verengt ist, zeigt mehr Lö̈gsfasern, und jene Bläter sind wahrscheinlich blosse Falten der Schicimhaut. Treviranus fand hei Aphrodite aculeata, , liurze dreiscitige Anhänge, die vicllcicht Rudimente von Zähnen sind." - Die Innenfäche des Koorpelmagens erscheint dicht quergestreift; sowoh! an der rechten als linken Hälfte desseblen werden die Querstreifen von zwei, gegen die Magenniindungen sich gabelig spaltenden Liingsstreifen durchsetzt, so dass man jederseits drei Himptroihen von Querstreifen wahrnimst. Versucht man die Srhlcimbaut des Magens abzuzielıen, so fundet man an diesen Läingsstreifen, weil hier dieselhe fester dej* knorpelharten Muskelschicht anhaftet, cinen Widerstand, und jch entdeckte, dass jene 
Langsfasern Furchen seien, in denen ziemlich statie, rorn und himen sieh gabelig theilende läden verdiefen. Lnter dem Mikroskop erkimule ich sogar, wie diese Fäden eine Reihe Fiweiterungen ouler Anschwellungen bildeten, ans welchen Querisichen hervortraten, jenen Quesstreitron entsprechend. Dem Anselıen mach nürrie ich die Füden fiur Serven halten, von frimen Cieliissen hegleitet, inindestens gewalurte ich auf der der Inskelwand zugekelurten seite der Schleimhaut ein . Yet\% ron schunal vierseitigen rechtwinkligen Maschen. - Von Zühnen am Sehlunde oder vor dem lingang zum Magen hahe irh nirgends eine Spur entieclit, den Pylurns aber markiren knorpliche Längsrippen, und rine Duplicatur der Schleimhant.

Gehen wir nun zun eigentlichen Durm über, aus dean man grossentheils dio Schlciunhau leicht ausschiilen kann, so fragt sich roszüglich welehe Bedeutung jene in ihn mündende Bentel hahen, ob sie, da bisher leeine den Zugang zu ihnen aus derm

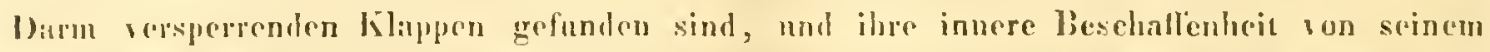

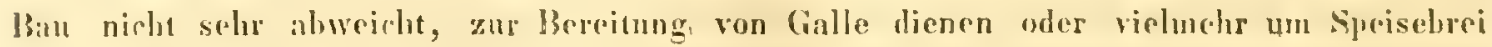
atrounelumen, und aus ihm Blut za bereiten. Der hitterliche Geschmack ihres Contentums Wiitre kein Beweis fïr jene Mrinung, weil, wie billas schon hrmerke, derselbe von den

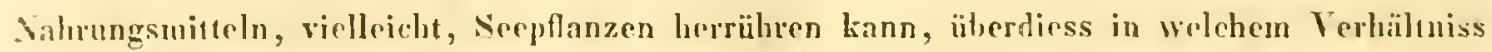
stiinde die Menge der fist bis zun After einfliessenden Galle zu dem Volumen des

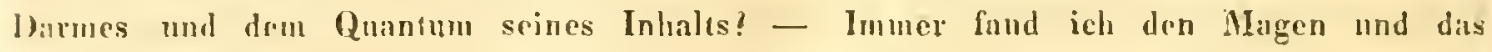
Darurohr leer, während die Anluänge gefült waren.

Nur eine Analogie spriache für die erste Ansicht: Rathke hat nämlicl am Bopỵrus eine Reihe ähnlicher enghalsiger Beutel des Darmkanals heschriehen, welehe er fïr Nereretionsorgane, und da bri jenem Thier die . Mlummgsorgane eben so wenig als hiee ankgeblildet sind, für ein Arquivalent derselhen hält. Alsein einestheils ist überlaupt hei den Crustiteen die Laber viel deulieher auxgepritigt als bei den Anneliten, wo man kaum arste Anfünge derselben entdeckt, und anderntheils ist das Contentum jener Brutel rine feltwachsartige Masse, hei der Aphrodite hingegen sieht der Inhalt derselben $\mathbf{w}$ ie Jarm-

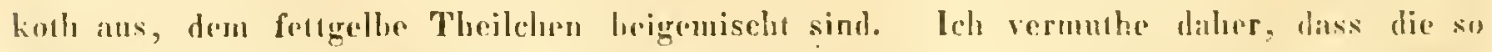
grefïssreiche Windung der Anhïnge diesen stost secernirt, in die llibhlung scibst aber der spreisedrei hineintritl.

lans gerade Darmohr unterseheidet sich in so fern von andern Anneliden, als in

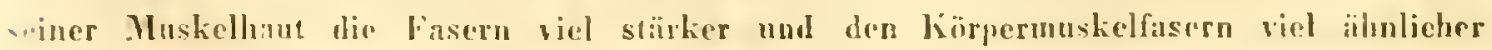
: ind als sonst, sir zeigren sogar rinen Sihimener. Sunst linden wir den barmkanal

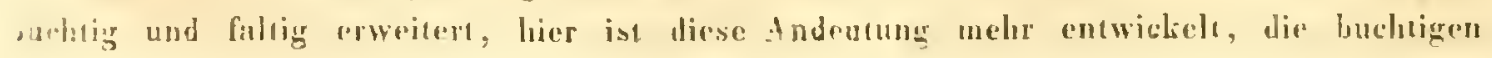


Limpiterungen sind gesonderte Blindsäcke geworden, und das Darmmo füht ilunen nü dron Stoff zur Verdaung zu, und den Unrath ab. Ganz anders redhich es sich, wie wir oben gesehen, mit den in den rerdauenden Kanal der Arenicoba mündenten Blasen, deren Inhalt ron dem des Darmes wesentlich rerschieden war.

Gehalten wird der Speisekanal theils an seinen seitlichen Erweiterungen durch die die Banchlöhle durchkeuzenden und bedeckenden Muskeln, theils durch besondere Dissepimente, welche, wie es scheint, zu einer eigenen Membran an ihren Basen verflessen, mintestens ist der Magen bestimmt ron einer besonderen dünnen IIant fest ïberzogen, und an der Banchflitche nimmt man über dem Nervenstrang eben so gut eine auskeidende IIaut wah als an der innern Rückenfläche, wo sie in der Mittellinie mit der zw eiten Körperlüille zusaụnaenstïsst.

\section{G $c$ i $s \&$ c.}

Wenn ïber die Respiration und ihre Organe bei diesem Thier ein Dunkel herrscht, so verhreitet es sich aurh ülıer einen grossen Tlıeil des Gefïsssystems, wovon der Grund in der ungewöhntich ludlen, blass gelblivbrothen Fathe des Blutes liegt. Aus der Vergleiehung meiner Beobachtungen in Ceste mit den . Hhandlungen iiber Aphrobte aeuleata von Pallas und Treviranus ergieht sich, diss meine Resultate mit den ilurigen übereinstimmen. Mitten auf den Daru zwischen ren Lrsprüngen seinel Inhänge verläuft ein sehr feiner Gefässstamm, dessen Blut kaum schwach chamois grofälbt ist, und einige Zeit nach dem Tole moch melor ausbleicht: er sendet in jedes Negment ein Paar langer Zweige, welche sich auf den Anhïngen und an den seiten des lïrpers vertheilen, und setzt sich üher den Magen fort, doch konnte ich ilun hier nur an dem linken Rande verfolgen und zwar bis жиг vordersten Spitze, wo er ein wenig gekräuselt ersehien, und sieh vermuthlich zum Cervenring hinabhengt. Die zu den vordersten Anhängen gehörigen Neste traten da aus ilum hervor, wo jene selhst in den Darm mïnden, und nicht in gleichmissigen, den Negmenten entsprechendrn, Interwallen. - Unter dem verilamenden Kanal sehe ich eincen drm obern ähnlichen, leirhter erkennbaren, stärkeren, ebenso sich verüstelnden Längsslamn, der jedoch, wenn mieh nicht etwas anders getüuscht hat, vor dem Schlunde grobelig gespalten ist. In dem Weingeistexemplar, an welehem ich diese Bemerkung machte, waren beirle ficlïsse zwar sehr galt aber doch ziemlich fest, farblos, enthiclten 1:ur noch eine wässerige lilüsigkeit, in der wenige liügelehen umbersehwammen, etwa 
so wie in den Polischen Blasen an den Sipunkeln, und latten eben darmu nichts von der Briehigheit anderer Annelidengefïsse. Jass der Nerrenstrang seine hrsombern Adern hesize, ist nicht zu bezweifeln, einmal, weil ich mich sehr wohl erinnere, dieselben an einel Aplorodice aculeata, und zuar viel dunkler gefärbt, geselen zu hahen, und dann, Wril ballas anführ, dass Redi den Jerrenstrang wegen seiner rothen Fürhung für rinen fiefüsssiumu gebalien.

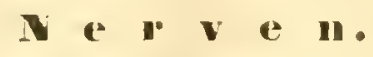

Wie der Nerrenstrang gelegen sei, haben wir selon when berïhrt, namlich in eine

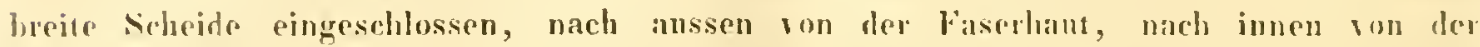
Membran der Bamchöhhle, und anflallend, ist, dass die Läingsumskelschichten, wohlse sonst unmitellate an ihm liegen, sieh hier soweit davon entformon, dass man noch dem

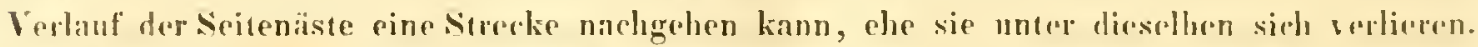
Hr hestoht wie gewähnlich aus zwei Strängen, dir von Neurilem mugehen sind, und zu lang groggenen Anscluwellungen sirh in den einzeluen Segmenten wrodicken, je drei l'ais

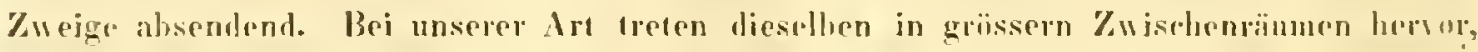

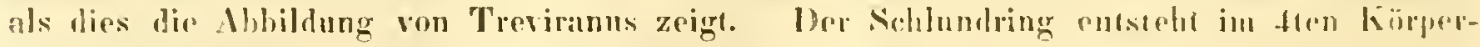

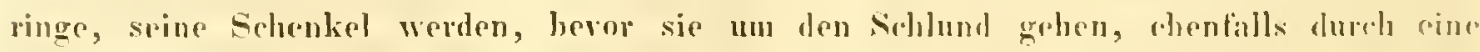

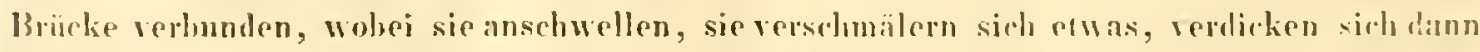

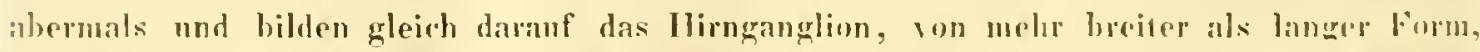

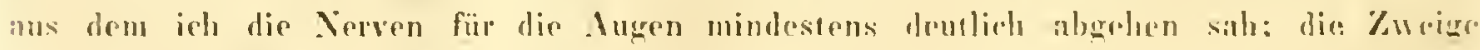
aber für die vorderen Segmone nnd für die Antennen balie ich noch nicht heranspripativen kïnmen.

Wenn Cuvies mil srinem Filet recurent denjunigen Stroifun bezeishnet bat, den

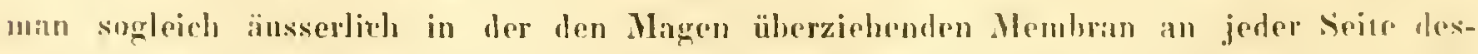

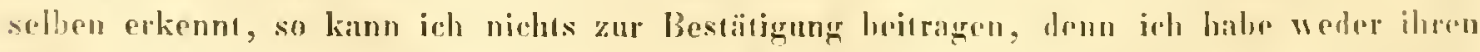
Lrsprung aus dem Schlundring gefunden, noch eine dehnlichkeit nuit gewöhnlichen Vor-

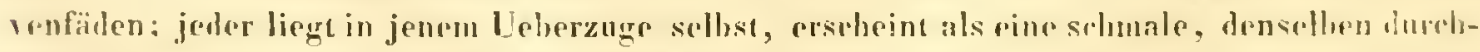

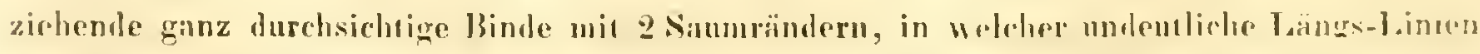

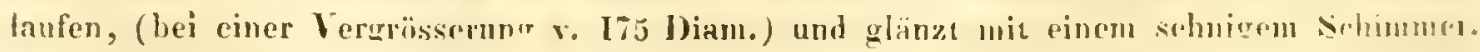




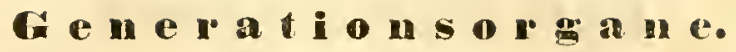

Ob Treviranus die Ovarien richtig beschreiht, möchte ich bezweifeln, an wohlerhaltenen Exemplaren habe ich sie anders gefunden. Die in ihnen enthaltenen Eierchen lildeten hiel zahlreiche von ciner dünnen, leicht zerreissharen, Haut ungebene Gruppen von traubiger Gestalt und einem fast noch grössern Volmmen als die so ansehnlichen Darmanhänge. Sie funden sich zu beiden Seiten des Dames, der so von ihnen umgehen ward, erstreckten sich his tief in die Borstenhïgel der obern und untern Reihe hinein, su dass die Borsten und ihre Muskeln rerdeckt wroden, und sendeten ehen so wie die Jamanhänge einzelne Klümpchen zwischen die cinander kreuzenden Muskelstränge del Seiten. Nach Treviranus Angabe sollen sich an den abwechselnden Borstenliigeln Oefinungen befinden, durch welche die Eier ausgeleert werden, leider habe ich selher sie nicht gesehen, gewiss aber sind sie sehr eng, weil sonst die in die Leiheshöhle gehlasene Loft durch sie entwichen wïre. Häufig fand ich Individuen, in welchen die Eier schon frei in den limmmern des Leihes lagen.

Bei allen mit deutlichen Eiersticken versehenen Individuen meiner Sammlung suchte ich rergeblich nach befruchtenden Organen, das letzte Exemplar aher, welches ich iffnete, enthielt zu meiner grossen Ueherraschung wedor lose noch in Orarien eingeschlossene Lier, und hier entdeckte ich zu beiden Seiten der Löngsmuskeln des Bauches und grossentheils ron den innersten Querunuskeln der segmente rerdeckt, schlauchartige, fast wie Hufeisen gekrümnte Organe, welche mit einer dickliclen weissen Flüssigkeit angefüllt schienen, und an die ron Treviranus heschriebenen erinnerten. In ilmen vernuthe ich die befruchtenden Orgáne, wenigstens deutet ihr Inhalt und ihr von mutleerten Ovarien ganz verschiedenes Ausselsen darauf hin; denıach wären also die Aphroditen getrenntes Geschlechtes, eine Behauptung die schon ror langer Zeit Pallas*) aufgestellt hat, und welche an den mancherlei wesentlichen Unterschieden dieser Thiere ron den übrigen Anneliden eine Stïtze findet.

\section{P $\quad \begin{array}{lllll} & \mathbf{y} & \mathbf{0} & \mathbf{e} & \end{array}$}

Da die lolynoen äusserlich schon so nahe den Aphroditen rerwandt sind, war ich un so begieriger zu erfahren, wie weit diese Aehnlichkeit in ihrer innern Organisation ginge. Ich stellte meine Untersuchung an Polynoe syuarnata an.

*) Pall. Miscell. Zool. pag. 20. 


\section{Polyuoc squanata.}

Pallas. Miscellanıa zoologica pag. 92. tab. VII.

Antales des sciences naturelles. Tome 27.

Beim blossen Ansehen ist auffallend, dass sich in unsrer lolynoe wiederum der eigenthïmliche Schimmer der Epidermis zeigt, den wir in den Vereiden, und st:̈rker in den buniceren und Amphinomeen finden. Auch nimnt hereits die betrichuliche Breite des Kürpers ab, unt stall eines Ovals tritt die freilich noch etwas verkürzte 1 urmgestalt atuf; zwar bleiben die Schupen immer noch selar anselonlich, aber die bei den Aphroditen so langen Stacheln der Schuppensegmente verschwinden hier ebenso wie die Piacher ron gekrüumuten Borsten, an der Basis der Schuppen.

Aurlonin und Edwards geben als Character ilurer Polynoe squanata an, dass die Schuppen vollständig die Räekenfläche bedecken, rechnen alser mit zu dieser Lit die Aphrodite punetala Müllers, bej weleher sich dieselben nicht in der Mlithellinie krenzen. Dir ron mir beschriebenen, in Italien gesammelten, Exemplare wïrlen silumblich zu 1 phrodite punetata gehören; in übrigen stimmen beide Species vollkonmen mil einander iiberein, nur dass das in den Annales des sciences naturelles abgelvildete Exemplar um ein Stiick breiter ist; eine billerenz, die, wie wir oben gesehen haben, bei I. hystrix anch rorkommut.

Der deulich alogesetzie Kopf trägt 5 Intennen und 4 aufsizzende schwatre lugen, van denen, weil der liope in das nïchst folgende Segment zum Theil hineingrougen werden kann, die hintern bisweilen unsichtbar werden. Die mpare Intenue und die zwei mittleren hilhen die Gestalt der ïhrigen Rürkencirren, sie sind diunn, an der Suluze knospenfärmig rerdickt, und die Verdielkung läuft in einen feinen Faden alus. Die ïussern, wothe irh aber linger als die unpatire linde - Elwalds gielst das Gegentheil an - sind starke, gegen das Eude weniger anschwellende, ganz mit frinen Spitzchen hesetzte liölen (Die Spitzehen scheinen nicht IIalare sondern Hautverlingerungen zu sein).

biejenigen Segmente, auf welchen Rückeneiren sokmmmen, wecliseln mit den

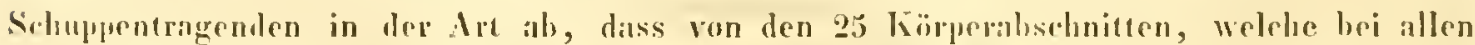
Individuen grzilhlt werden, der 1ste, 3te, 4te, 6te, Ste, It. s. w. 1Ste, 20ste, 22oste mit selhupen rersellen sind. -

Die bei Iphrodite so deulich doppehen Borstenhiigel sind hier anf ainen, kanm

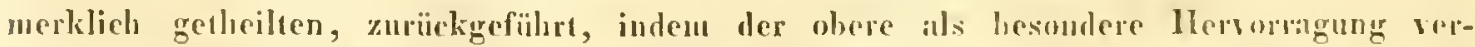
schwindet, und das ihun zugehörige Bïndel ans der Rü̈cksnfliche des allein ausgehildeten unteren heromspriesst. Uebrigens findet keine Verscliedenheil der Borsten narla den

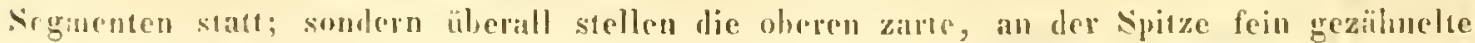


Ilare vor, die untern aher, welehe in flachgedrückien Biiseheln stehen, starke, rylindrische gegen das freie Ende in. eine Art Hohlkelule oder linne auslaufende Borsten. Die Ränder der Hohlkehle sind mit scharfen Zälınen bewaffnet. - Jedes Büschel gruppirt sich um einen Stiel oder Nadel (acioule), an den sich die bewegenden Muskeln setzen, und der auch ein parar Spitzen an den Seiten zeigt.

An allen Segmenten erscheinen kleine untere Cirren, der längste daron am ersten Segment, welches wiederum unmittelbar nelen dem liopf liegt und gar keine Borsten enthiilt. Am After stehen gabelig zwei Cirren, wie in Eunice.

In der etwas schillernden, glänzenden Oberhaut erkennt man rom Umfang jedes segments gegen dessen Mitte zusammenlaufende Furchen auf der Riickenfläche. Die sichuppen bilden weniger ein festes Continum mit den Häuten, weil sie an ihrer Basis schärfer algegrenzt sind, und leicht alofallen. Thre Farbe ist grau, sowohl anf der Oherals Unterflärhe mit haunen Punkten hesetzt, die Anheftungsstelle bleilht ungefïrbt und durchscheinend: dass jedoch ihr Rand gefranzt sei, was Edwards angieht, kann ich nicht finden. Bei grnauerer Betrachtung wird man hemerken, dass die Punkte stumpfe Wïrzchen sind, wetche rielleicht jenen Nehenschuppen unserer Iphrodite entsprechen, und dass die Färhung ron dem Piguent auf dem zweiten innern das Carum der Schuppe zunäehst unschliessenden Blatt herrührt, (die Schuppen der Aphrodite hystrix erschienen Indurch bräunlich und riolett). - Uehrigens sind die Wärzehen der Oherseite viel zahlreicher als die unteren.

Im wesentliehen stimmen die Muskellagen mit denen der Aphroditen iiherein, sind aber doch in einigen Stücken modifieirt: so schimmert z. B. der Darmkanal nicht in einer munnterhrochenen Mittellinie durch den Rïcken durch, weil an den Grenzen der Abschnitte deutliche starke Querfusern querïherlinufen, und die Breite der Scheide, in weleher der Nerrenstrang liegt d. h. die Futernung zwischen den Längsmuskeln der Bauchfläche, ist minder bedemend.

Die Anschwellungen des Nerrenstranges gleichen den an Aphrodite beschriebenen; jedes Segment emprängt wie dort 3 l'aar Fäden, von denen der mittelśse entschieden der stärkste ist, am Sochlundring existirt eine Brïcke, das Hirnganglion sah zweilaplug aus, und sande die Augenueren ab.

Am rerdauenden Kanal hemerk man eine starke Enurickelung der Muskeln, weldie theils z.n seiner befestignng an die Wandung des Kirppers, theils zur Verkürzung seiner Länge dienen. Jene hilden in jedem Segment xienlich hreite, senkrecht stehende Binden,

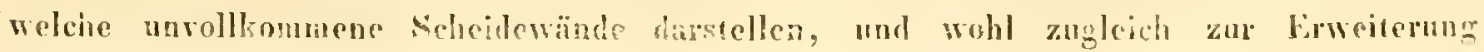


Hes Darmes dureh ihe (untration beikagen. - Der Lebergang rom Magen zum Darm wird äusserlich durch einen liürtol ron zwïlf ansehnlichon, ron dou einen zum andern grhenden, Muskelbïndeln markim, - rino Jusordungr, welcher hei A. hystrix nichts ähnliches entspricht. Ausserdem erkenut man an den seiten desselben jenen membranösen hier aber stälieren Streifen, Welcher von vordern Ende des Magens sich zum hintern crstreckt. - Zwar besitzt dieser 'Theil des Verdaungskanales nicht die antlillende Ilärte, wir dort, ist aber dafür an der Cardia mit zwei l'aar Kiefern lewafthet. Jeder derselhen bresclut ans einer hornigen, durch einen seitlichen Fortsatz mit der benachbarten articulirenden Plate, aus der ein gekrimmted Zahn hervortritt. Vor den Kiefern rrseheint vin Kranz kumel, platt gedrückt dreieckiger Köpperchen, welche beim Hervorstülpen dos Rïssels dessen Spitze einnehmen, - ich riblle ungefïhr 16. - An dem l'ylurus wird son der Sshleimbaut eine Duplicatur gebildet. - Jie Darmanhänge verzweigen sich wrniger und treten als einfache, in ein paar, (mischen den Muskeln sich verkriechende) siarkchen auslaufende, Schlïuche auf; deren Anzahl auch nur li beträgt. - Vom Gefasssystem habe ich nichts weiter hinzuzusetzen, als dass das Blut auch ganz hell gefärlı ist, und alles übrige daran dem der Aplıroditrn ghleich kummut.

Die wielstige und auch wegen der Aphroditen sehr interessante Frage, oh die PoIynen gretrenntes Geschlechtes seien oder Zwitter, hin ich für jetzt nicht in Stande z.u lïsen: die wenigen Fxemplare welchẻ mir zu Gebote waren, enthielten sümntlich Eicrchen, und atsser ihnen nichts jenen lefruclitenden Organen ähnliches. 


\section{der beschriebenen Genera nach ihrer Organisation.}

Dassen wir von den hisher beschriebenen Annulaten das Characteristische kurz zusammen, so wird es nicht genügen, sie, wie hisher geschehen, unter zwei Ordnungen zu bringen, mag man dieselben mun als Dorsibranehes und Tuhionles mil Cuvier, oder als Nereidene und serpuleae mit Savigny anmehmen. Ich werde die rewandien Gavmngen zusammenstellen, ihren liau mit wenigen Worten angeben, und so hieraus eine andere Ginlleilnng dieser Thiere ahleiten.

$$
\text { Arenicola. - Terebella. }
$$

Olune liopf, Augen und Antennen; (bei Terehella cine Menge contractiler Fühler am Vorderende des körpers). Der Körper in ungleiche Ringel zerfallend, sein vorderer Theil dieker als der hintere.

Ilaut, grlanzlos, olne schillerndes Farbenspiel.

Bewegungswerkzenge: jederseits zwei lieilien bililend, die Borsien der oberen rns den unseren schon anf dell ersien Inblick sehr verschieden, jene einfach hartörmig, in Birscheln, diese hakenfïrmig, ginz klein, in Kanmreihen auf der Banchseite stehend. - Beide kommen nur in einer Strecke des k̈̈rpers zusammen vor, weiterhin fehlen beide (Arenirola), bider es geht mur eine Reihe fort (Terebella). Keine Spur von Cirren an den Bewegungsurgantu.

Muskeln. Die Längsmuskeln sind mehr als in andern Anneliden zu neben einander liegenden Hauptlündeln gesammelt. Wenige Dissepimente, und diese nur in rovlern und hintern Körpertheil.

Verdaungsurgane: sehr cinfach, den Anfang des verdauenden Kanals bilder leci Arenicola noch ein weit vorstïlpbarer, mit Papillen besetzter, Rüssel (älınlich dem Sipunkel): Damnkanal änssersi dünnwandig, mit einer Anlage zur Windung, ein Magen kaum zu unterscheiden. Hïlsorgane nur hei lrenicola vorhanden.

It hmungsorgane: Cuntratile Kiemen, die sich nur über einen Theil des Kingpers erstrecken.

Gofässsystem. Selir zusammengesetzt, aher e in Ilauptrüclien - und ein Ilauphbauchgefïss; ein Theil des Darmblutes fliesst in rigene sich contrahirende Behälter, und sun da zu den Kiemen. - Blur: dunkelroth.

Nerrensystem. Der Verrenstring rus zwei ęng rerbundenen Strängen bestehend: statl eines grossen Gehirnganglions ein doppelter Knoten. Der Schluntring ohne Brülie.

Generationsurgane. Diese Thiere sind Zwitrer; die Lier fallen, nachdem die Orarien zerrissen, in die Bauchhöhle: die hefruchtenrlen Organe liegen paarweise an der Baucliseile, aher nur iun merien Theile des lacilus. 
Salrung und lachensint. Sie bauen sich läbren in den Sand (Arenieola) oder

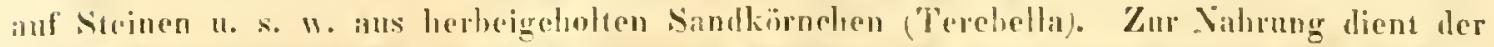
dem Mrersande locigemischle: thierische Sehlrom.

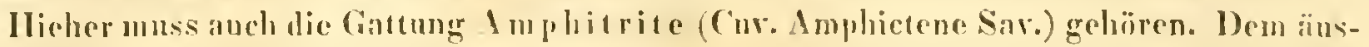
sern l3au nach stelit sie neben Terelella, ler innere alber, soviel ich aus den Cirundzïgen ersehe, dic l'allas*) ron ibrer Anatomie grgehen, hat überdies einiges mit Arenicola gemein. Am meisten fällt die Abwriclung anf, dass der Magen deutlich algegrenzt, und der l)arm, durrly (نine doppelte krïmung Jeeimal nehen einander gelegt ist, auch soll die Maut schön irisiren. $S a b e l l a$, Serpula.

Olıne gesomlerten liopf und Augen. Körper fester, gedrungener, gleielmäissiger gebaut, der vordere Theil mit einem fleischigen Ilalskiagen versehen.

I aut ohne glänzendes Farhenspiel, aher doch, zumal im vordern Theil, selän gefärlut.

Bewegungswerkzenge ählioh der vorigen lbheilung, aher beide hrihron kunmen in der granzen Länge des Kärpers rom und mit dem allinllenden Lmstandre, dass sie

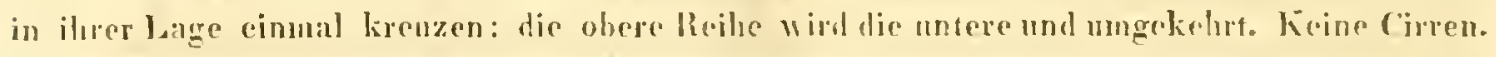

Muskela in dickeren Tagen, oler ganze Kï̈rwe durh Dixsepimente in lianmere

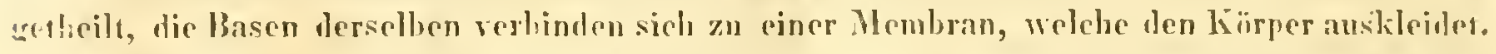

Verdaumgsolgane. Wer Jorukanal ist mit dusnahme soines geraden Anfangs in diner engen Spirale gewunden, und nicht sehr dickwandig. Mundiaflinung unhewallinef: llialfsorgane follen.

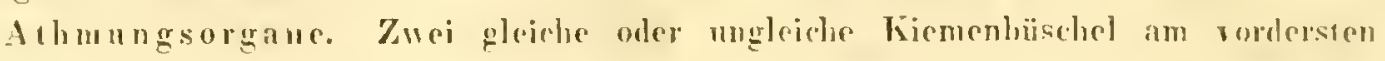

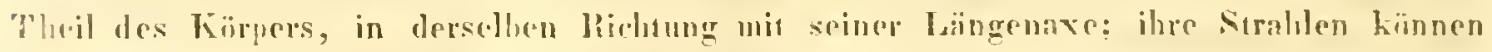
zuar nicht contrahit, aber wie die basis, and der sie stehen, zusammengerullt werlen: zu jodem gehoin ein Cirrns; zwivelen den Kiemen ist die Mundiitlnung.

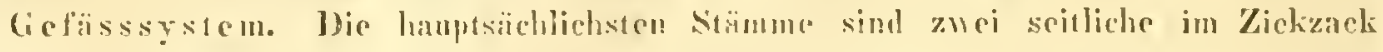

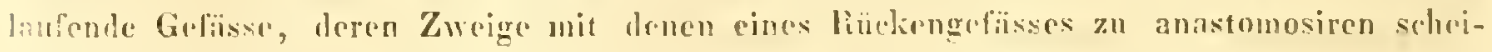

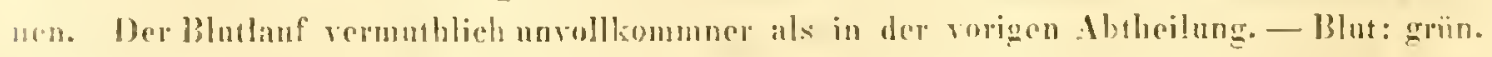

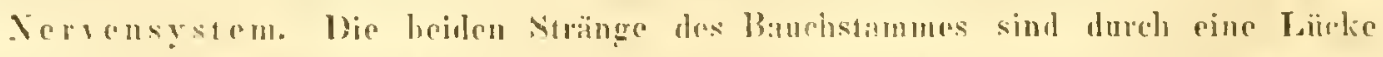

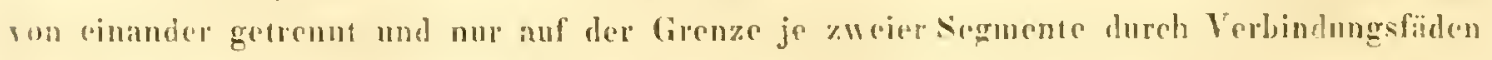

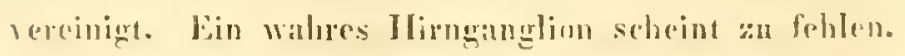

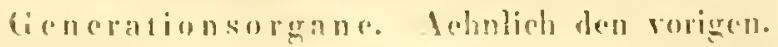

Labensweise. Sie bauen sich freistehende. lederartige (Nabella) oder balkige Ribluren (Siprinla).

$$
\text { Cir r l } u l u s .
$$

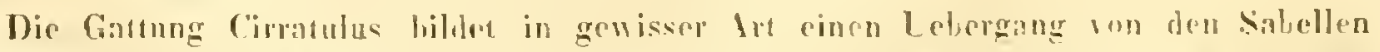

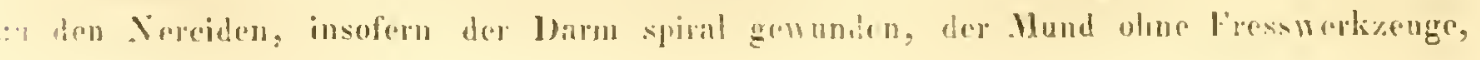

") H'all. Miscell. Zool. p. 128. 


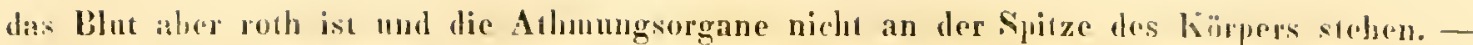
Dit Geschlochusorgane bedïrfen noch einer genaueren I utersuchung ian friscluen Zustande.

$$
\text { E. un ice, Onuphis. }
$$

Deutlich abgegrenzter liopf mit Augen und Autennen; der Kïrper gleichmïssigr gebaut. llaut stots perlmuterglïnzend oder opalisirend, oft überdies schiin gefïrbt.

Bewegungsorgane nicht in zwei, durch einenZwischenraum getrennten, Reilsen, sondern nur in einer Reihe, deren Borstenbüschel aber in eine obere und untere Iälfte zerfallen. - Die untern Borsten sind mit bewafineten Spitzen versehen. An lieiden komuen Cirren vor. Muskeln in staken Iagen, aluer die Dissepimente selıwicher als bei den Sabellen.

Verdaum gsorgane: Jharyus etwas vorstïlplar, mit zahlocichen kiefern bewaffnct, der Magen rom Jaru unterschieden: Darm dickwandig, gerade verlaufend aber mit luchtigen lirweiterungen; ohne llïlisorgane.

Atlumugsorgane: Kiemon, fast in der gauzen länge des Körpers in Gestalt mohr oder mindor ainfacher, nicht contractiler, Biischel.

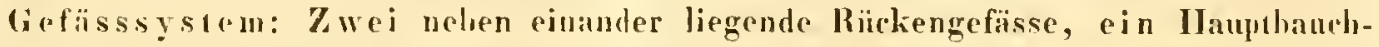
urvöiss, dessen zu den Kicmen gehende Aeste an ihrer Basis eine (pulsirende) Anschwrollung zeigen. - IBhut roth.

Nervensystem. Aus einem ausgebildeten lianganglion entspringen himerwärts Nor-

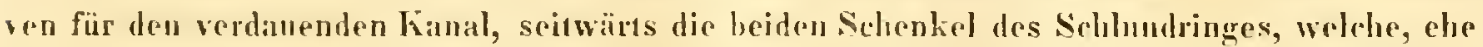
sie sich zun Bauchstrang vereinen, durch ein patar Fäden - Brieke - verlunden werden.

Generationsorgane. Sie sind Zwitter: mit Ausnalume der iordersten librerringe hat joder scin Ovarium und sein befruchutudes Organ auf heiden Seiten.

Lebonsar1. Nie wohnen in Selwämmen, oder banen sich Rähren atus Sand, oder sugar hornige (yliuder, (Onuplis) und uähren sich rormmblich wan kleinen Seetlicren.

$$
\text { L. I c o r } \quad i \text { s. }
$$

Sarlı IJ. Rathkes Untersurlungen schliesst sich Lycopis nalıe an diese (ienera an: wesentliche Verschiedenhejen firdru iu fiefïssysten statt, wo nur e in Räeken- nnd ein Batuch-

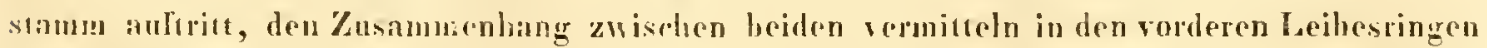

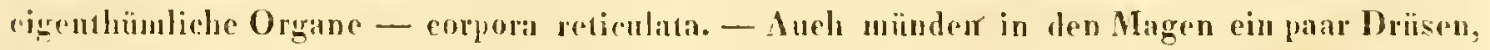
und die Brwrangwwerkzenge - cinfahe Borstenbündel — stehen jederseits in zw ei Reilien.

- Die kicmen sind getbeilte Blärdene -

$$
P l e i 0 n e .
$$

Dillerenxen von Lycoris und Eunice zeigrn sich lesouders im Gebisssystem: nehen

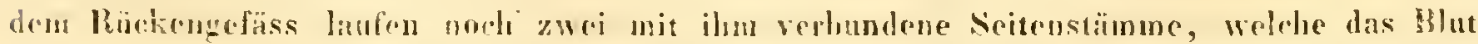

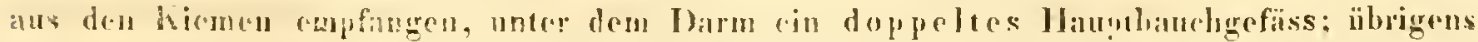

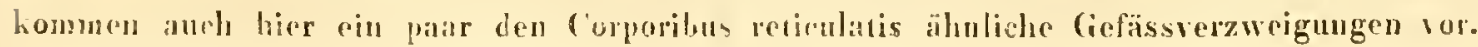


Dem lharyux fehlen die Kiefern, dem Magen die briden Irïsen.

Die liemen sind contuctile Bïschel, und insofern den Arenicolen ibnlich.

Im Jerrensystem sehen wir ausser dem mittleren Batuehstrang noeh zwei seitliche mit ihm dureh Querzweige forthufend zusammenhängende, ausserdem stimmen Schlundring und Gehirn wit den Eunicen ziendich ïberein.

1)ie Bewegungswedkzeuge bestehen jederseits in zwei Reihen von Haarbüscheln.

$$
\text { Aplerodite, Polynoe. }
$$

Dentlich gesonderter Kouf uit Augen und Autennen, brrite Wïrmer, deren Rückonseito mit Sehuppen bedeckt ist.

II ülerdeckt (Iplirodite).

Buwegungswerkzeuge. Zu jezwri Reihen (Aphrodite)oder in ein er, (Polynoe) dann

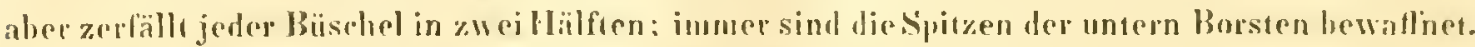

Muskeln. Die Inordutng der Muskeln sohr zusammengesetzt. Das Innere des kïrpers von Dissepimenten dnrehschnitlen.

Verdatungsorgitne. Der lbaryne sustulpbar, öfores mit Kiefern und einem

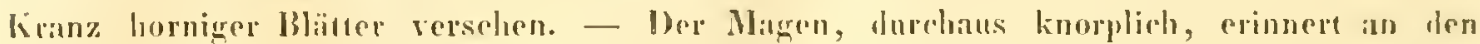
mancher Inseeten, und ist salur ressehieden von dem ïbrigen Theil des Verdaungskanals, in den cine doppelte Reihe viollappiger Blindsä̈lse mündet. Sein Verlanf ist grade.

Ithmungsolgane; wo volbanden, Kiemen, loch scheinen sie ofi zu fehlen.

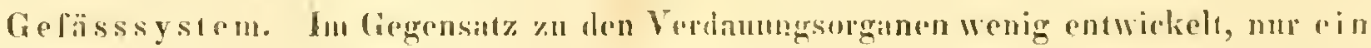

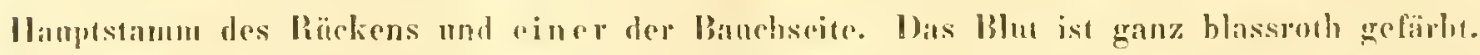

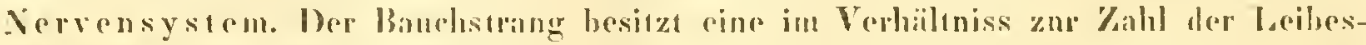
ringe gresse Menge von Inschwellungen, indem anf jeden dersellen drei kommen.

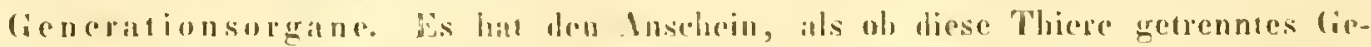
shlechtes wïren.

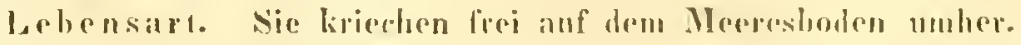

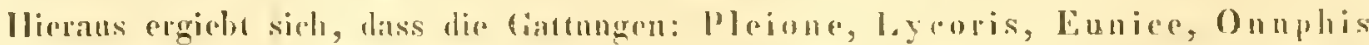

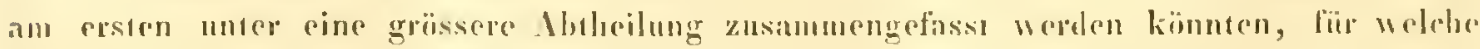

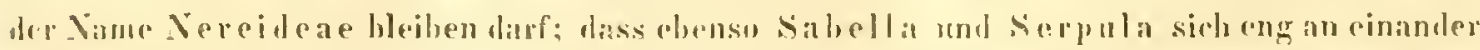

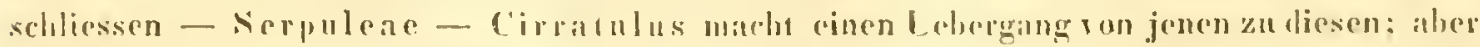

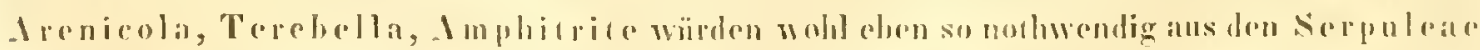

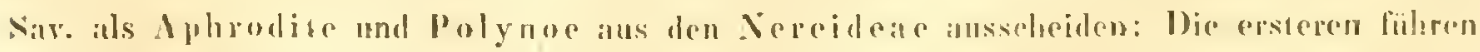

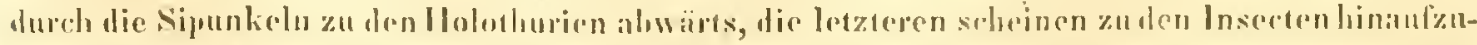

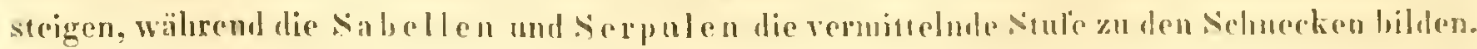




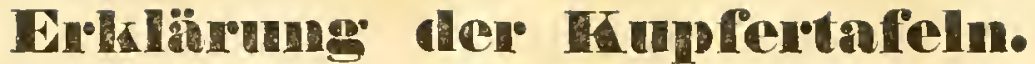

\author{
T a f e 1 I. \\ Arenicola pincatorum.
}

Fig. 1 .

Dis Thier ist ron der Rückenseite anfgeschnitten; mur das hintere Stïck ist unversehrt erelassen, um einige Kiemen und Borstenhïndel und die Papillen des letzten Drittheils (des Schwanzstückes) zı zeigen.

a. Dic Längsmuskelschicht, welehe zunächst die Leiheshöhle anskleidet.

b. Vier seitliche schmale Lärken in ihr, welche den vier Keihen der Bewegungsorgane entsprechen; die untern den Reiben der IIakenborsten, die obern den Reilien der Hiarborsten.

c. Die innern Querunuskeln, durchsichtige breite Binden, welche neben dem Terienstrang entspringen, und sicl an die ohere frenze der obern Lü̈cken (h) inseriren.

d'. Krstes Dissepiment; es hat eine doppelte Wandung, und die beiden Blätter derselben weichen am Schlunde so weit aus einander, dass sie den Ramn eines Doppelkegels einschliessen.

$\mathbf{1}^{2}$. Zueites Dissepiment.

$\mathrm{d}^{3}$. Drittes Dissepiment. Weiterhin hören diese Dissepimente auf, his zun hintersten Drittheil des Thieres.

a. Was linke der beiden Bcutelchen, welche aun hintern Bhatt des ersten Dissepimentes sitzen.

f. Die in die Lacileshöhle hineinagenden Hïlften der Borstenbüschel, welche sämm!lich in den obern Lürken der Lüngsmnskelschicht stehen - sie lilden 19 Paare.

gr. Die nach anssen herworragende Ilälfte des Borstenbündels und dahinter die Kiemenluïschel; letztere fangen an Jten Borstenhündel ( 7 ) an.

h. Die beiden in den verdatuenden Kanal mündenden gelhen Blasen, welche vermuthlich die Stelle der Leber vertreten.

k. í. i. Der rerdanende kanal.

k. Die Mundöffnung an der Spizze des hier eingezogenen Rüssels.

i’. Der weite Theil des speiselianals, weleher mehr nder minder hin und her gewunden ist, hinter der Kinmünd ng der geelben Bhasen beginnt, und viclleicht dem 
Mngen zu vergleichen ist. Dir vor ihu liegende enge, ron den Dissepiunenten unfasste llubeilung entspriolse dann dem Oesoplangus.

i. Irr hintree, wiederum ferengie Theil des Speisekinals, der eigentliehe Darm, urlelier als rin gerades Rohr lis zum Ifter rerläuft.

1. Har inter.

m. Die fo jederseits in den unterr Jü̈cken der Lällgsmuskelschich gelegenen, an der labloswandung befestigten und nach aussen miindenden Blasen oder Babsel, die iele für die leefienchenden Organe halee.

n. Der Xervenstrang, hegleitet von seinen Gefëssen (Vasa nerroso-abdominalia).

Vul Dis auf dem Vordaumgskanal liegende, pulsirende Rürkengefass (Vas dorsale).

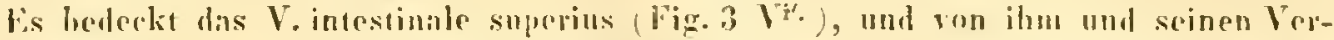
zucigungen geben obere lestr zu deu hintersten b liemen und den ressen 3 Borstenlüindeln.

Die äbrigen Kiemen erhales ihe oberen leste ron den Vasis intestinalibus infe-

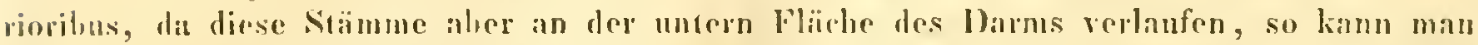
diesellen in dieser ligur nieht selien, sondron mur einen Theil ihrer leste: man erblickt diese, so wie die ron la imuse nelen den Iesten des V. ventr. pre

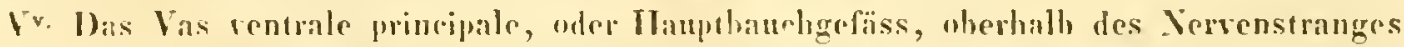
und unterlatb des Verdiusugskanals gelegen. lis sender untere deste zu allen kiemenpataren and Borstenbiindeln und speist amel die Vasa nervoso-abdominalia.

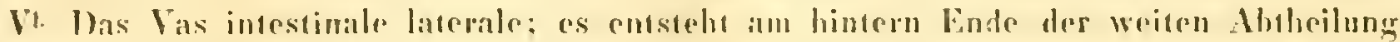

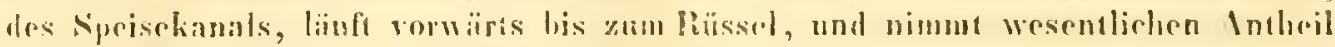

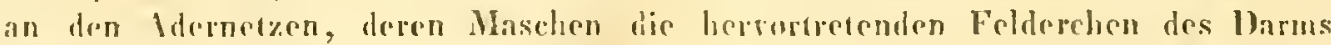
mustrieken.

X. Itie linke der hoviden pulsirenden Inechwellungen des V. infest. lat. - dor

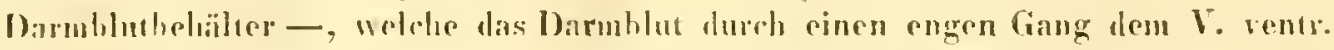

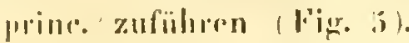

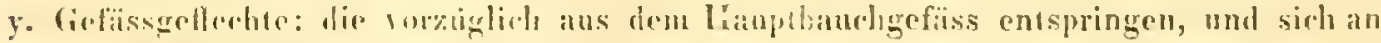
dir Muskelligen wertheiben.

$$
\text { Fig. } 2 .
$$

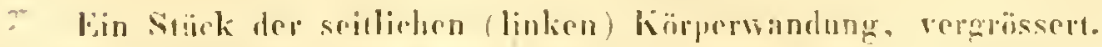

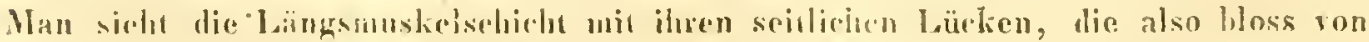
der atussern Ringliasersoliseht bederkt sind.

r. Die durelsichtigen musküben Binden, wie in Wig. I.

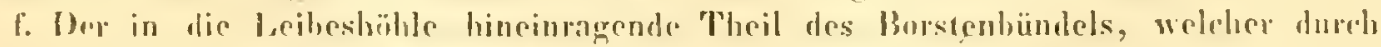

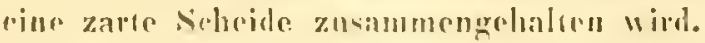

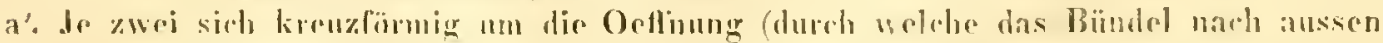

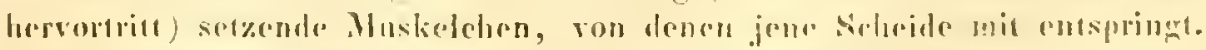

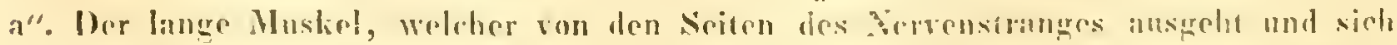

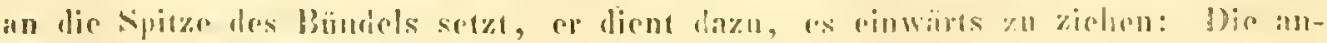

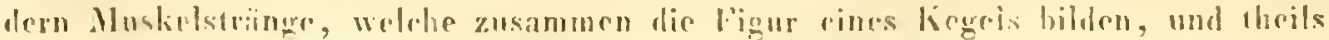


aus der Jängsmuskelschieht, theils aus der äusseru Ringmuskelsehicht entstehen, bewirken sein Hervortreten und die seilliche Bewegung.

n. Eines ron den befruchtenden Organen, und zwar das erste, linke.

v. Der z.n ihm tretende $\Lambda$ st des Vas rentrale principale; lev erste von $\mathbf{v}^{\mathrm{v}}$ ahgehende Gabelaweig hildet mit der Reihe der folgenden das Vas nervoso-abdominale

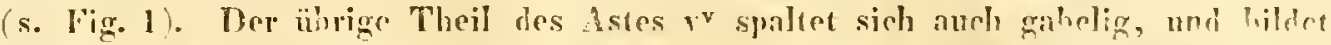
cine eigenthimliche kammatige Verzweigung, theils anf dem befruchensen Organ, theils gegen das rorliegende Borstenbündel hin, wo zu ihm ein oberer fist wn Vas dorsale stösst.

1. Der Ist rom Vas dorsale.

\section{Fig. 3.}

Ein Sitük des Darns, sehr rergrössert, von der Seite gesehen, um dic Vertheilung der Gefïsse zu zeigen.

Vv Das Vas rentrale princ.; es hängt durch feine Zweige mit dem Darm zusammen, und sehiekt das ron den Muskeln und dem Darm crhaltene Blut in die Kieman.

(j. 7. Die sielle der Gen und Ften Kieme, und die zu ihnen tretenden Aeste der beiden respectiven Ilanptstïmme.

Vi. Das linke ron den feiden nahe neben cinander liegenden Vasis intestinalibus inferioribus, welche von den ersten 6 kiemen Blut empfangen.

$\mathrm{Y}^{\prime}$. Das Vas intestinale superius, welches dicht unter den Rückengefïss liegt, und durch feine Zweige mit ilum verbunden ist.

Vd. Das Bückengefïss selhst; zu ihm strömt das Blnt aus den hintersten Kiemen.

Vs. Schräge Verbindungszweige der Stämme $V^{i} V^{i}$, von welchen die den Darun unstrickenden Masclien der Gefässnetze entspringen.

Der im vordern Noschnict des Verdaungskanals vorkommenden Vasa intestinalia lateralia ist bereits hei Fig. I. Erwähnung gethan.

Fig. 4.

Fines ron den erlahenen Felderchen des Darms, wie es unter dem zusammengesedzten Mikroseop erscheint: man sieht daran die Säckehen, welehe in dessen Höhlung hineinragen, und vermuthlicl zum Einsaugen des speisebreies dienen.

\section{Fig. 5.}

Das Srück des verdanenden Kanals, welches in der Region zwischen dem driven und vicren Borstenbünlel liegr, vergrössert.

h. Die in den Speiseksnal mündende gelbe Blase der rechten Seite.

i. Ber Oesophingris.

i'. Der weite Theil des S'peisekanals.

Td Das Rückengefiss, dureh ein Ligament dem Darm rerbunden.

H. Was seitliche Darmgefiiss (wie in l'ig. 1).

Iv. Das Hanphanchgefiiss, dureh ein Ligament an den Darm geheftet.

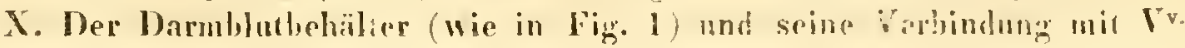


Fig. 6.

1)er vorderste Theil der Arenieola, ion oben geölnel, vergrössert.

b. Die Anfinge der seitlichen vier Lürken.

i. Der Oesophiggus.

d. d'. Die leiden Blätter des ersten Dissepimentes, so geäfnet, dass man in den жwischen ilmen befindlichen Kwischenraum hineinsicht.

c. Die am hintern Blatt hïngenden Beutelehen.

\section{Fig. 7.}

I)r vorlerste Theil der Arenicola, rergrïssert, aber seitlich unten nelen rem Xerrenstrange auligrschnitten.

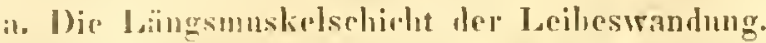

1. Das ersu lBorstenlüinlel, vor ihn ist die Insertionsstelle des ersten Dissepimentes markirt.

n. Der Jersenstrange, mit den ihn legleitemen Vasis nerveso-ahdominalibus.

1). Die briden Schenkel desselhen, die den Sedulundring bildent.

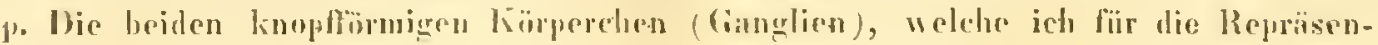
tanten des fichirnganglions laalir.

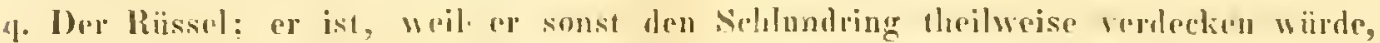
aus seiner natürlichen Lage gelsacht, und nach vorn äbergeschlagen.

\section{Fig. 8.}

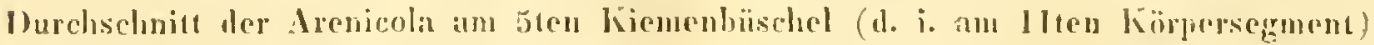

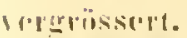

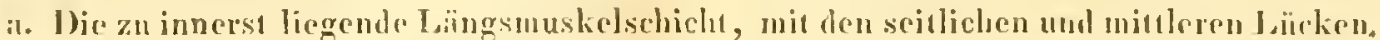

a'. Dit: äussere Hingumskolschicht.

c. Die innern bon dem Nerrenstrang zur whern Grenze der scitlichen obers Lücke gelsenden Querluinden.

f. IVir Borstonhiindel in iluen kegelfümigen Wülsten und die liemenbüsclocl. (I)ie Muskoln der Borstembiundel sind entfernt).

I\%. Dir kammartigg grestellen Jakrmborsten in ilıren hroiten Wülsten,

i. [)er In:m.

n. Der (aus zwei Strïngen bestehende) Nervenstrang.

i. Hic I'igmentage mit den C'orium.

s. Dir Eipidermis.

lid. Vis dursale.

$V^{\prime} i^{\prime}$ Vis intestinale superius.

Vi. Visit intestinalia inferiorat, und ilare kiemenase.

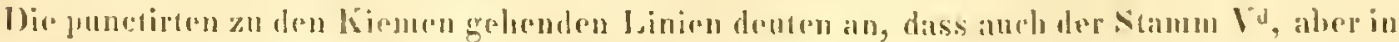

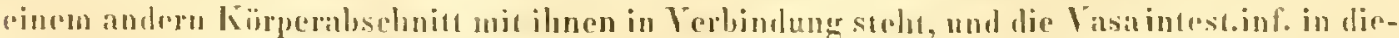

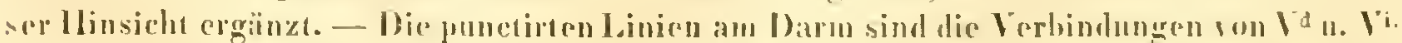

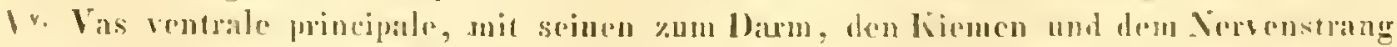

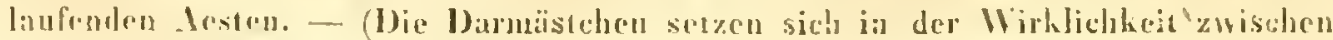
den beillen li an). 
Fïg. 9.

Die kammartige Gefässverzweigung aus Fig. 2, selır stark vergrössert.

Fig. 10.

Die Spitze einer Haarborste stark vergrössert.

Fig. 11.

IIakenborsten, sehr vergrössert.

Fig. 12.

Fin Stïck Epidermis von dem an den Rüssel ansıssenden Theil des Körpers nit den ihu inhaftenden Feldern der Pigmentschicht.

$$
\text { T a f e } 1 \text { lí. }
$$

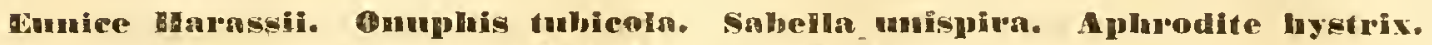
Tolynoe stguananta.

li u n ice II a r a s i i Fig. 1. 2. 3. 4. 6. S. 9.

Fig. 1.

Vorderer Theil des Wumes, ron der Rürkenscite aufgesehnitten.

A. Der liopf mit seinen 5 Antennen, welcher sich theilweise zarückgezogen bat in das erste Segment des Lacibes (1).

1. Das breite ersic Segment.

2. Das жreite mit den beiden ihun angehörigen rirrew.

n. Die Längsmuskelschicht der Rückenfä̈che nach beideu Sciten ats einander greschlagen.

$s^{\prime}$. Die Streifen diman, an welchen sich die Uisscpincnte befestigen.

$\therefore$ Die Quermakleln, die in jedem Segment rom Nervenstrang zu den Seiten des Kïrpers laufen.

p. Dic I'harynsmasse, in welcher dic Kicfern stceken.

n. Muskelbündel, welche die Pharynzmasse nit der Leibeswandung rerhinden.

n’. Muskelhündel die den auf ilı liegenden Oesophagus an sie selbst befestigen.

o. Der Oesoplingus. - Er entsteht roru und ohen aus dem Pharyux, und setze sich in den äusserlich vou Darm nicht eben verschicdenen Magen fort.

भ. Her Magen.

Vd Vd. Das doppelie, auf dem rerdumenden Kinnal liegende Rückengefäss. Beide Siärume sind ron cinander durch das den Darm an dic Pä̈kenflächc befestigende Rückenligiment getrennt. - Jeder ron ilinen gyebt lesie zum Dirm, den Muskeln und Jen Kiemen, vorn aher stossen beide Stämme zusammen zu einem einzigen, der sich nach kurzem Verlanf wieder spaltet.

n. Die zu den Kiemen und Borstenhündeln gehenden Aeste der Rückengefässe.

$$
\text { Fig. } 2 .
$$

Der ganze rerdauende Kanal ist abgelöst, und vorn übergeschlagen, so dass mat den soust ron ihm bedeckten Nerrenstrang und dic Innentlïle der Banchseite sieht. 


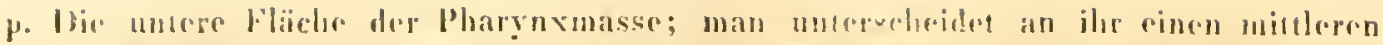

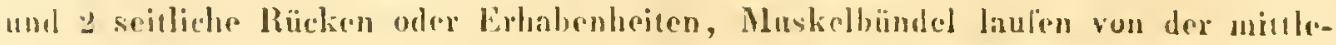
ren narl rorn (in der figur nach hinten) hinüber. (n).

y. Mor Migen.

r. Der Vervenstung, Welcher die Mittellinie der Bauchfliche derchlïuft.

$r^{\prime}$. Der ron ihı gelildete Schlumdring, einige Muskelloündel gehu von der Pharyurmasse her über ilun limweg.

s. Inmere Queputskeln, die von der Seite des Nervenstranges entspringen, und iuhro die Isangsmuslieln der Bawehseite hinweggrhend sich an der untern Gren\%e der bingrumskeln des Rärkens inserien. Zwischen dirsen leiden Längsumskel-

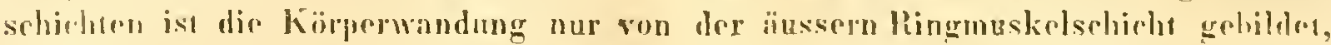
und in dieser Lärke befindrn sich die in die Bauchlöhle lineinagenden Rorstrnhïndel mil ihren Muskeln.

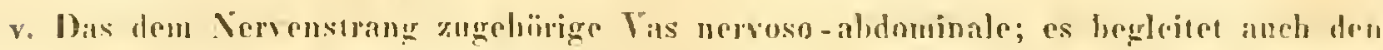

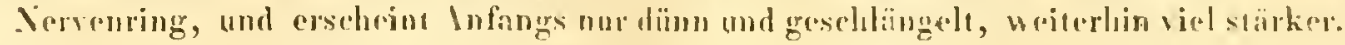

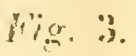

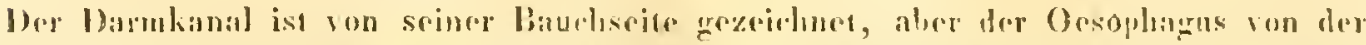

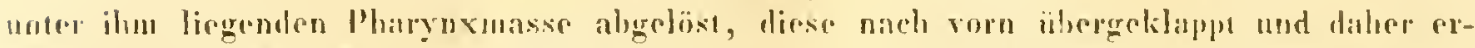

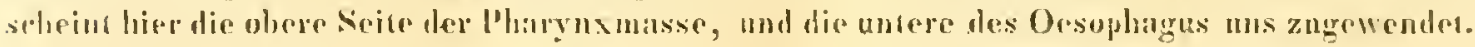

p. J)er Pharyon.

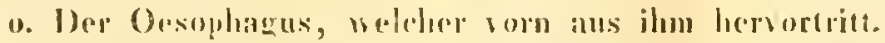

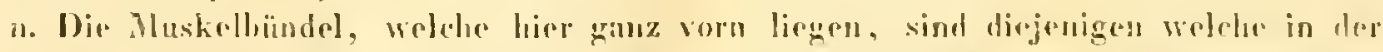

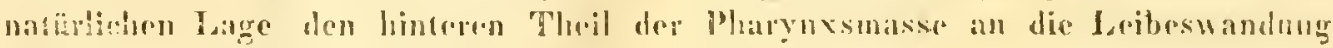
bofestigen, mol als lictmirtoren wirken.

i. Xerronfiden, welehr aus dens Cirhimganglion entspringen, und den Oesoplangus

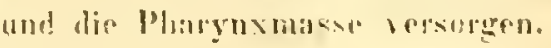

4. Der. Ihisan.

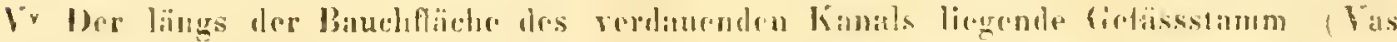

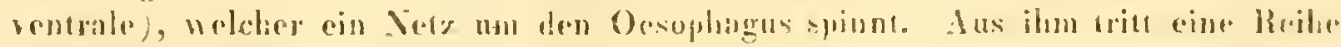

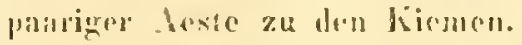

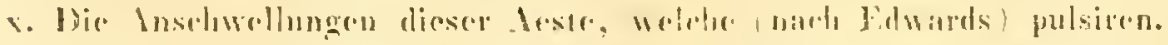

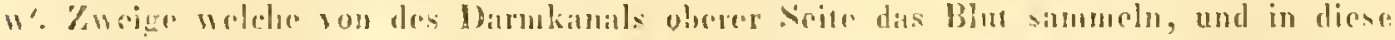
Amilum allungen füliren.

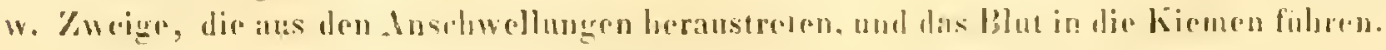

$$
\text { i.i... } 4 \text {. }
$$

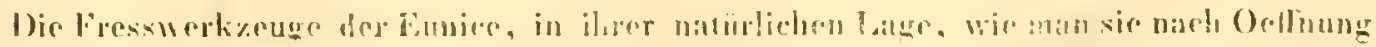

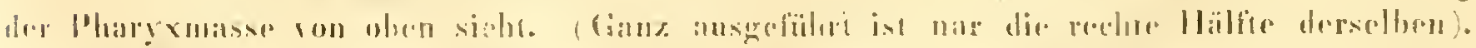

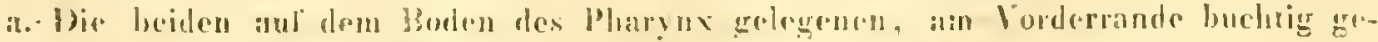

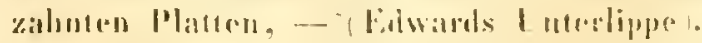

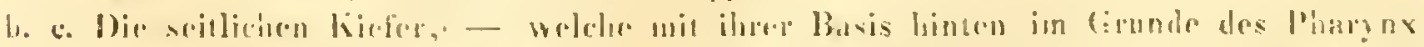

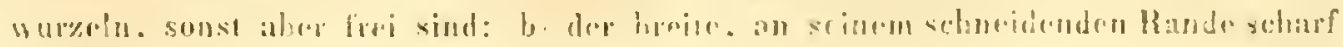

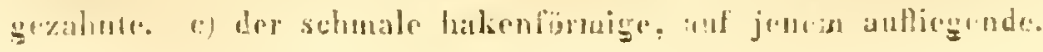


d. Die kleinen Kieferstïcke, welche elenfills seitlich aber vor b. c. sich hefunden; ilur schneidendre Ramd stelit senkrecht gegen den rou b, hicr aber sind beide: stark von einander entfernt, und diher liegr'n sie mehr als sic stchen.

e. f. Lin paatr winzige Stiickchen, welche ron ejnem d zum andern hiniberlaufen und also rine $\Lambda \mathrm{rt}$ llalbgürtel bilden.

g. Ber unpaare liefer der linken Seite, welcher auf der rechten nur als Rudinent rorhanden ist.

$$
\text { Fig. 6. }
$$

Ein paar von den mittleren Segmenten, ganz ansgehreitet. (Min sielit nur die rechte Hälfte, aber stark rergrössert, der larmkanal ist entferut).

v. Jas Vas nerroso-abdmminale; es erscheint hier sehr statk angeschwollen, und bederkt den Nervenstrang gïnzlich: Serine Frweiterungen entsiprechen den Ginglien des Nervenstranges. - Zur recht'n ron diesem Gefïss sieht man dir: Längsmuskelschicht der Banchseite.

1. Das Viss ventrale, ahgelöst voun rerdauenden Kanal; es befindel sich oberhallb des Vas nervosu-abdominale.

$x$. Die Anschwellung, in welcher das Barmblut sich sammelt, elie es in die liepmrin fliesst.

w. Der aus ihr heraustretende zur Kicme gehende Zweig.

1. Der vom Vas dursale zur Kicme laufende Zweig, an seiner Basis algeschniten.

s. Vie inuern Qucrmushellüudel, welche von der Mittellinie der Banchflïche - dem Yas nerroso-abdominale - entspringen, und sich an der untern Grenze der längsmuskelschicht des Rückens inseriven.

z. Jie Ovarien. Sie zeigen sich in Hersellsen Liicke der Längsmuskelschichten, in welcher die Borstenbündsl ihren !latz finden, und man sieht den nach innen hinriuragenden Theil derkelben auf den Ovarion aufliegen. (Die Muskeln, Welclse sic bewegen, sind entfernt).

y. Dir an der Girenze der Längsnusker.In der Rückenschicht gelegenen und theilweise von jhr verdeckten beutelförmigen Organe, welche ich für die hefruchtenden halte; um das hintere mehr hloss zu legen sind hier die Quermuskeln (s) und ein Theil der Lü̈ngsmuskeln entfernt.

$$
\text { Fig. } 8 .
$$

Ansicht des rordern Theils der Eunice von der linken Seite, so dass aber unehr ron der Banchffïche als von der Rückenfläche erscheint, und auch ein Theil der rechteu lliilfte jenseits der Batichfurche zu sehen ist. (Die Bauchfurche markirt äusserlich den Verlauf des tervenstranges).

A. Der zweilappige Kopfo

13. Dir aul ilm sitzenden fünf Anterinen.

1. Diss erste, sehr hreite Segment, unter dessen Rand der Kiopf sich zurücligezogen hat.

9. Das zweite, sclimale, durch keine vollstïndige Ringfurche von ilum gretrennt. Mit dem dritten Segment beginnen die Borstenbündel und ihrs (irren, cin unterer. 
uni rin nberer; die Rovile derselloen erheht sich allmählig bis etwa zum ften

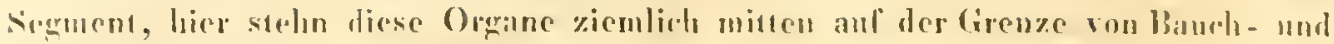

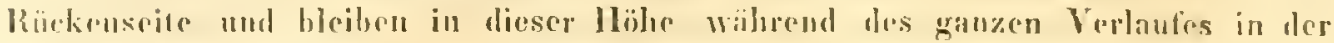
Janger des Thiores.

5. Das fünfte Segrment, an welehem zuerst die liemenfalınen audieren.

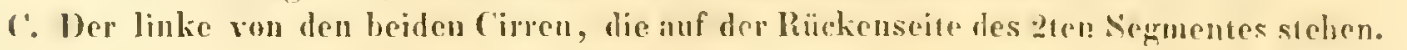

$$
\text { fig. } 9 .
$$

Der vomlere Theil des Nemensystems, vergrissert.

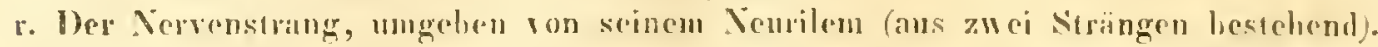

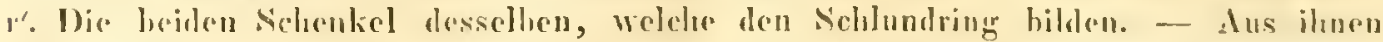
treten : Zweige nach ansson für die vordersten Segmente, und andere narlo innen zur Windung des Schlumrles.

k. Die Brürke, welehe die Śchenkel verbindet, ehe sie den Selibund ann\% umgehen.

l. Das Corbirnganglion, auf deu man oben die beiden Jrsprungsstedlen dre ganz kurzen Augennerven wahrnimmu.

i. Die heiden solır anschulichen Nervenfiiden, welche ans dem Gelirn linterwäts cutspringen, sich bald zu ciner langgezogenen Anschmellung vereinigen, und dann den Oesophagrus umfassen (s. Fig. 3).

$$
\begin{gathered}
\text { Onuplis tubicola. } \\
\text { Fig. } 10 .
\end{gathered}
$$

Die selar vergä̈sserte Spitze ciner der untern Borsien aus den Borstenlündeln der Onuphis. Sie endet in einen zweitheiligen liknenhaken.

$$
\begin{aligned}
& \text { S a be l I a u n is pir a. Fig. 5. 7. 11. 12. 16. 17. } 15 . \\
& \text { Fig. } 12 .
\end{aligned}
$$

Der rodere Theil der Sabella von bben aufgeseluniten; die beiden Hälfen sind stark anscinander erangen. - (Tergrisseri).

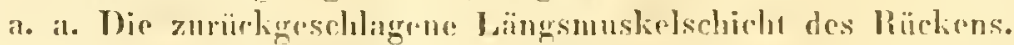

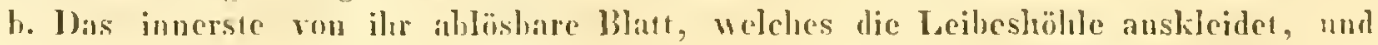
but whehem dic Dissepineute auserelien.

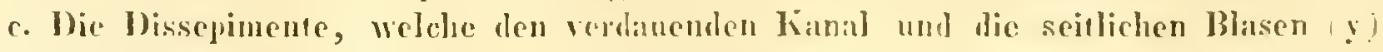
umfissen.

d. Dic Tappen am ersten Seguent, welchen einen zweilleiligen Ringkragen bildrn, und die lBasis aler kiemen umgelen.

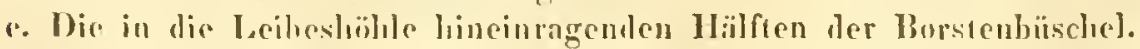

f. Ior bedatende lianal, in don ersten $S$ Abselmitlon als rin gerades, nur ath-

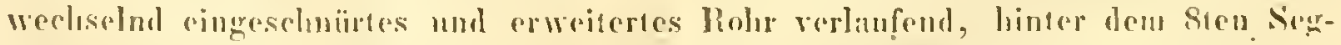

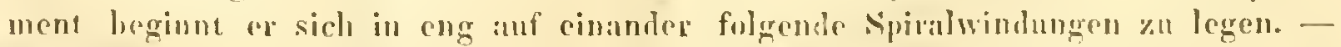

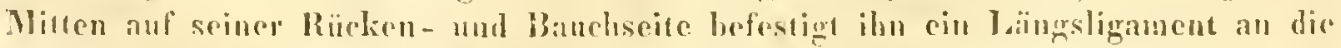

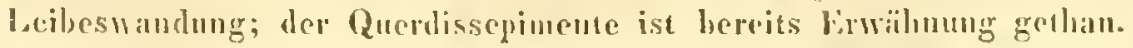


r. Der Trichter, welchrn die Hant bei dem Ilmeintreten in den Speisekanal un die Mundiafnung hildel.

h. h'. Die beiden Kiemenhiischel. - In diesem Exemplar ist der rechte (h) der kleinere, der zur Spirale entwickele ded linke (h'); doch sind die oberen Enden ihrer Fäden, wohl zu zwei Dritheil, abgeschniten.

i. Die beiden Fühlfïden, welche an den oberen Enden der heideu Kirmenbüschel stehen.

y. Der ansehnlich lange, nehen dem speisekanal zur linken liegende beutelformige lï̈per; won dem rechten sieht man, weil er grossentheils rerdeckt ist, nur wenig: - ich suche in iluen befruchendro Organe.

z. Tose Eierchen, welche in den Segmenten hiuter dem Sten his zum Ende des Thieres rorkommen.

V. Der starke Gefissstamm, der der Basis der Kiemen parallel in ihnen rerliult, und eine der Anzahl iher Fïden entsprechende Menge von Zweigen absendet. $\mathrm{Er}$ ist an seinem unteren Ende ahgerissen, man sieht aher dic Fortsetzung am Anfange des Kïrpers selbst nehen dem Schlunde: sie spaltet sich hier gahelig; der innere Ist stösst mit deut der andern Seite zusammen nu das liürkengefïss Vd zu elzeugen, der äussere begieht sich nach hinteu, und ein Nobenzweig von ihm nach unten, jener wird das Seitengefïss Vl.

T. Das Rürkengefïss.

V. Das scilliche Gefïss, welches zwischen der Leibeswandung und dem llam sowohl zur rechten als zur linken in Zickzack rerlänft.

X. Zwei auf deu verdauenden Kanal liegende schwammige hasenähnliche Kärjer, die aus Gefïssconroluten beider eben genannter Gefïssstïmme zu besichen scheinen.

\section{Fig. 7.}

Win Stück des über dem Nervenstrang liegenden Tas nervoso-abdominale mit seinen parigen, amffallend stark geschlängelien Mesten, selur vergrössert dargestellt.

\section{Fig. 5.}

Wine ron den Hakenhorsten, stark vergrössert; aus ihnen liestehen die kammehen ron Borsten, Welche an der Rückenseite der Sabella stehen über den llatrborsten (mit Ausnahme der ersien 8 Segmente, wo die Ordnung ungekeht, und wic in den Arenicolen mind Terebeilen ist).

Fig. 11.

Fine Spitze von den Ilaarborsien bei derselbeu Vergrössenong; an dem einen Rande erkennt man feine Fäserchen, wodureh die Borsten sich mit einamber zum Büschel rerlinden.

$$
\text { Fig. } 16 .
$$

lin Stïck rom Tervensystem aus zwei hintern Segmenten des Kö̈pers, etwa 5 mal vergrössert. - Es hesteht aus 2 von einandere abstehenden Strängen r. r, welehe aul" den Grenzen der Segmente durch je 2 Querfïden rerbunden sind, und so das Musehn 
riner Sirticktoiter crhalten. Aus jedem Ahschnitt treten 2-3 stirkere Fiden zwisehen den Quormakeln herror. - Die Längsmuskeln, welche dieselben bedecken, sind entfermt.

(a) Dir (irenze der beiden Segrmente.

\section{Fig 18.}

liin milteres stük der Sabellin, vergrössert, von oben gesehen.

e. Die fleischigen 11 ülste, welche dic IJaaborstenhïschel tragen.

it. Kin 'Theil der Lïngsmuskelschicht; rechts und links ist sie entfurut.

b. Das darunter liegende Blatt, Welches zunächst die Leibeshöhle übredeckt.

f. Der Dixin.

1. Ilie seitlichen Gelïssstämme, welche im Zickzack lanfen und dreicrlyi Aeste in jorlem Segment absenden, zwei oberflichliche, einen davon zur Rïcken-und eimen zur Bauchfliche, und einen dritten quer nach innen zum Darmkanal gehenden !1).

Fig. 17.

Strellt diese Vertheilung besonders tar, -

D. ist der oborflïchliche, zum liücken gehende Ast.

A. der obertiächliche, nach dex Banchscite sich werndende.

I. der quer nach innen, mitten das Dissepiment durchlinfende, dem Darm angehibige.

$$
\text { po } 1 \text { y } n \text { o e } 5 \text { q } 11 \text { a } m \text { in } t \text { a. Fig. } 13 \text {. }
$$

Fig. 13.

Der Magen lieses Thieres, sehr vergrössert dargestellt, von oben geüfnetas

a. Der Schlund, Welcher als Riissel hervorgestülpt werden kann.

b. Die zarten homigen dreieckigen Blïtchen, anf dessen hiutcrer Circuze: beim Hervorteten des Riissels hilden sie einen liranz ron Spitzen.

c. Ilie 4 hakigen kiefer am Anfing des Magens:

d. Oer sehr dickwandige knorperlig barte Magen selber.

- Sicin dureh rine Fitun - Duplicatur der Schleimhaut bezeichmeter Pylorm.

f. Der Darm.

g. Hir vordren dor in ihn mündenden Blindsioke, analog den Appendices pyloricao der Fisctire.

4 phrodite h gst rix Fig. 14. 15.

Fig. 14.

Fin Nïïck von det Bunchseite von oben hetrachtet, vergrïssert. Dor Ditrmkanal ist "ntforut, inan siche nur dir Reihe der untern Borstenkegel, das Norvensystrin, die Musl.eln und Gririen.

a. Wre Vervastrang, er bildet in jedem Segment 3 Anschwellungen. und lingt zwinchen 2 durebscheiaenden blintern. 
a'. Die nuitteren und etwas grösseren dar Inseliwellangen.

わ. Die Längsmuskelschirht des Batuches.

b. Die äussere Ringsumskelschichı, welche gegen die Nitte des kö̈rers hin las pine von den durelsscheinenden Blïtern hildet, zwischen denen der Nervenstrang liegt; das andere durehscheinende Blatt ist die Auskleidung der Ieciheshöhle.

c. Mụskelhïndel, die von der innern Grenze der Längsmuskelschicht entspringen, und mitten durch die Jeibesböhle aufwärts stejgen; sie verstärken die Dissepimente auf den Gienzen der Segmente.

d. Quermuskeln, die von der innern Grenze der Lïngsmuskelsehicht nach den Grenzon der Borstenkegel gehen.

c. Schrïge Muskelfasern, wolclıe sich vou der äusseren Grenze Iler Längsmuskclschich in die Borstenliegel begeben.

f. Insertionsstelle für die Muskeln der Borstenhiizdel.

g. Die untern Borstenkergel aufgeschnitten; in einigen sind dic an der Spitze gaheligen Borsten gelassen.

h. Das Ovarium des rordersten von den hier abgebildeten Segmenten.

$$
\text { Fig. } 15 .
$$

d". Ein Stück der Schleimhaut, welche den Magen der Iphrodite auskleidet, stark vergrössert. - Man erkennt ein ihr anhaftendes maschiges Netz, wahrselieinlicls von Giefüssen herrührend.

d'. Der Viuden, der bein Ablösen derselben von der linorpeligen Muskelschielat mit ahgerissen wirl, und den ich für einen Nerven halce.

$c^{\prime}$. Die Siclle, wo er sich oben theilt. 

Fies:

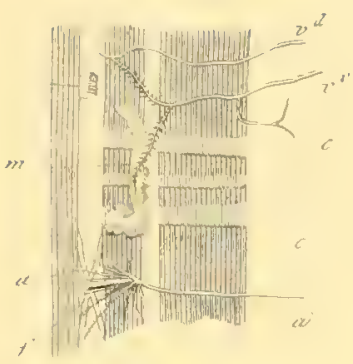

Five...

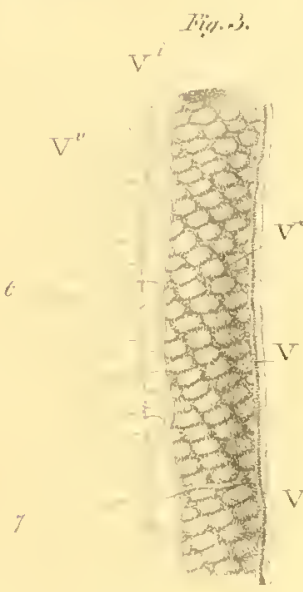

Fig.

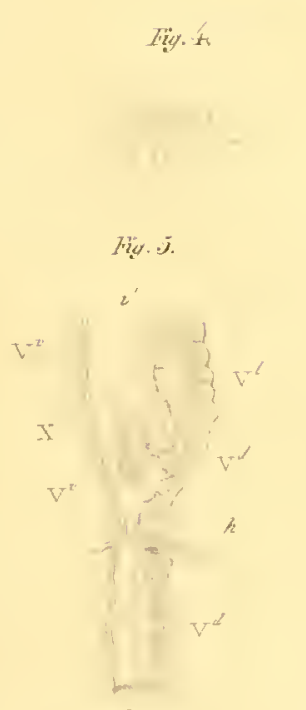

I"x. 1.

h
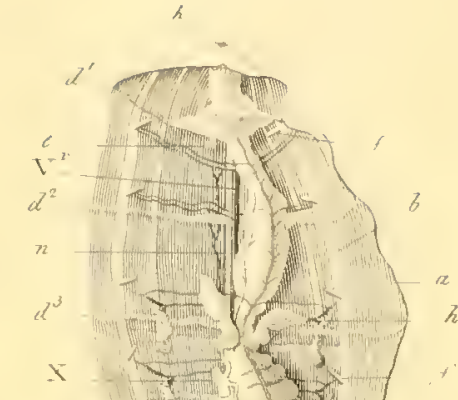

$v^{6}$
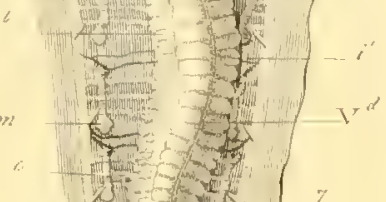

or

$v^{d}$
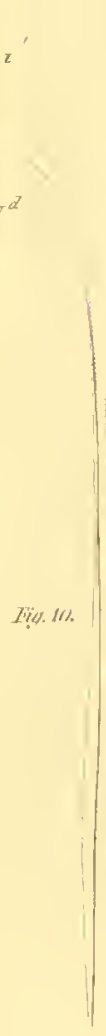

Fiv. 11.

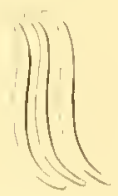

Fig.ti.

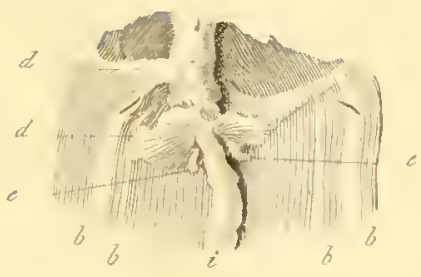

Fig.:

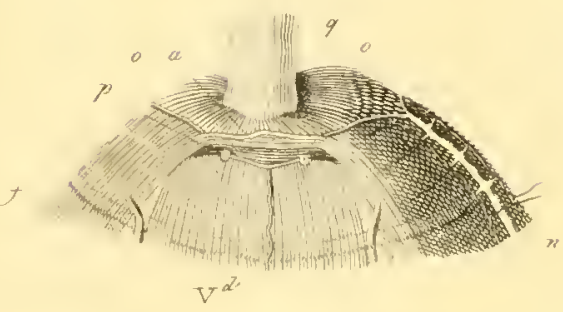

คัพ
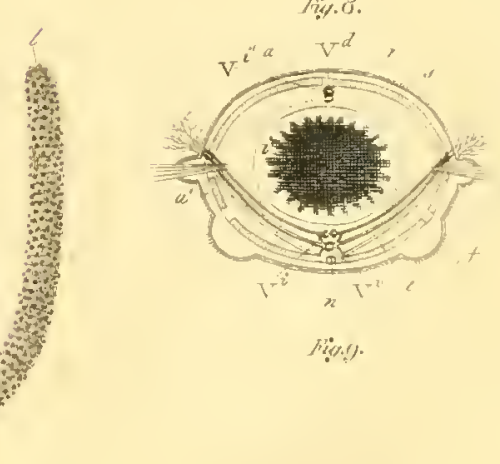

Min!
Fig. $1:$

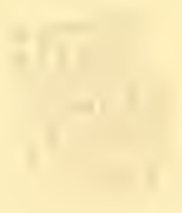


Fis:.

Sis.

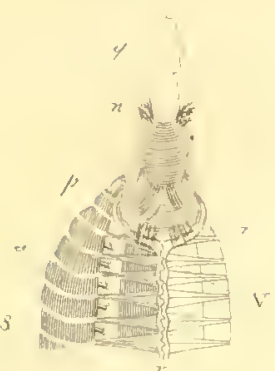

Find 4 .

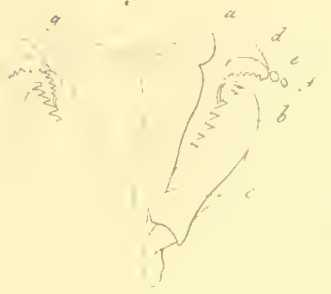

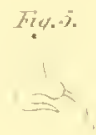

Figne".

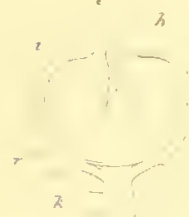

Fu, 14.

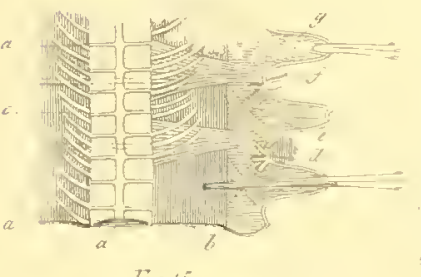

Fia. $1 \%$
Figy:
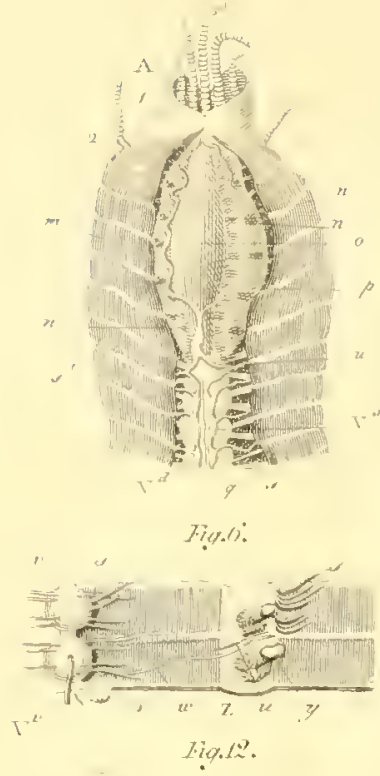

10.12.

Fry.11.<smiles>C=CC</smiles>

Fieno
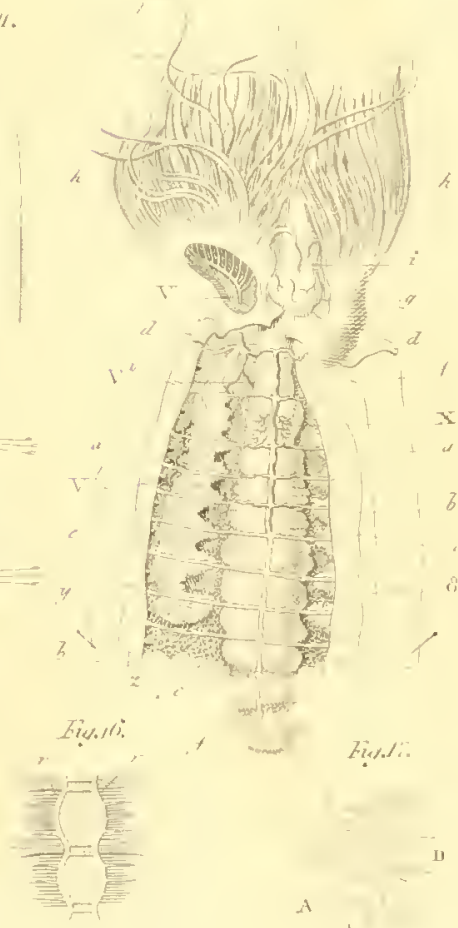

Fin. $\%$

IIJI, II.
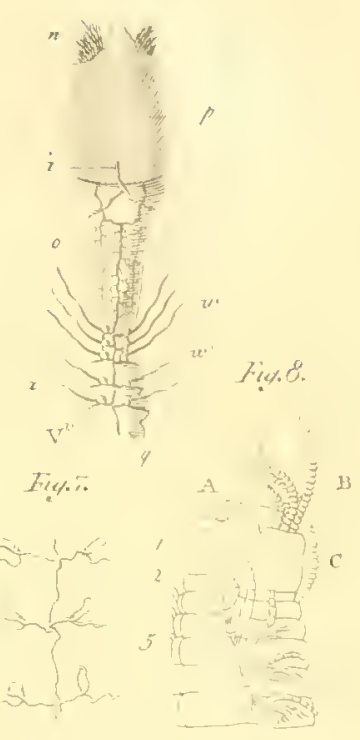

find. 3.
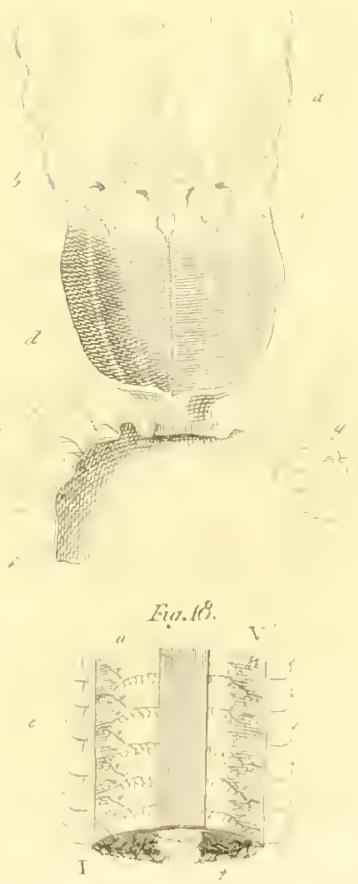


$$
3,+\sum_{x+1}^{3} \cdot 10
$$







and

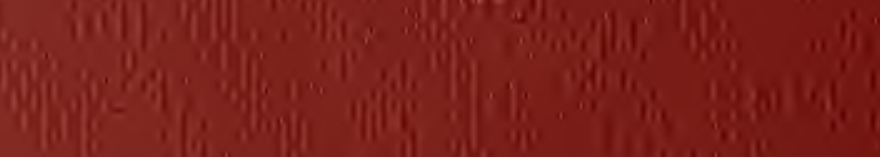

(1)

Whe (19

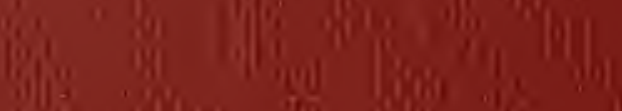

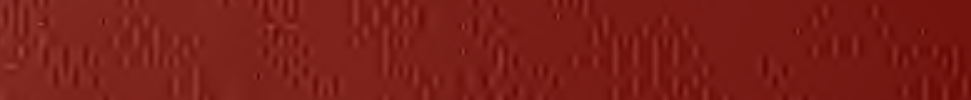

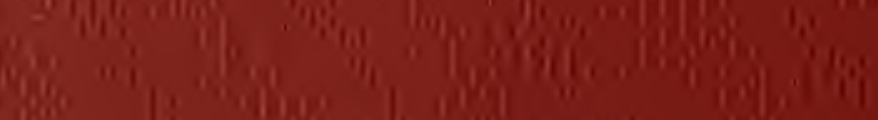

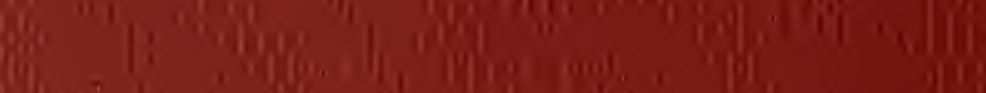

10.

(1.)

2.4

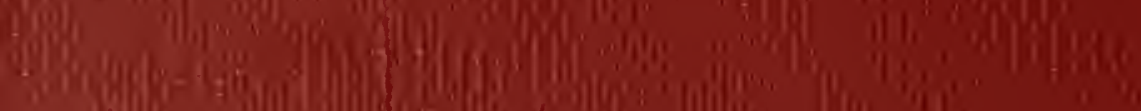

Tou (1) 00 (14) (2) 140 86. 1.

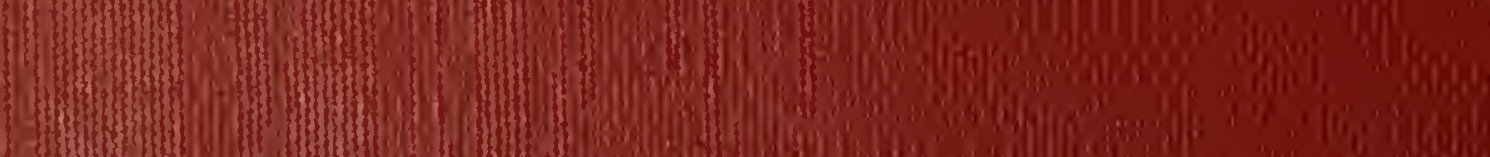

